\begin{tabular}{c} 
MARINE \\
BIOLOGICAL \\
LABORATORY \\
\hline LIBRARY \\
\hline $\begin{array}{c}\text { WOOOS HOLE, MASS. } \\
\text { W. H. O. I. }\end{array}$ \\
\hline
\end{tabular}

\title{
SWIMMING BEHAVIOR AND ENERGETICS OF SHARKS
}

by

JILL VICTORIA SCHAROLD

B.S., Biological Sciences

Michigan Technological University (1982)

Submitted in partial fulfillment of the requirements for the degree of

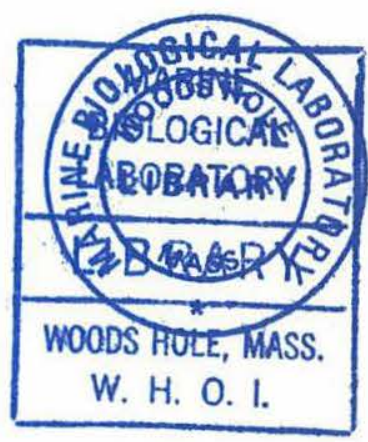

DOCTOR OF PHILOSOPHY

at the

MASSACHUSETTS INSTITUTE OF TECHNOLOGY

and the

WOODS HOLE OCEANOGRAPHIC INSTITUTION

December 1988

\section{(C) Jill v. Scharold 1989 A11 rights reserved}

The author hereby grants to MIT and WHOI permission to reproduce and distribute copies of this thesis document in whole or in part.MARINE

Signature of Author

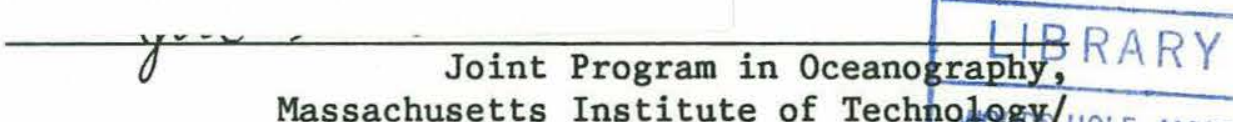
Massachusetts Institute of Technofogy/HOLE, MASS. Woods Hole Oceanographic Institution. H. O. I.

Associate Scientist, Woods Hole Oceanographic Institution Thesis Supervisor

Accepted by

Dr. Donald M. Anderson

Chairman, Joint Committee for Biological Oceanography, Massachusetts Institute of Technology/ Woods Hole Oceanographic Institution

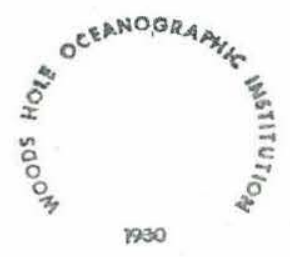




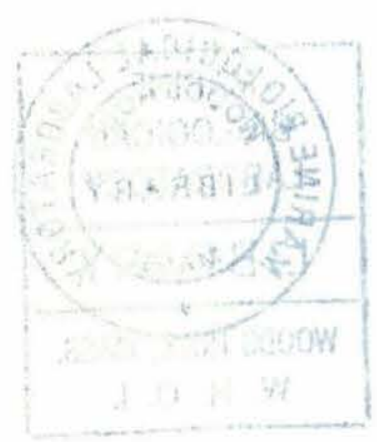




\title{
SWIMMING BEHAVIOR AND ENERGETICS OF SHARKS
}

by

\section{Jill Victoria Scharold}

\author{
Submitted to the Massachusetts Institute of Technology/ \\ Woods Hole Oceanographic Institution \\ Joint Program in Biological Oceanography \\ in partial fulfillment of the requirements for \\ the degree of Doctor of Philosophy
}

\begin{abstract}
In a field study of blue shark swimming behavior, acoustic telemetry was used to record depth, swimming speed and tailbeat frequency from free-ranging blue sharks (Prionace glauca) in northwestern Atlantic slope waters. Records obtained from five sharks show a consistent pattern of vertical migration between the surface and depths as great as 450 meters, with the deepest dives occurring during the daytime and shallower dives at night. Mean swimming speed was $44.5 \pm 1.6$ (X+S.E.) $\mathrm{cm} \cdot \mathrm{s}^{-1}\left(0.179 \pm 0.014\right.$ lengths. $\left.\mathrm{s}^{-1}\right)$ for three sharks, with short bursts up to $1 \overline{8} 0 \mathrm{~cm} \cdot \mathrm{s}^{-1}$. Mean tailbeat frequency was $0.335 \pm 0.021$ beats.s $\mathbf{s}^{-1}$. Measurement of swimming speed and rate of vertical movement during dives permits calculation of angles of ascent and descent. For 84 dives deeper than $50 \mathrm{~m}$, the descent angle averaged $8.0 \pm 0.7$ degrees from the horizontal while the ascent angle was $6.4 \pm$ 0.5 degrees. Tailbeat records indicate that blue sharks actively swam downward during most of the descent, with brief periods of gliding which appear to be associated with the most rapid descent rates. The observed diving behavior does not match that predicted by theory to be energetica11y optimal for migration, and may instead represent a strategy for encountering and capturing prey.

Heart rate, metabolic rate and activity were simultaneously recorded in the laboratory from lemon sharks (Negaprion brevirostris) during rest and spontaneous exercise, and from leopard sharks (Triakis semifasciata) during steady swimming at controlled speeds to evaluate the usefulness of heart rate as a measure of field metabolic rate. Heart rate was monitored by acoustic telemetry using a frequency modulated ECG transmitter, and metabolic rate was measured as oxygen consumption rate. For seven lemon sharks at $25^{\circ} \mathrm{C}$, mean resting values for heart rate and oxygen consumption rate were $52.0 \pm 0.4$ (S.E.) beats.min ${ }^{-1}$ and $162.0 \pm 2.0$ (S.E.) $\mathrm{mg} 0_{2} \cdot \mathrm{kg}^{-1} \mathrm{hr}^{-1}$, respectively. Both parameters increased significantly $(\mathrm{p}<.001)$ during swimming, to means of $55.9 \pm 0.2$ beats min $^{-1}$ and $233.6 \pm 2.3$ mg $0_{2} \cdot \mathrm{kg}^{-1} \mathrm{hr}^{-1}$, at a mean swimming speed of $0.400 \pm 0.003$ body
\end{abstract}


lengths $\mathrm{s}^{-1}$. For seven leopard sharks at $16^{\circ} \mathrm{C}$, mean resting heart rate and oxygen consumption rate were $36.6 \pm 1.8$ beats.min ${ }^{-1}$ and $105.3 \pm 35.6 \mathrm{mg} 0_{2} \cdot \mathrm{kg}^{-1} \cdot \mathrm{hr}^{-1}$. While swimming at the maximum sustained speed $\left(0.84 \pm 0.03\right.$ lengths. $\left.\mathrm{s}^{-1}\right)$ for $30-60$ minutes, these rates were $46.9 \pm 0.9$ beats. $\mathrm{min}^{-1}$ and $229.3 \pm 13.2 \mathrm{mg}$ $\mathrm{O}_{2} \cdot \mathrm{kg}^{-1} \cdot \mathrm{hr}^{-1}$. The observed elevations in heart rate from rest to exercise account for $20 \%$ of the increase in oxygen uptake in the lemon shark and $32 \%$ in the leopard shark, leaving the remainder to be brought about by increases in stroke volume and/or arteriovenous oxygen difference. Significant linear regressions of oxygen consumption rate on heart rate were obtained for both 1 emon sharks and leopard sharks; separate regressions were obtained for individual lemon sharks. Heart rate was approximately as closely correlated to oxygen consumption rate as was swimming speed.

Thesis Supervisor: Dr. Judith McDowe11 Capuzzo

Title: Associate Scientist

Woods Hole Oceanographic Institution 


\section{ACKNOWLEDGEMENTS}

I gratefully acknowledge the support and guidance of Dr. Francis G. Carey and of my thesis advisor, Dr. Judith McDowe11 Capuzzo. Sincere thanks are also due to the rest of the thesis committee members, Dr. Keith D. Stolzenbach, Dr. Samue1 H. Gruber, and John G. Casey, who contributed help and advice during the course of the research, and who read and commented on the manuscript.

Sincere appreciation is extended to Drs. S.H. Gruber and J.B. Graham, who generously granted use of laboratory facilities and animals for the respirometry experiments. I am also grateful to their students and technicians for encouragement and assistance, particularly N.C. Lai and W.R. Lowe11 at S.I.0. and S. Pardo, J. Morrissey, E. Cortes, B. Wetherbee and J. Tatelman at R.S.M.A.S. I thank D. Leavitt and B. Lancaster for advice and assistance in setting up the respirometer, and J. Kanwisher and R. Koehler for help in designing the ECG transmitters. I am greatly indebted to the many shark trackers who helped to record data during the field studies.

I am sincerely grateful to the many staff and students at W.H.O.I. who provided assistance during all phases of this project. Too numerous to mention a11 by name, these include but are not limited to: members of the biology department, J.C.B.0., the education office, graphic services, and the library; V. Starczak and D. Leavitt, who provided advice on data analysis; M. Freadman, who chaired the qualifying exam; D. Stoecker, who chaired the defense; N. Marcus, S. Chisolm, and R. Naiman, who served on the first year review committee, and $\mathrm{K}$. 01son and N. Conway, my patient office-mates. I appreciate the help and encouragement of the NMFS Narragansett Laboratory Apex Predator Investigation Group, including J. Casey, H. Pratt, C. Stillwe11, N. Kohler, L. Natanson, and G. Skomal. Last, but not least, I thank my family for their constant encouragement, concern, and faith.

Financial support throughout this project was from several sources: the WHOI education office, a grant from the Coastal Research Center to the author, and NSF grants OCE-8311512 to FGC, OCE-8743949 to SHG, and DCB-8416852 to JBG. 
Great are the works of the LORD;

they are studied by a11 who delight in them.

Psalm 111:2 
TABLE OF CONTENTS

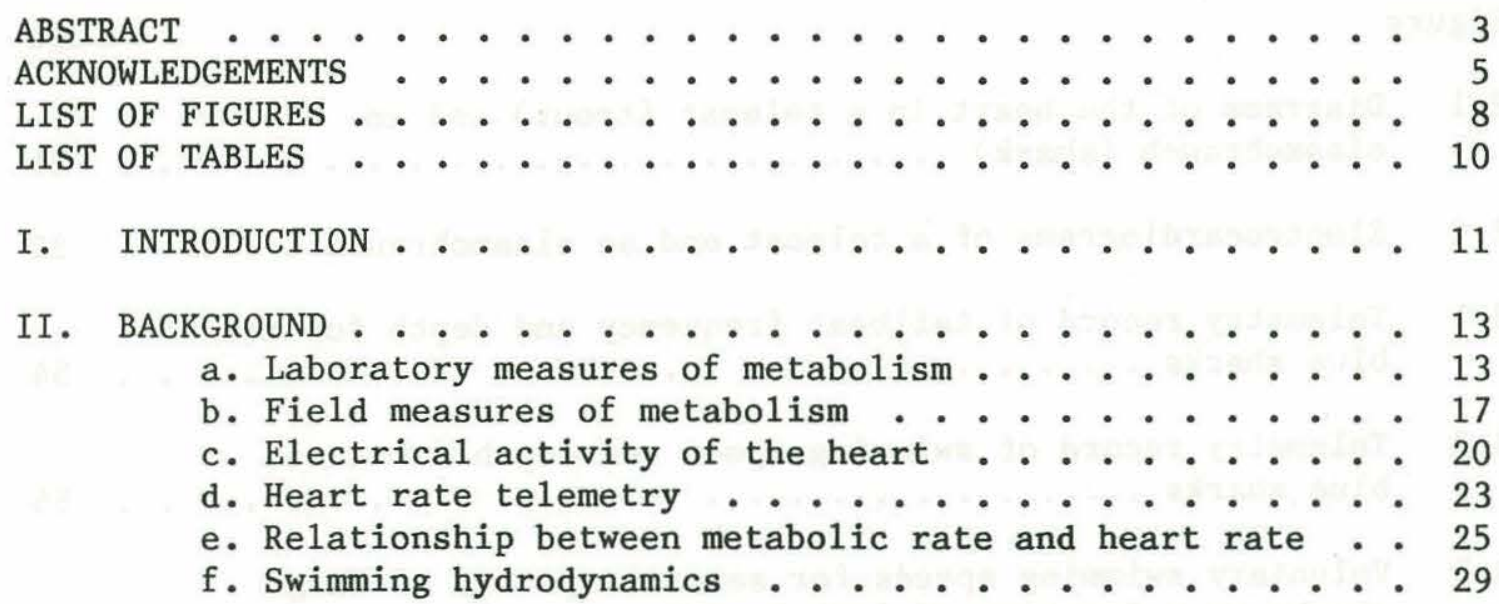

III. BEHAVIOR OF THE FREE-SWIMMING BLUE SHARK, Prionace glauca:

DEPTH, SPEED, AND TAILBEAT FREQUENCY . . . . . . . 45

a. Abstract ............... . . 45

b. Introduction ........... . . 46

c. Methods ............... . . 48 48

d. Results ................ 52

e. Discussion ............... 61

IV. TELEMETERED HEART RATE AS A MEASURE OF METABOLIC RATE

IN THE LEMON SHARK, Negaprion brevirostris . . . . . . 75

a. Abstract ................ 75

b. Introduction ............. 76

c. Methods ............... . . 78

d. Results ............... . . 85

e. Discussion .............. 92

V. METABOLIC RATE, HEART RATE, AND TAILBEAT FREQUENCY DURING

SUSTAINED SWIMMING IN THE LEOPARD SHARK, Triakis semifasciata 105

a. Abstract .............. 105

b. Introduction ............ 106

c. Methods ................ 108

d. Results .................. 111

e. Discussion ............... 123

VI. CONCLUSION . . . . . . . . . . . . . . . . 135

VII. REFERENCES . . . . . . . . . . . . . . . . 141

BIOGRAPHICAL NOTE . . . . . . . . . . . . . 152 


\section{LIST OF FIGURES}

Figure

Page

2.1 Diagrams of the heart in a teleost (trout) and an elasmobranch (shark) ............ 21

2.2 Electrocardiograms of a teleost and an elasmobranch . . . 22

3.1 Telemetry record of tailbeat frequency and depth for two blue sharks ............... 54

3.2 Telemetry record of swimming speed and depth for three blue sharks ................ 55

3.3 Voluntary swimming speeds for several species of large sharks as a function of fork length ........... 63

3.4 Mean tailbeat frequency as a function of relative swimming speed for several species of sharks ........... 67

3.5 Nondimensional energy savings achieved by glide-and-swim behavior as a function of swimming angle for various gliding angles ................ 71

4.1 Circuit for the ultrasonic electrocardiogram (ECG) transmitter ................ 79

4.2 Placement of the ECG transmitter and electrodes ...... 82

4.3 24-hour record of speed, oxygen consumption rate, and heart rate for a juvenile lemon shark .......... 88

4.4 Relationship of oxygen consumption rate and relative swimming speed in 7 juvenile lemon sharks at $25^{\circ} \mathrm{C} . . . .89$

4.5 Relationship between metabolic rate and heart rate in 7 juvenile lemon sharks at $25^{\circ} \mathrm{C}$. . . . . . . . . 90

4.6 Individual regressions of oxygen consumption rate on heart rate for 7 juvenile lemon sharks . . . . . . . . 91

4.7 0xygen consumption vs swimming speed for the lemon shark at $25^{\circ} \mathrm{C}$ and $22^{\circ} \mathrm{C}$, and for several teleosts . . . . . 94

5.1 Relationship between tailbeat frequency and relative swimming speed for 7 leopard sharks carrying ECG transmitters and 5 control sharks . . . . . . . . . 115 
5.2 Relationship between mean tailbeat frequency and mean relative swimming speed for 7 instrumented sharks and 4 control sharks ................ 116

5.3 Relationship between oxygen consumption rate and relative swimming speed for 7 leopard sharks carrying ECG

transmitters and 5 control sharks . . . . . . . . 118

5.4 Mean oxygen consumption rate at a given absolute speed as a function of relative swimming speed for 7 instrumented sharks and 5 control sharks ............. 119

5.5 Relationship between oxygen consumption rate and heart rate for 7 leopard sharks .............. 120

5.6 Relationship between mean oxygen consumption rate and mean heart rate for 7 leopard sharks ............. 121

5.7 Relationships between tailbeat frequency and relative swimming speed for the leopard shark, the blacktip shark, the brown smooth-hound, and teleosts .......... 124

5.8 Relationships between oxygen consumption rate and relative swimming speed for the leopard shark, the lemon shark at $25^{\circ} \mathrm{C}$ and at $22^{\circ} \mathrm{C}$, and several teleosts ........ 127

5.9 Relationships between oxygen consumption rate and heart rate for several sharks and teleosts . . . . . . . 130 
Table

3.1 Length, sex, tagging date, and duration of track for five blue sharks instrumented with depth, swimming speed and tailbeat transmitters............ 53

3.2 Rate of change in depth, swimming speed, swimming angle, and tailbeat frequency for dives with depth change greater than $50 \mathrm{~m}$ and for dives with depth change greater than $150 \mathrm{~m}$. . 57

3.3 Mean swimming speeds and tailbeat frequencies for five blue sharks ................ 58

4.1 Length, weight, and sex of seven juvenile lemon sharks . . 86

4.2 0xygen consumption rate, heart rate, and swimming speed for seven lemon sharks ............. . 86

4.3 Percentage contribution of heart rate to increases in metabolic rate for several species of teleosts, sharks, mammals, and birds ................ 99

4.4 Cardiovascular adjustments to exercise in trout, dogfish, and the lemon shark . . . . . . . . . . . . 101

5.1 Length, weight, and sex of seven experimental and five control leopard sharks ............... 112

5.2 0xygen consumption rate and heart rate at rest and at maximum sustained speeds for seven leopard sharks with heart rate transmitters and five control sharks . . . . . 122 


\section{INTRODUCTION}

Although sharks (Order Selachii) comprise a widespread, diverse, and successful group, relatively little is known of their ecology. In part this is due to difficulties associated with observation and maintenance, particularly of the large, active pelagic species (Ne1son 1977, Gruber 1980). Nevertheless, as top predators, sharks play an important role in marine ecosystems which deserves investigation. Studies of bioenergetics can provide a useful framework in which to examine the relationships between an organism and its environment. Quantification of the rates of energy input, expenditure, and storage can serve as a basis for estimating the impact of shark populations on community processes, and for evaluating the effectiveness of various behavioral, physiological and morphological adaptations. A key variable in the energy budget is the energy expenditure associated with metabolic processes. Although a few measurements of metabolism under conditions of rest and moderate activity have been made on sharks in the laboratory (Brett and Blackburn 1978, Gruber 1982, Nixon and Gruber 1988), the energetic costs of daily activity in the field remain unknown. Acoustic telemetry techniques have made it possible to monitor environmental and physiological parameters from free-swimming fish (Stasko and Pincock 1977). Heart rate is one such parameter which has been proposed as an indicator of metabolic rate (Priede 1983), and it may be possible to use heart rate telemetry to 
estimate field metabolic rates in sharks. This information would aid in estimating energy costs associated with various observed behavior patterns and determining minimum energy requirements of shark populations.

The present research is an investigation of swimming behavior and energetics in several species of sharks, and consists of two main parts. The first is a field study of swimming behavior in the blue shark, Prionace glauca, in which acoustic telemetry was used to monitor depth, swimming speed, and tailbeat frequencies from free-swimming sharks. The observed behavior patterns were then evaluated in terms of energetic efficiency by comparing them with swimming behavior predicted to be most efficient based on theoretical considerations. The second part consists of laboratory studies in which actual energetic costs associated with swimming activity were measured concurrent1y with heart rates in two species of sharks to determine whether telemetered heart rate may be a useful indicator of metabolic rate for field studies. In one of these lab studies, heart rate, metabolic rate and swimming speed were simultaneously measured from lemon sharks (Negaprion brevirostris) during rest and spontaneous activity. In the second study, heart rate and metabolic rate were monitored in leopard sharks (Triakis semifasciata) swimming at controlled speeds. This research program was undertaken to gain information on swimming behavior of sharks in the field, to increase knowledge of metabolic costs of swimming in sharks, and to investigate a technique (heart rate telemetry) which could provide a link between relationships obtained in the laboratory and behavior exhibited in the field. 


\section{BACKGROUND}

\section{Laboratory Measures of Metabolism}

Energy metabolism refers to the total expenditure of chemical energy by an organism. Metabolic rates can be determined under laboratory conditions by calorimetry, in which the heat production associated with changes in chemical free energy is measured, or by indirect calorimetry in which energy expenditure is derived from measurements of associated chemical changes (Kleiber 1961). The latter method is commonly used in metabolic studies of $\mathrm{fish}$, since low heat production levels coupled with the high heat capacity of water make direct calorimetry difficult (Brett and Groves 1979). Specifically, the technique of respirometry uses measurements of gas exchange to estimate metabolic rate. The amount of energy released per liter of oxygen consumed in aerobic metabolism is relatively constant regardless of the substrate used, ranging from $4.5 \mathrm{kcal} / 1$ for protein to $5.0 \mathrm{kcal} / 1$ for carbohydrates, so oxygen consumption rate can be used as an estimate of metabolic rate (Schmidt-Nielsen 1979). For fish, the oxycalorific coefficient is approximately $4.63 \mathrm{kcal}$ per liter $\mathrm{O}_{2}$ (Brett and Groves 1979).

Several levels of metabolism, based on activity, have been defined for experimental purposes (Brett and Groves 1979, Priede 1985). Standard metabolism approximates the energy expenditure required to maintain an animal at rest in a nonstressed, 
postabsorptive state. Generally, this is considered to correspond to minimum activity levels observed (resting metabolism). Routine metabolism refers to the rate of energy expenditure associated with spontaneous activity levels. Active metabolism refers to the maximum aerobic metabolic rate, and is determined by the rate of energy expenditure at the maximum level of activity that can be sustained for prolonged periods. The difference between active metabolism and standard metabolism is the metabolic scope. During burst swimming or severe prolonged exercise, energy may be additionally supplied by anaerobic processes. This contribution to total metabolism is estimated from the quantity of oxygen consumed during repayment of the oxygen debt following exercise (Brett 1964).

Activity is one of the major variables influencing metabolic rate in fish (Brett and Groves 1979). In fast swimming teleosts, activity can elevate metabolic rate by as much as ten times above the standard rate. Active metabolic rates of teleosts have been found to vary from $160-1000 \mathrm{mgO} \mathrm{kgg}^{-1} \mathrm{hr}^{-1}$, as compared to standard rates of $30-230$ $\mathrm{mgO} \mathrm{O}_{2} \mathrm{~kg}^{-1} \mathrm{hr}^{-1}$. Burst swimming may involve energy expenditure at ten times the active rate (Brett 1972). Oxygen consumption has been found to increase exponentially with swimming speed in several species of teleosts (Brett 1964, Webb 1971b, review by Beamish 1978). Standard metabolic rate is related to size according to the equation $M=a x W^{b}$, where $M$ is the metabolic rate, $W$ is body mass, and $\mathrm{a}$ and $\mathrm{b}$ are fitted constants for a given species (Webb 1978b). In fish values for $b$ are genera1ly in the range of $0.76-0.86$ (Glass 1969). Weight-specific active metabolic rate appears to be 
essentially independent of weight in salmonids in the temperature range of $5-20^{\circ} \mathrm{C}$ (Brett and Glass 1973 ).

Standard metabolic rates increase with temperature, with $Q_{10}$ values of about 2.3 within the normal temperature range for a given species (Fry 1971). In salmonids, active metabolic rate has been found to increase with temperature up to a maximum at $15^{\circ} \mathrm{C}$, beyond which it declines (Brett 1964).

Feeding is associated with an increase in metabolic rate, known as the heat increment, which results from energy costs associated with food processing (reviewed by Brett and Groves 1979, Jobling 1981). The heat increment is ration dependent, and may show a linear increase with feeding leve1 up to the maximum ration, or may level of $f$ at high rations. The magnitude of the effect increases with increasing levels of digestible energy and particularly with increasing proportions of digestible protein in the ration.

Relatively few values for oxygen consumption and metabolic rates have been reported for sharks, particularly for unrestrained specimens (reviewed by Brett and Blackburn 1978).

Resting metabolic rates of $60-80 \mathrm{mgO} \cdot \mathrm{kg}^{-1} \mathrm{hr}^{-1}$ were obtained for 200-800 g specimens of the rough hound, Scyliorhinus canicula, at $12^{\circ} \mathrm{C}$ (Hughes and Umezawa 1968, Short et a1 1979). Butler and Taylor (1975) found that resting metabolic rate in $\underline{\mathbf{S}}$. canicula increased from 40 to $64 \mathrm{mgO}_{2} \cdot \mathrm{kg}^{-1} \mathrm{hr}^{-1}$ with an increase in temperature from $7^{\circ} \mathrm{C}$ to $17^{\circ} \mathrm{C}$, a $Q_{10}$ of 2.2 .

Pritchard et al (1958) obtained a log linear relationship with a 
slope of 0.74 between metabolic rate and body mass in resting female Pacific dogfish, Squalus suckleyi (= acanthias). At $13^{\circ} \mathrm{C}$, the resting oxygen consumption ranged from $44 \mathrm{mgO} \mathrm{kgg}^{-1} \mathrm{hr}^{-1}$ for an 8 $\mathrm{kg}$ specimen to $64 \mathrm{mgO} \mathrm{.kg}^{-1} \mathrm{hr}^{-1}$ for a $1 \mathrm{~kg}$ specimen.

Studies on restrained larger spotted dogfish, Scyliorhinus stellaris, at $17^{\circ} \mathrm{C}$ gave values for resting metabolic rate of $45-60$ $\mathrm{mgO}_{2} \cdot \mathrm{kg}^{-1} \mathrm{hr}^{-1}$ for specimens of about $2 \mathrm{~kg}$ (Piiper and Schumann 1967, Baumgarten-Schumann and Piiper 1968).

Piiper et al (1977) measured oxygen consumption during rest and spontaneous swimming in S. stellaris by determining oxygen content of inspired and expired water. For specimens with an average weight of $2-3 \mathrm{~kg}$, the average resting metabolic rate was about 100 $\mathrm{mgO} \mathrm{kgg}^{-1} \mathrm{hr}^{-1}$, and the routine metabolic rate (while swimming at $22-24 \mathrm{~cm} / \mathrm{s}$ ) was $170 \mathrm{mg0} \cdot \mathrm{kg}^{-1} \mathrm{hr}^{-1}$ at $18^{\circ} \mathrm{C}$.

Brett and Blackburn (1978) measured oxygen consumption in active spiny dogfish, Squalus acanthias, using a tunnel respirometer and a sealed tank. For specimens of $2 \mathrm{~kg}$ mean weight at $10^{\circ} \mathrm{C}$, they obtained a mean resting metabolic rate of $32 \mathrm{mgO} \cdot \mathrm{kg}^{-1} \mathrm{hr}^{-1}$, routine rate of $49 \mathrm{mg} \mathrm{O}_{2} / \mathrm{kg} / \mathrm{hr}$, and an active metabolic rate of 88 $\mathrm{mgO} \mathrm{O}_{2} \cdot \mathrm{kg}^{-1} \mathrm{hr}^{-1}$.

Gruber (1982, 1984) and Bushnel1 (1982) used an annular respirometer to obtain metabolic rates associated with rest and spontaneous swimming in the lemon shark, Negaprion brevirostris. For sharks with an average weight of $2 \mathrm{~kg}$ at a temperature of $23^{\circ} \mathrm{C}$, the average resting oxygen consumption rate was $136 \mathrm{mgO} \mathrm{gkg}^{-1} \mathrm{hr}^{-1}$, and the routine rate (while swimming at 0.4 body lengths/s) was 167 
$\mathrm{mgO}_{2} / \mathrm{kg} / \mathrm{hr}$. The maximum recorded metabolic rate, associated with sustained swimming at 0.6 lengths $/ \mathrm{s}$, was $323 \mathrm{mg} 0_{2} \cdot \mathrm{kg}^{-1} \mathrm{hr}^{-1}$.

It appears that for those species for which oxygen consumption measurements are available, the metabolic rates for sharks lie near the lowest values for teleosts (Brett and Blackburn 1978), with the exception of lemon sharks. This may be related to the fact that most studies have been performed on relatively sluggish species at low temperatures. Adjusting metabolic rates recorded in dogfish for temperature brings these measurements closer to the value for the tropical lemon shark. Much of the variation in recorded values may be due to differing experimental techniques.

\section{Field Estimates of Metabolism}

Several approaches have been used to estimate the metabolic costs of activity in free-swimming fishes. The Winberg rule involves approximating field metabolic rates as a fixed multiple of the standard rate measured under appropriate laboratory conditions (Mann 1978). Laboratory measurements of routine activity have been used directly as approximations of field metabolic rates, or modified based on theoretical considerations of foraging costs, estimates of field growth rates, and coupling of ration and activity metabolism (Ware 1975, 1978; Kerr 1982). Activity patterns in the field, however, are generally different from those observed under laboratory conditions. Brett (1973) obtained direct measurements of the cost of migration in salmon by measuring changes in body composition at different points along the migratory route. This was possible due to 
the fact that migrating salmon do not feed, and large numbers of specimens were available.

Use of telemetry techniques makes more direct observation of activity possible (reviewed by Stasko and Pincock 1977). Transmitters can be used to locate fish at measured time intervals, thereby estimating average swimming speeds. These activity levels can then be correlated with metabolic costs measured for various levels of performance under laboratory conditions (Young et a1 1972), and a time-activity budget can be used to estimate the energy cost of activity in the field. Holliday et al (1974) used these techniques to estimate the energy expended in swimming by brown trout. The accuracy of this method depends on the frequency with which positions are plotted, and does not account for path curvature between points. Swimming speed has been telemetered in several species of sharks both by plotting position and using transmitters designed to measure intantaneous swimming speed (Standora and Nelson 1977, Sciarotta and Nelson 1977, Carey et a1 1982, Gruber 1982, Gruber et a1 1988). Attempts have been made to find physiological parameters which can be measured in the field and correlated with activity metabolism. Ross et a1 (1981) determined tailbeat frequencies from electromyograms (EMGs) obtained from trout, and Rogers et al (1984) developed a telemetry system using EMG transmitters to assess locomotory activity in free-ranging trout. Weatherley et al (1982) recorded electromyograms from the axial musculature of trout which were correlated with oxygen consumption. They obtained separate correlations between EMG measurements and oxygen consumption rates 
under conditions of spontaneous and forced swimming, presumably due to the increased use of non-axial muscles during spontaneous activity. This method could be used to estimate activity metabolism, but variations in metabolic rate due to other factors, such as temperature changes, feeding, stress, and diel rhythms would not be detected. Rogers and Weatherley (1983) developed a transmitter to record electromyograms from the opercular musculature, but did not obtain a satisfactory correlation between oxygen uptake and frequency of respiratory movements.

Priede and Young (1977) used a heart rate transmitter to obtain continuous records of cardiac rhythms from brown trout under field conditions. The fish exhibited elevated heart rates following release, corresponding with high rates of locomotory activity as determined by position fixes. Periods of high heart rate were recorded which were not accompanied by detectable changes in location. A diel rhythm was observed, with higher heart rates during the day. In a study of heart rate and oxygen consumption in rainbow trout, brown trout, and cod, Priede and Tytler (1977) found that although the range in metabolic rate for a given heart rate was too large to use heart rate as a measure of metabolism, it was possible to estimate the maximum metabolic rate for a given heart rate. Using this information combined with field measurements of heart rates, they concluded that the routine metabolic rate of free-ranging brown trout was not more than 1.55 times the standard rate. Heart rate data can be analyzed to obtain information on stress, physiological and behavioral rhythms, and environmental stimuli (Priede 1983), and thus may be more 
indicative of total metabolic rates than measures of activity alone.

\section{Electrical Activity of the Heart}

The fish heart consists of four chambers in series: The sinus venosus, atrium, ventricle, and bulbus arteriosus (telosts) or conus arteriosus (elasmobranchs) (Fig. 2.1). The functioning of the heart is described by Satche11 (1971). Heartbeats consist of a series of rhythmic contractions of the cardiac muscle mass, with the contraction of each cell associated with an action potential (Randa11 1978). Contraction is initiated in the pacemaker cells, and an electrical wave of excitation spreads over the heart, with the wave pattern determined by the nature and degree of coupling between cells. Large numbers of cells acting synchronously produce voltages which can be measured between various points of the body, and an electrocardiogram (ECG or EKG) is a recording of these changes in electrical potential resulting from heart activity. The waveform of the ECG is dependent on the physiological condition of the heart and the nature and placement of the recording electrodes.

ECG's have been recorded from several fishes and are similar to those of other vertebrate hearts (reviewed by Randal1 1968, Satchel1 1971) (Fig. 2.2). Leads are usually implanted in the tissue below the heart. A recording from a single heartbeat consists of a $P$ wave, associated with depolarization of the atrium, followed by a QRS wave complex signalling depolarization of the ventricle, and a $\mathrm{T}$ wave associated with repolarization of the ventricle. In addition, a V wave, corresponding to depolarization of the sinus venosus, has been 

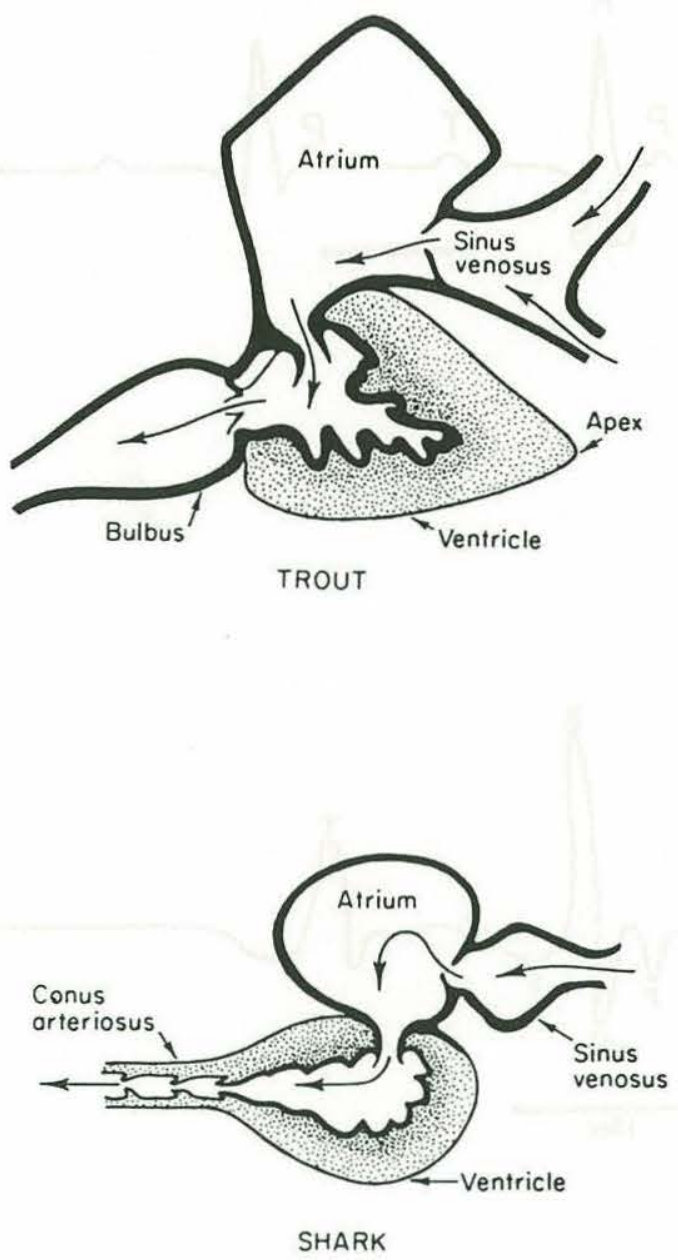

Fig. 2.1 Diagrams of the heart in a teleost (trout) and an elasmobranch (shark). From Randa11 (1968). 
a.

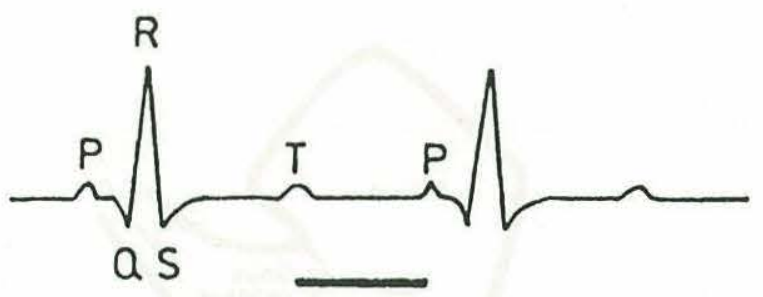

b.

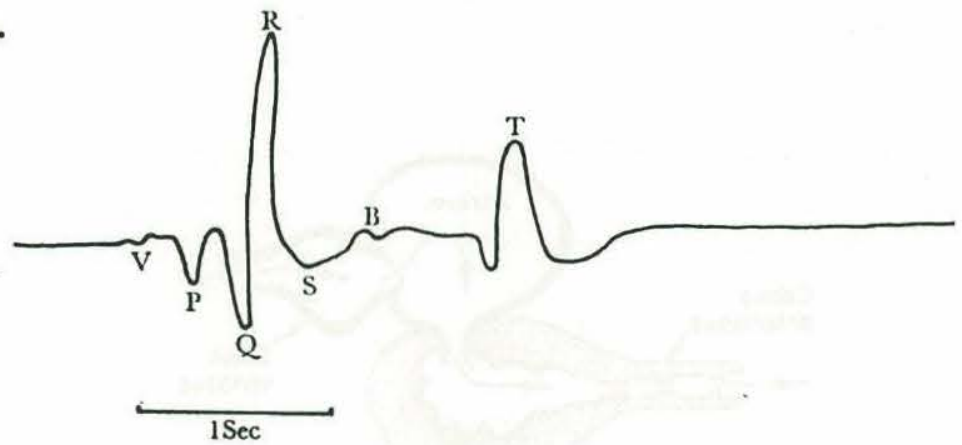

Fig. 2.2 Electrocardiograms of a teleost (a) and an elasmobranch (b). From Priede (1983) and Satche11 (1971). 
recorded in fish. A signal corresponding to the depolarization of the conus arteriosus, termed the B wave or Bd complex, has been observed in elasmobranchs (Kisch 1948). Similar ECG's have been recorded from swimming lemon sharks (Gilbert and Douglas 1963).

\section{Heart Rate Telemetry}

Frank (1968) used an FM radio transmitter to record ECGs from free-swimming rainbow trout. Studies by Nomura et al (1972) and Roberts et al (1973) have used radiotelemetry to make ECG recordings from rainbow trout, salmon, and goldfish under controlled conditions. Radio telemetry is not possible in seawater, due to the strong attenuation of radio waves, and acoustic transmitters are used for underwater telemetry (Kanwisher et al 1974). Several types of acoustic heartbeat transmitters have been developed and used in field conditions (reviewed by Priede 1983):

1. Frequency modulated heartbeat transmitter. This type of transmitter was used by Kanwisher et al (1974) and Wardle and Kanwisher (1974) to obtain ECG recordings from cod and salmon in laboratory tanks, and from tuna in Hawaii. The transmitter emits a continuous $50 \mathrm{kHz}$ carrier wave, and ECG voltages are detected and transformed into variations of the carrier frequency. The tag is carried in the stomach or externally, with the metal casing acting as the indifferent reference electrode, and the test lead inserted into the skin below the heart. Battery life was about three weeks with a range on the order of a hundred meters. This type of transmitter gives a complete record of the ECG, but the continuous output results 
in a high drain on the power supply.

2. Triggered pulse heartbeat transmitter. This was used by Priede and Tytler (1977) to record heart rates from brown trout in a 1ake. The transmitter uses the QRS wave to trigger individual sound pulses. The original transmitter operated at $220 \mathrm{kHz}$, and had a battery life of one week and a range of $400 \mathrm{~m}$. Lower frequency tags $(80 \mathrm{kHz})$ can have a range up to $2 \mathrm{~km}$. The advantage of this type of tag is a lower energy requirement, allowing a stronger pulse and greater range for a given power supply. However, no information is obtained on the shape of the ECG wave. In addition, there tends to be a decrease in measured ECG amplitude with time, which may compromise the trigger circuit.

3. Pulse transponder. This system was used by Storeton-West et a1 (1978) to record heart rates of plaice in the open sea. The QRS wave is used to trigger a pulse from the transmitter which activates a 1istening sonar to send an interrrogation pulse. The tag then responds with a second pulse which can be used to determine range. 4. Impedance pulse trigger system. This type of transmitter, described by Bottoms and Marlow (1979), uses an impedance measuring circuit to detect heartbeats. Heart movement produces a change in impedance between two electrodes on either side of the heart and triggers a sound pulse. This type of system was developed for use on invertebrates, and can be used to detect various types of movement. 


\section{Relationship between Heart Rate and Metabolic Rate}

A11 oxygen consumed by the tissues in respiratory metabolism is carried in the blood pumped by the heart. The relationship between heart rate and metabolic rate is therefore given by the Fick equation: 0xygen consumption rate $=\mathrm{HR} \times \mathrm{SV} \times\left(\mathrm{Ca}_{2}-\mathrm{Cv}_{2}\right)$

where $\mathrm{HR}$ is heart rate, $\mathrm{SV}$ is stroke volume, and $\mathrm{Ca}_{2}$ and $\mathrm{Cv}_{2}$ are arterial and venous oxygen contents (Schmidt-Nielsen 1979). Cardiac output, the flow rate of blood from the heart, is the product of heart rate and stroke volume. Oxygen pulse, the quantity of oxygen transported per heart beat, is the product of stroke volume and arteriovenous oxygen difference. In order to have a close relationship between metabolic rate and heart rate, oxygen pulse must remain constant or change predictably with changes in metabolic oxygen requirements (Webster 1967).

To support demands of increased metabolic rate, cardiovascular oxygen delivery may be increased by increasing either of the three variables in the Fick equation: heart rate, stroke volume, and oxygen extraction by the tissues. The relative contributions of the components of the oxygen transport system in adjusting to changes in metabolic rate in fish are rather poorly understood (Kiceniuk and Jones 1977).

In general, increased levels of activity are associated with elevated heart rates in fish. Wardle and Kanwisher (1974) monitored the heart rates of cod in laboratory tanks and found that when cruising speed was increased, heart rate also increased. Episodes of burst swimming were followed by periods of elevated heart rate, with 
the duration and maximum rate related to the distance covered. When chased to exhaustion, heart rates remained at high levels for time periods corresponding to the time required to repay oxygen debt. Kneis and Siegmund (1976) found strong correlations between heart rate and activity in carp under laboratory conditions. Priede (1974) demonstrated correlations between heart rate, swimming speed, and recovery from oxygen debt following activity in trout. In rainbow trout, Kiceniuk and Jones (1977) observed 1ittle change in heart rate with swimming speed at low velocities, while at higher speeds, heart rate increased linearly with speed up to the maximum heart rate. Sutterlin (1969) reported a similar relation between heart rate and swimming speed in brown trout, with maximum heart rate $60 \%$ higher than the resting rate; $25-35 \%$ increases in heart rate were observed with exercise in two other species of teleosts.

Johansen et al (1966) observed small increases in heart rate (not more than 20-30\%) during prolonged swimming in squalus suckleyi (= acanthias) and Heterodontus portusjacksoni, whereas Hanson (1967) reported $30-60 \%$ increases in heart rate during swimming in squalus. Scyliorhinus stellaris exhibited a $7 \%$ increase in heart rate with spontaneous swimming (Piiper et a1, 1977).

Reduced heart rates have been reported at the onset of exercise in both teleosts and elasmobranchs, probably in response to the disturbance used to initiate exercise (Stevens et al 1972, Wardle and Kanwisher 1974, Hanson 1967). Cardiac inhibition is commonly exhibited by fish in response to various external and physiological stimuli (Wardle and Kanwisher 1974, Randal1 1970). Bradycardia has 
been observed in lemon sharks in response to low frequency, high amplitude sounds (Nelson 1967).

Heart rates also increase with temperature. Stevens et a1 (1972) found that the heart rate of lingcod increased 2-3 times with a $6^{\circ} \mathrm{C}$ rise in temperature. Siegmund and Voge1 (1977) found that heart rates and activity levels in carp were mutually correlated with cyclic changes in temperature. Sudak and Wilbur (1960) reported a tripling of heart rate with a $10^{\circ} \mathrm{C}$ temperature increase in pithed Mustelus canis, and Hanson (1967) found a $Q_{10}$ of 1.8 for heart rate in intact Squalus suckleyi (= acanthias).

The relative contribution of heart rate to changes in cardiac output has been investigated in several studies. Stevens and Randa11 $(1967 \mathrm{a}, \mathrm{b})$ measured heart rate and oxygen consumption and calculated arterial and venous oxygen contents in rainbow trout during rest and moderate exercise. Increased cardiac output, corresponding to a five-fold increase in oxygen consumption, resulted from relatively large increases in stroke volume and sma11 (15\%) increases in heart rate. Kiceniuk and Jones (1977), using similar methods, found that a doubling of cardiac output resulted from a $30 \%$ increase in heart rate and $50 \%$ increase in stroke volume, whereas tripling of the cardiac output was accompanied by $40 \%$ increase in heart rate and $120 \%$ increase in stroke volume.

Piiper et al (1977), working with Scyliorhinus, found that spontaneous exercise resulting in a $50 \%$ increase in oxygen consumption was associated with a $7 \%$ increase in heart rate and $60 \%$ increase in stroke volume. Johansen et al (1966) used a Doppler ultrasonic blood 
flowmeter to telemeter blood velocity from the ventral aorta in swimming Squalus and Heterodontus, from which they calcuated volume flow rates. No significant increase in heart rate or blood flow rate was observed during exercise periods of 3-20 minutes.

In general, it appears that for $\mathrm{fish}$, changes in cardiac output during exercise are the result of large changes in stroke volume and relatively smal1 changes in heart rate (Randal1 1968). Although this may confound the relation between heart rate and metabolic rate, heart rate may still prove to be a useful indicator of energy expenditure, as demonstrated by Priede and Tytler (1977). They measured heart rate and oxygen consumption in three species of teleosts at different swimming speeds. Although the variability in oxygen consumption at any given heart rate was too great to use heart rate as a linear estimator of metabolic rate, it was possible to establish a more precise relationship between heart rate and maximum metabolic rate. At low heart rates, metabolic rate must also be low, whereas at high heart rates, metabolic rate may fall within a wider range. Although observed heart rate changes may be sma11, they may correspond to large changes in metabolic rate, and sma11 variations observed in extended heart rate records could provide considerable information on changes in metabolic rate (Priede and Tytler 1977).

Armstrong (1986) obtained a significant linear regression between heart rate and oxygen consumption rates in laboratory pike (Esox 1ucius) under conditions of rest, spontaneous activity, feeding and digestion. A single regression was applicable within a temperature range of $5-15^{\circ} \mathrm{C}$, for heart rates up to 55 beats.min ${ }^{-1}$. He used 
postprandial elevations in heart rate to estimate energy expenditure associated with food handling and digestion, and from this was able to estimate meal size with an error of less than $10 \%$. These studies suggest that heart rate may be a significant indicator of metabolic rate, and that heart rate telemetry from fish could additionally provide information on energy consumption, feeding frequency, and digestion rates (Priede 1983, Armstrong 1986).

\section{Swimming Hydrodynamics}

Fish are poikilotherms, with relatively low maintenance energy requirements, and the cost of locomotion is expected to be a major component of the energy budget (Brett and Groves 1979). Before examining the swimming behavior and energy cost of swimming in sharks, it would be useful to examine the basic hydrodynamic principles determining swimming energetics. Many sharks swim continuously, and any adaptations that increase swimming efficiency would be of particular importance.

The forces acting on a swimming fish can be resolved into vertical and horizontal components. The forces in the vertical direction are weight, buoyancy, and 1 ift, and those in the horizontal plane are thrust and drag. For constant speed horizontal motion to occur, opposing forces must be balanced (Magnuson 1978). When these forces are not in equilibrium, acceleration is produced.

The weight of a fish is equal to its mass times gravitational acceleration. This is opposed by a buoyant force equal to the weight of water displaced by its body volume. To maintain position in the 
water column, any excess weight (not offset by buoyancy) must be balanced by hydrodynamic lift produced during swimming (Magnuson 1978). When moving through a fluid, extended pectoral fins act as hydrofoils. Water flows faster over the upper surfaces, and the resulting pressure differential produces a net lift force. The lift force is given by the equation:

$$
L=1 / 2 \rho C_{L} \quad S_{L} U^{2}
$$

where $\mathrm{L}$ is hydrodynamic 1 ift, $\rho$ is the density of the water, $C_{L}$ is the lift coefficient, $S_{L}$ is the surface area of the lifting surface, and $U$ is the swimming speed. For fish which are negatively buoyant, a minimum sustained swimming speed is required for hydrostatic equilibrium (Magnuson 1970). The minimum speed is dependent on the density of the fish and the properties of the lifting surfaces. Sharks, lacking a swimbladder, are denser than water, with a submerged weight in seawater equal to $1 \%-7 \%$ of the weight in air (Bone and Roberts 1969). The negative buoyancy of sharks requires constant swimming and a minimum energetic output for pelagic species, and increases the importance of adaptations for efficient swimming. In many species, a large liver with high oil content supplies significant buoyancy (Baldridge 1970, 1972). Many pelagic sharks possess relatively large pectoral fins, which would further reduce surface loading, or weight borne per unit area of lifting surface. The heterocercal tail is thought to produce a lift force (Alexander 1965), although a more recent analysis indicates that the net effect of the heterocercal tail is to generate a force directed forward and downward through the center of balance, which is of $\mathrm{fset}$ by the planing action 
of the fins and head (Thomson and Simanek 1977). In addition, the cambered shape of sharks may allow the body to act as a hydrofoil, producing a component of 1ift (Harris 1936, Aleyev 1977). A dorsoventrally compressed caudal peduncle in some species may also generate lift as a result of lateral swimming movements (Weihs 1981a).

Drag, a force resisting the movement of a body through a fluid, results from frictional and inertial (pressure) forces (Webb 1978a). Drag can be subdivided into the following components: 1) friction drag; 2) form or pressure drag, which results from distortion of flow as the body moves through the fluid; 3) induced drag, which results from energy lost to vortices produced by fins, and 4) gill resistance (Magnuson 1978).

Friction drag, the integrated shear stress, arises from viscous forces acting in the boundary layer (Webb 1978a, White 1979). At the surface of the body, the fluid moves at the same velocity as the body (no-slip condition), and at some distance from the surface, flow velocity is independent of the body. The boundary layer is the region of flow adjacent to the body surface in which the velocity rapidly increases to $1 \%$ of the velocity of the outer flow. This is a region of high velocity gradients, resulting in frictional resistance to motion.

Pressure or form drag occurs as a result of distortion of flow around the body (Webb 1978a). The deformation of streamlines results in velocity changes which are accompanied by pressure variations. Velocity increases and pressure decreases to the shoulder (point of 
maximum width), resulting in a favorable pressure gradient in the direction of flow. Toward the trailing edge, velocity decreases and pressure increases. The resulting unfavorable pressure gradient promotes backflow in the boundary layer, which causes the boundary layer to separate from the body, forming a wake. The loss of kinetic energy to the wake is one component of form drag. The pressure across the wake (separated region) is lower than the pressure upstream (stagnation region), causing a net pressure force acting along the body resisting motion. The magnitude of the pressure drag depends on the point at which flow separation occurs, and is lowest on streamlined bodies, where separation occurs near the trailing edge. The drag force on a body with wetted surface area $S$ moving at speed $U$ through a fluid of density $\rho$ is given by the equation:

$$
D=1 / 2 C_{D} \rho S U^{2}
$$

where

$$
C_{D}=C_{f}+C_{p}
$$

$C_{D}$ is the total drag coefficient, $C_{f}$ is the frictional drag coefficient, and $C_{p}$ is the pressure drag coefficient (Webb 1975). The frictional drag coefficient can be estimated on the basis of Reynolds number $\left(R_{L}\right)$, the ratio of inertial to viscous forces. For laminar boundary layer flow $\left(R_{\mathrm{L}}<5 \times 10^{5}\right)$,

$$
C_{f}=1.33 \mathrm{R}_{\mathrm{L}}^{-0.5} \text {, }
$$

and for turbulent boundary layer flow $\left(R_{\mathrm{L}}>5 \times 10^{5}\right)$,

$$
\mathrm{C}_{f}=0.072 \mathrm{R}_{\mathrm{L}}^{-0.2} \text {, }
$$

where

$$
R_{L}=U L / V
$$

with $U$ equal to speed, I equal to length, and $v$ the viscosity of water. The relative contribution of friction and pressure drag 
depends on body shape, especially thickness. The total drag coefficient can be estimated from $\mathrm{C}_{\mathrm{f}}$ and the ratio of body depth to length (d/1) according to the equation (Hoerner 1958):

$$
C_{D}=C_{f}\left[1+1.5(d / 1)^{1 \cdot 5}+7(d / 1)^{3}\right]
$$

The factor in brackets has been estimated at approximately 1.2 for fish (Bainbridge 1961). It is important to note that these equations are for drag on rigid bodies in fluid flow. The drag forces on a flexible body in unsteady motion, such as a swimming fish, are poorly understood and can only be estimated indirectly (Webb 1978a).

Induced drag results from the production of lift and thrust forces on pectoral and caudal fins (Webb 1975, Magnuson 1978). This component of drag represents an increase over the combined friction and form drag for a body of equivalent size and shape which is not generating these forces. Pressure differences between opposite surfaces of pectoral and caudal fins produce cross flows at the tips of the fins which result in the formation of longitudinal fin tip vortices. In addition, acceleration of the water by the caudal $\mathrm{f}$ in produces vortices at the trailing edge of the fin. The induced drag is equivalent to the energy dissipated in these tip and trailing edge vortices.

Another component of drag on a swimming fish is that due to gill resistance (Brown and Muir 1970). Many pelagic fish, including sharks, employ ram ventilation, in which water is passed over the gills by swimming with the mouth open. The drag associated with water flow through the mouth and gills is proportional to ventilation volume, swimming speed, and pressure drop across the gills. 
Drag estimates for fish have been obtained by calculating the drag for rigid bodies of similar shape, or by measuring drag on dead fish or models (Webb 1975). The theoretical drag for a rigid fish-shaped body is the minimum possible value for drag on a swimming fish. The thrust force required for constant speed swimming is equal to the actual total drag, so any features which minimize drag would be expected to increase swimming efficiency.

Sharks possess a number of morphological adaptions which may function in drag reduction. Streamlining is of prime importance in reducing drag at high $R_{L}$ (White 1979), and is characteristic of fish shapes, including those of sharks (Thomson and Simanek 1977). A we11-designed fusiform body delays the separation of the boundary layer by having the point of maximum thickness placed back toward the middle of the body, with a gradually tapering tail. Drag is within $10 \%$ of the minimum value for a given volume when the fineness ratio (ratio of length to maximum thickness) is between 3 and 7 (Webb 1975). Typical values for sharks, including the blue shark, are 5.6 to 7 (Aleyev 1977). In many species of sharks, the body has elliptical cross sections with the long axis oriented horizontally near the head and anterior to the tail, and with the long axis oriented vertically at midbody. This may serve to reduce drag associated with lateral motions during swimming, as well as improving maneuverability (Weihs 1981a).

A boundary layer with turbulent flow is more resistant to separation than one with laminar flow (White 1979). The dermal denticles of sharks may serve to increase surface roughness, thereby 
inducing turbulent boundary layer flow, delaying separation, and reducing pressure drag (Bone and Howarth 1966). Longitudinally oriented ridges on the scales of pelagic sharks may reduce frictional drag by as much as $8 \%$ by influencing flow patterns in the boundary layer (Reif and Dinelacker 1982, Raschi and Musick 1984). The ridges are lower and more closely spaced for optimum drag reduction at high speeds as compared to low speeds. In several species of sharks, ridge heights and spacings were found to approach those predicted to maximize drag reduction at theoretical cruising speeds, and were closer to optimal values for burst speeds in faster species (Raschi and E1som 1986). Ridge dimensions for blue shark scales were optimal for a slower speed than that predicted by theory (Raschi and Musick 1984).

Induced drag from a fin is inversely proportional to the square of the span (Magnuson 1978). Fins with high aspect ratios (ratio of span to mean chord), such as the 1ong, narrow pectoral fins of the blue shark or the lunate tail of the mako, result in relatively low values of induced drag per unit of lift or thrust produced. In addition, when the caudal fin has a scooped out trailing edge, the central portion is filled by a vortex sheet, which functions as a continuation of the fin without increasing the surface area and frictional drag (Webb 1978a).

For constant speed forward motion to occur, a thrust force equal in magnitude to drag must be produced. Most fish generate thrust by lateral oscillations of the body and caudal $\mathrm{fin}$ which accelerate masses of water adjacent to the fish. In this undulatory mode of 
propulsion, described by Gray (1933) and summarized by Blake (1984), a wave of lateral movement travels down the body. The body can be considered to consist of a series of short segments which move with a periodic, transverse motion, with each segment lagging behind the one before it. Thrust results when a propulsive segment subtends a positive angle of attack to the incident water flow. This occurs when the propulsive wave travels down the body at a speed greater than the swimming speed of the fish.

Hydromechanical models developed by Lighthil1 (1969, 1970) and Wu (1971) and summarized by Webb $(1975,1978 a)$ describe the net effect of body movements in terms of trailing edge kinematics. A series of interacting propulsive segments progressively increase the momentum of the water surrounding the fish, with the maximum values attained at the trailing edge. The net thrust resulting from propulsive movements is equal to the rate at which the trailing edge transfers momentum to the wake. The total power generated by the trailing edge is the rate at which work is done against the wake momentum and is given by:

$$
\mathrm{P}=\mathrm{m} \cdot \mathrm{w} \cdot \mathrm{U} \cdot \mathrm{W}
$$

where $m$ is virtual mass (the mass of water affected by propulsive movements), $w$ is the velocity given to the water, $U$ is the swimming velocity, and $W$ is the lateral velocity of the trailing edge. Some kinetic energy is lost to the wake, and the net thrust power available to overcome drag is then

$$
P_{T}=P-1 / 2 m w^{2} U \text {. }
$$

Breder (1926) and Lindsey (1978) described and classified the swimming movements of fish based on the number of propulsive 
wavelengths contained in one body length, and the pattern of increasing amplitude of motion along the body. Fish which swim in the anguilliform mode possess more than half a wavelength in a body length, and lateral amplitude of motion is large over the entire body, increasing toward the tail. In the carangiform mode, less than one half wavelength is contained in the body, and large amplitude lateral movements are confined to the posterior half or third of the body. Subcarangiform swimmers have a wave pattern similar to the anguilliform mode, and a pattern of lateral amplitude similar to the carangiform mode. Variations in swimming modes are associated with variations in body form. Anguilliform swimmers possess elongate, flexible bodies, while carangiform swimmers have fusiform, less flexible bodies, and caudal fins of high aspect ratio, which are more efficient at producing thrust.

These swimming motions increase the drag force on the fish (Webb 1978a). Pressure drag is increased because lateral movements encourage cross flow and result in a more extensive wake. Locomotory movements decrease boundary layer thickness on the leading edges of propulsive segments, increasing the velocity gradient and thus the frictional drag. In addition, body movements generate a vortex force which is poorly correlated with trailing edge movements and which increases with time. The momentum associated with this force increases energy losses to the wake without increasing thrust.

These effects are greatest in anguilliform swimmers, which have large lateral movements involving most of the body. In carangiform swimmers, most of the body is held rigid, with large amplitude motions 
only at the tail, reducing the drag increment due to swimming and the magnitude of the time-dependent vortex force. Based on a hydromechanical model and motion pictures of swimming fish, Lighthill (1971) calculated the drag (= thrust) on an anguilliform swimmer (dace). He estimated the drag while swimming to be four times the theoretical drag calculated for an inactive, gliding fish moving through the water at the same speed. Webb (1971a, 1975) estimated swimming drag for trout, a subcarangiform swimmer, based on the effects of added drag loads on swimming kinematics, and found the swimming drag to be three to five times the theoretical gliding drag. The power output of swimming goldfish (another subcarangiform swimmer), estimated from oxygen consumption rate and an assumed $80 \%$ propeller efficiency, was 3.6 times that required to balance the theoretical gliding drag (Smit 1965). The ratio of swimming drag to gliding drag is expected to be less than 1.5 for carangiform swimmers (Weihs 1984, Magnuson 1978).

Thomson and Simanek (1977) classified sharks into four groups based on body form. Group 1 includes streamlined, fusiform sharks possessing a deep body, narrow caudal peduncle with lateral kee1, and high aspect ratio tail. These carangiform swimmers include the large, pelagic lamnid sharks. Sharks in Group 2 are more generalized, with elongate fusiform bodies and tail with a lower heterocercal angle. Many of the carcharhinid sharks are included in this group. Group 3 contains less fusiform, bottom-dwelling sharks with low aspect ratio tails. Group 4 contains squaloid sharks, which lack an anal fin. Webb and Keyes (1982), in a study of swimming kinematics on 
sharks in groups 2 and 3, concluded that they can be classified as anguilliform to subcarangiform swimmers, with the greatest increase in lateral amplitude occurring on the third quarter of the body. Trends in body form and locomotory pattern are similar to those in teleosts, with more carangiform species having more fusiform bodies and deeper tails, and more anguilliform swimmers having more elongate bodies. Tailbeat frequency is the only kinematic variable affecting thrust in teleosts over most of the speed range (Bainbridge 1958, Hunter and Zweife1 1971). Tailbeat frequency shows a linear increase with swimming speed, whereas tailbeat amplitude and propulsive wavelength remain constant. In contrast, sharks modify both tailbeat amplitude and the length of the propulsive wave in addition to tailbeat frequency with changes in swimming speed (Webb and Keyes 1982). These adjustments may be explained in terms of optimizing hydrodynamic interactions between median fins (Lighthi11 1970, Webb 1978a, Webb and Keyes 1982). The trailing edge of each median fin sheds a vortex sheet which flows along the body at the speed of the fish. When there is a second re-entrant fin (a downstream $f$ in with depth at least as great as that of the vortex sheet), the vortex sheet from the upstream $f$ in is absorbed at the leading edge of the second fin without affecting the downstream wake. The net effect is that the vortex sheet fills the gap between the two fins, producing thrust as though there were a continuous $f$ in, but with reduced body surface area and therefore reduced drag. When the median fins are widely spaced, as is the case with the first dorsal fin and caudal fin in sharks (second dorsal is not re-entrant), the vortices shed by the trailing 
edges of these fins can interact to produce a net increase in thrust and efficiency. This effect is maximized when the phase difference between the movements of the incident vortex sheet and the leading edge of the downstream $\mathrm{fin}$ is greater than $0.5 \pi$. The phase difference was close to or greater than this value in several species of sharks swimming at voluntary speeds (Gray 1933, Webb and Keyes 1982). It is possible that, in sharks, wavelength and amplitude are modified in addition to tailbeat frequency with increased speed to maintain an optimal phase difference while increasing thrust (Webb and Keyes 1982).

In addition to morphological adaptations described above for minimizing drag and increasing efficiency of thrust production, behavioral adaptations may reduce the energy requirements for swimming. One of the most obvious parameters that can be adjusted is swimming speed. Weihs (1973b) calculated a theoretical optimal swimming speed for fish, i.e. the constant speed at which the energy expended per unit distance traveled is minimal. The rate of energy expenditure for locomotion is given by the equation:

$$
\mathrm{n} P=\mathrm{T} U
$$

where $\mathrm{P}$ is propulsive power, $\mathrm{n}$ is efficiency, $\mathrm{T}$ is thrust, and $\mathrm{U}$ is swimming speed. The total rate of energy expenditure is then given by:

$$
E=P+M
$$

where $M$ is the standard metabolic rate. Assuming $M$ to be constant, subsituting theoretical and empirical relationships between speed, thrust, and efficiency, and solving for the speed at which the distance covered per unit of energy expended is maximum, the optimal 
speed is estimated to be the speed at which the total rate of energy consumption is approximately two times the standard metabolic rate. By applying empirical relationships between size, speed, and metabolic rate, Weihs (1977) obtained an equation for optimum speed as a function of length:

$$
\mathrm{U}_{0}=0.50 \mathrm{~L}_{\mathrm{f}}^{0.43}
$$

where $\mathrm{U}_{0}$ is optimum speed in $\mathrm{m} \cdot \mathrm{s}^{-1}$, and $\mathrm{L}_{\mathrm{f}}$ is fork length in $\mathrm{m}$. Ware (1978) obtained the same exponent for salmon using metabolic parameters. Voluntary swimming speeds observed for several species of sharks are close to predicted optimal cruising speeds (Weihs et al 1981, Weihs 1984). Swimming with currents would result in additional distance covered per unit of energy expended (Weihs 1984).

Another potential energy-efficient swimming behavior is burst and coast swimming (Weihs 1974). This involves alternating periods of acceleration and inactive gliding. The theoretical energy savings achieved by swimming in this mode instead of swimming at constant speed are based on the reduced drag of a coasting fish relative to an actively swimming one. Savings of more than $50 \%$ in the energy required to cover a given distance are possible, with the relative energy savings depending on the ratio of swimming drag to gliding drag, and the initial and final speeds of each phase. Savings are greatest for fish with high drag ratios (such as anguilliform swimmers) and a short burst phase (1-2 propulsive cycles). This behavior is theoretically advantageous for high speed anaerobic swimming as well as long term steady cruising (Videler and Weihs 1982). Burst and coast swimming has been observed in several species 
of fish, and kinematic data from cod and saithe indicate that these fish use initial and final velocities close to those predicted to maximize savings (Weihs 1974, Videler and Weihs 1982).

A variation of this two-phase swimming mode which would be possible for negatively buoyant fish such as sharks involves an extended glide period, using the submerged weight of the fish to provide thrust while coasting downward (Weihs 1973a). The fish would sink to some depth, after which it would actively swim back to the original depth. Again, the reduced energy cost of swimming in this mode relative to constant speed horizontal swimming is based on the reduced drag force during gliding as compared to swimming. Although the potential energy lost during sinking must be made up by active upward swimming, the net cost of forward movement is reduced by having a portion of this forward movement being accomplished by gliding, during which drag and therefore the required thrust are reduced. The energy savings possible in the swim-and-glide mode depend on the drag ratio and the angles of descent and ascent. For anguilliform swimmers, more than $50 \%$ savings in the energy needed to cross a given distance relative to constant speed horizontal swimming would be theoretically possible. Flounders have been observed to utilize a swim-and-g1ide pattern (011a et a1 1972), and periodic depth changes have been recorded from several negatively buoyant species, including skipjack tuna (Yuen 1970), swordfish (Carey and Robison 1981), and mako sharks and blue sharks (Carey et a1 1981, Carey and Scharold in review). If this diving behavior is associated with a two phase swimming mode, the energy savings from gliding would result in 
significant increases in range for a given energy expenditure. This gain in range, along with the rapid depth changes made possible by the lack of a swim bladder, would increase the sea-space available to the fish, and these advantages of negative buoyancy may compensate for the requirement of continuous movement to produce 1ift (Weihs 1973a). 


\section{BEHAVIOR OF THE FREE-SWIMMING BLUE SHARK, Prionace glauca: DEPTH, SPEED AND TAILBEAT FREQUENCY}

\section{ABSTRACT}

Acoustic telemetry was used to record depth, swimming speed and tailbeat frequency from blue sharks in northwestern Atlantic slope waters near Hudson Canyon. Records obtained from five sharks show a consistent pattern of vertical migration between the surface and depths as great as 450 meters, with the deepest dives occurring during the daytime and shallower dives at night. Mean swimming speed was

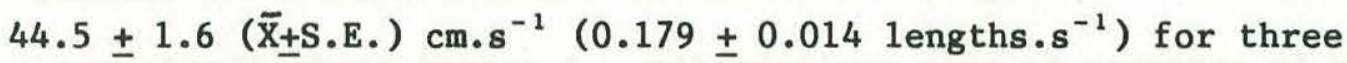
sharks, with short bursts up to $180 \mathrm{~cm} \cdot \mathrm{s}^{-1}$. Mean tailbeat frequency was $0.335 \pm 0.021$ beats. $\mathrm{s}^{-1}$. Measurement of swimming speed and rate of vertical movement during dives permits calculation of angles of ascent and descent. For 84 dives deeper than $50 \mathrm{~m}$, the descent angle averaged $8.0 \pm 0.7$ degrees from the horizontal while the ascent angle was $6.4 \pm 0.5$ degrees. Tailbeat records indicate that blue sharks actively swam downward during most of the descent, with brief periods of gliding which appear to be associated with the most rapid descent rates. The observed diving behavior does not match that predicted by theory to be energetically optimum for migration, and may instead represent a strategy for encountering and capturing prey. 


\section{INTRODUCTION}

The blue shark, Prionace glauca, is one of the most abundant pelagic sharks and is widely distributed in tropical, subtropical, and temperate waters (Bigelow and Schroeder 1953, Compagno 1984), yet relatively little is known of its swimming behavior. Tagging studies have revealed some of the large-scale movement patterns of blue sharks (Casey 1985). On a smaller scale, Sciarrotta and Nelson (1977) reported diel behavior of blue sharks near California, recording depth, swimming speed, temperature, and rate of horizontal movement by telemetry. The sharks remained near the surface, showed an increase in activity levels at night, and exhibited onshore/offshore movements, probably in response to prey availability. A second study (Landesman 1984) recorded several dives to depths greater than 170 meters. Blue sharks have been reported from greater depths in both the Atlantic and Pacific (Pethon 1970, Davies and Bradley 1972).

Swimming is expected to account for a major proportion of energy expenditure in pelagic sharks. Sharks are negatively buoyant (Bone and Roberts 1969), and must maintain position in the water column by swimming at speeds sufficient to produce the required lift forces on pectoral fins, as do tunas (Magnuson 1970). Tagging studies in the Atlantic have shown that blue sharks migrate extensively for purposes of reproduction, feeding, and/or to remain in optimum temperature ranges (Stevens 1976, Casey 1985). Swimming is also involved in locating and capturing prey and ventilating the gills. Since locomotion costs may represent a significant proportion of total 
energy output for the blue shark, adaptations to reduce the energy cost of swimming would be of major importance.

Sharks possess numerous morphological features which have been proposed to increase swimming efficiency (Bone and Howarth 1966, Weihs 1981a, Webb and Keyes 1982). Behavioral adaptations may result in energy savings as we11. Based on energetic considerations, Weihs (1973b) derived a relationship to predict optimal cruising speeds. The voluntary swimming speeds observed for several species of sharks were close to these predicted values (Weihs et a1 1981, 1984). Blue sharks are reported to spend periods of time swimming slowly in surface waters (Bigelow and Schroeder 1953); this slow swimming may be an energy conserving mechanism. The energy cost of migration could also be reduced by making use of currents (Weihs 1984). Another energy-efficient swimming behavior which could be employed by negatively buoyant fish involves a two-phase swimming pattern consisting of periods of passive downward gliding followed by active swimming back up to the starting depth (Weihs 1973a). In theory, this swimming pattern could result in energy savings of more than $50 \%$ relative to constant horizontal swimming. The potential energy savings result from the reduced drag forces on a gliding fish as compared to an actively swimming one. The savings are greatest for fish which swim in the anguilliform or subcarangiform modes typical of carcharhinid sharks (Webb and Keyes 1982). Blue sharks in slope waters of the northwestern Atlantic have been observed to make regular excursions between the surface and depths to 250 or more meters (Carey and Gibson 1987). Several other blue sharks exhibited similar 
behavior, one of which swam to depths as great as 600 meters (Carey and Scharold in review). This deep diving behavior is associated with directed movements offshore and southward and is observed during late summer and fall, the period of migration to the winter range (Casey 1985). Thus the blue shark, a negatively buoyant anguilliform swimmer exhibiting long distance migrations and periodic diving behavior, is a good candidate to benefit from the two-phase swimming strategy. This study was conducted to determine whether the vertical swimming patterns observed in blue sharks may be associated with a two phase swimming mode.

\section{METHODS}

Acoustic telemetry was used to follow the horizontal and vertical movements of blue sharks and to record their tailbeat frequencies and swimming speeds. Experiments were performed in North Atlantic slope water southeast of Long Island, New York. A total of five sharks were fitted with depth, tailbeat and/or speed transmitters and tracked for 1-4 days during late summer-early autumn of 1984-1986.

\section{Transmitters}

The depth transmitters used in this study are described in detail in Carey and Robison (1981) and Carey and Scharold (in review). For two of the sharks (Nos 12 and 14), single-channel depth transmitters were used. Two-channel multiplex transmitters were used on sharks 16 and 23, with one channe1 transmitting depth and the other channe1 transmitting speed. The dimensions of the multiplex transmitters were approximately $14 \mathrm{~cm} \times 5 \mathrm{~cm} \times 3 \mathrm{~cm}$ and they weighed $90 \mathrm{~g}$ in water. The 
multiplex cycle period was 256 seconds, with 1.5 min of each cycle transmitting depth data, and 2.5 min transmitting speed. A water temperature transmitter was used instead of a depth transmitter on shark 22 .

The tailbeat transmitter used a reed switch (Hamlin MSRR2185) arranged so that movement of a hinged vane with each tail stroke produced a $40 \mathrm{kHz}, 30 \mathrm{~ms}$ acoustic pulse. The transmitter was cast in plastic epoxy (Hyso1) and mounted on a polycarbonate (Lexan) chassis. The chassis extended behind the transmitter and formed a frame which supported the vane and the reed switch. A magnet (Hamlin H31604) was mounted on the vane so that deflection of the vane caused the switch to close once in each full tailbeat cycle. The dimensions of the transmitter were $3 \mathrm{~cm} \times 3 \mathrm{~cm} \times 12 \mathrm{~cm}$, with a weight in water of $50 \mathrm{~g}$. The overall length of the chassis was $22 \mathrm{~cm}$ with a frame height of 6 $\mathrm{cm}$. The transmitter was secured to the skin of the animal using plastic cable ties passed through holes at each end of the chassis.

The speed sensor in two of the swimming speed transmitters was a four-bladed propeller connected to the transmitter by a $30 \mathrm{~cm}$ long flexible cable. The propeller was made of syntactic foam with a blade diameter of approximately $7 \mathrm{~cm}$ and was weighted to neutral buoyancy so that it would align with the flow. A magnet in the propeller shaft activated a reed switch encased in the shaft housing once for each revolution of the propeller. A debounce circuit and a divide by four circuit generated one sound pulse $(32.768 \mathrm{kHz})$ for every four revolutions.

In a third transmitter, the speed sensor was modified from a 
plastic surfboard speedometer which consisted of a rotor in a streamlined plastic housing with openings allowing water to flow past the rotor. A magnet mounted on the rotor closed a magnetic switch in the housing once for each revolution of the rotor.

The speed sensors were calibrated by towing in a flume with a variable speed electric cart. The frequency of revolution of the propeller was measured during timed runs over a $10 \mathrm{~m}$ section of the tank. Rotation frequency was linear with speed over a range of 10 $\mathrm{cm} \cdot \mathrm{s}^{-1}$ to $120 \mathrm{~cm} \cdot \mathrm{s}^{-1}$ (the maximum towing speed).

\section{Tagging}

Blue sharks used in the experiments were caught with longline gear, using Atlantic mackerel, menhaden, or squid as bait. Each shark was brought alongside the vesse1, the tail looped with a cable passed through a metal pole, and lifted to the deck with a hydraulic crane. A hose was placed in the mouth to irrigate the gills with a low pressure stream of seawater. The depth transmitter, depth-speed multiplex transmitter, or speed and water temperature transmitters were attached to the base of the first dorsal fin using a plastic cable tie passed through a hole in the fin. For speed transmitters, the propeller cable was additionally secured to the tip of the first dorsal fin, allowing the propeller to trail behind the fin with minimal interference. For the transmitter in which the speed sensor was a surfboard speedometer, the speedometer housing was secured with sutures to the side of the first dorsal fin with the opening oriented forward. The tailbeat transmitter was secured to the dorsal midline of the tail using the base of the second dorsal fin and the skin along 
the midline of the tail anterior to the precaudal groove as points of attachment. The shark was then returned to the water, after a total time of approximately 10 minutes on deck.

\section{Tracking}

The receiving equipment was similar to that described in Carey and Robison (1981). Directional hydrophones were towed alongside the vesse1, with 1istening direction remotely controlled. The ship's course approximated the horizontal movement of the shark. The bearing to the shark was determined by the direction from which the hydrophones picked up the strongest transmitter signals. The ship was steered toward the signal source, and position was plotted (Loran C) when the ship was directly over the shark, as determined by equal signal strength in all directions. Position was plotted at approximately hour1y intervals.

In the early experiments, depth and tailbeat frequency data were taken manually every five minutes, more frequently when the shark was changing depth and less frequently when it was on the surface, where contact was occasionally lost due to poor propagation conditions. Depth was determined by timing a fixed number of pulses to the nearest $0.01 \mathrm{~s}$ and converting the pulse frequency to depth using a calibration curve for the transmitter. Tailbeat pulses were timed in the same manner and converted to frequencies. In later experiments, depth (or temperature) and swimming speed data were continuously recorded on a portable computer, using the system described by Carey and Scharold (in review). The data files were later edited and averaged to obtain one value of depth and speed for each multiplex data period. For 
shark 22, temperature data were converted to depth using an isotherm-depth plot constructed from bathythermograph casts made approximately every 4 hours .

\section{RESULTS}

Five blue sharks were tagged and tracked for 1-4 days each. Information on the individual sharks is presented in Table 3.1 . Swimming speed transmitters were attached to three sharks. Tailbeat transmitters were attached to a11 five animals, but due to breakage, fouling, or malfunction, continuous tailbeat records were obtained only from the two sharks which did not carry speed transmitters. Simultaneous records of speed and tailbeat frequency were obtained on1y from shark 22, where the tailbeat transmitter worked intermittently for several hours.

Figure 3.1 is a plot of depth and tailbeat frequency with time for sharks 12 and 14. Depth and swimming speed for sharks 16, 22 and 23 are shown in Figure 3.2. The sharks repeatedly swam between the surface and depths of $100-450 \mathrm{~m}$, making dives at approximately 1-2 hour intervals. Time at maximum depth was short, with ascent beginning almost immediately. For sharks 16, 22, and 23, there appears to be a diel pattern to the dives, with deeper dives (200-400 m) occurring during the day and shallower, more frequent dives at night.

A summary of swimming speed, tailbeat frequency, rate of depth change, and swimming angle during descent and ascent for 84 dives of depth change greater than $50 \mathrm{~m}$, and for 27 dives deeper than $150 \mathrm{~m}$, is 
Table 3.1. Length, sex, tagging date, and duration of track for five blue sharks tagged with depth, swimming speed and tailbeat transmitters.

\begin{tabular}{|c|c|c|c|c|c|}
\hline NO. & SEX & $\begin{array}{l}\text { FORK LENGTH } \\
\text { CM }\end{array}$ & DATE TAGGED & $\begin{array}{l}\text { DURATION } \\
\text { OF TRACK }\end{array}$ & $\begin{array}{l}\text { TRANSMITTER } \\
\text { TYPE }\end{array}$ \\
\hline 12 & M & 200 & $09 / 27 / 84$ & $85 \mathrm{hr}$ & depth, tailbeat \\
\hline 14 & M & 247 & $10 / 09 / 84$ & $13 \mathrm{hr}$ & depth, tailbeat \\
\hline 16 & M & 223 & $10 / 27 / 85$ & $46 \mathrm{hr}$ & $\begin{array}{l}\text { depth, speed, } \\
\text { tailbeat* }\end{array}$ \\
\hline 22 & M & 271 & $08 / 09 / 86$ & $32 \mathrm{hr}$ & $\begin{array}{c}\text { water temperature, } \\
\text { speed, tailbeat }\end{array}$ \\
\hline 23 & M & 262 & $08 / 16 / 86$ & $56 \mathrm{hr}$ & $\begin{array}{l}\text { depth, speed, } \\
\text { tailbeat }\end{array}$ \\
\hline
\end{tabular}




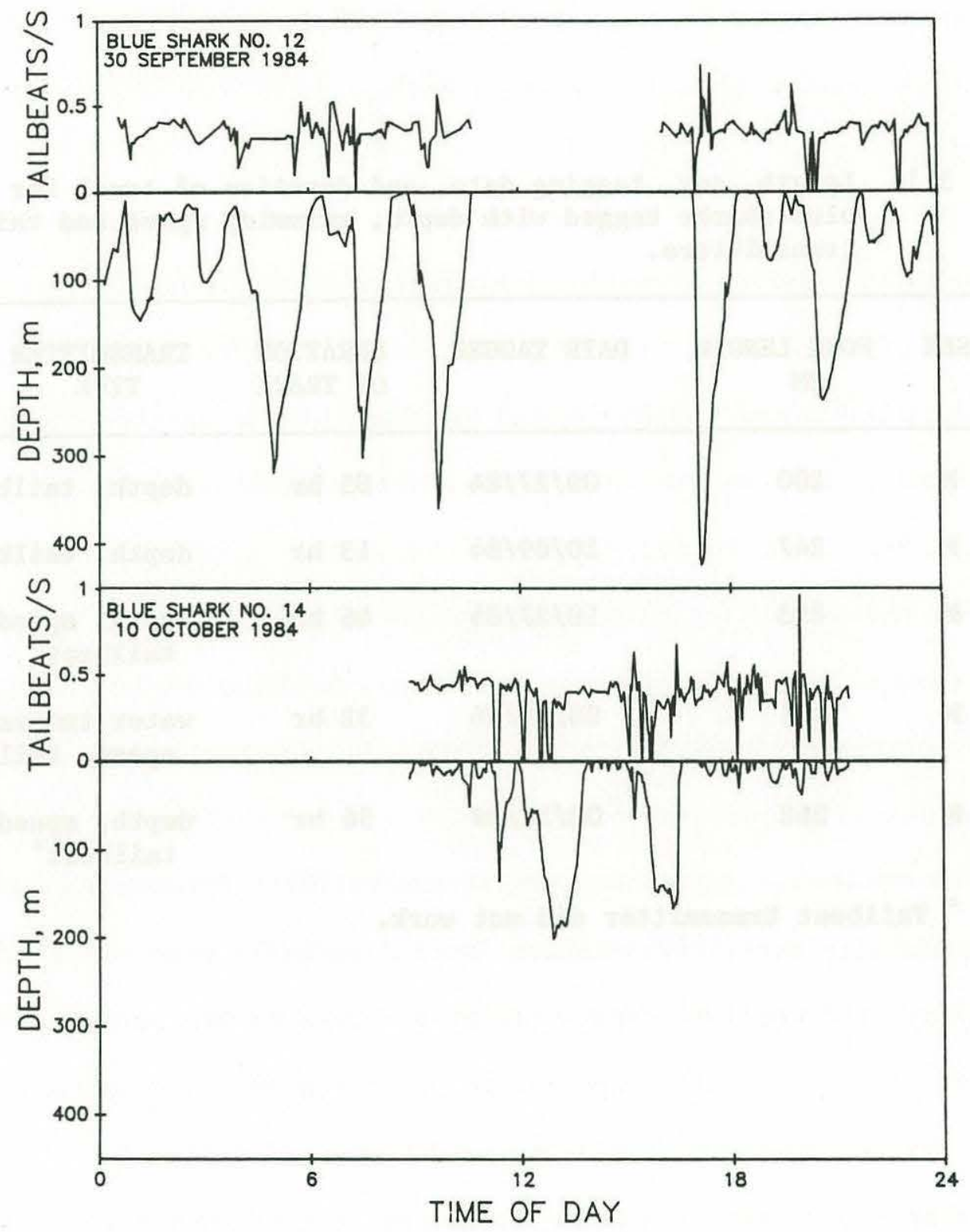

Fig. 3.1 Telemetry record of tailbeat frequency (upper 1ine) and depth (lower line) for blue sharks 12 and 14. Each box represents one day. 


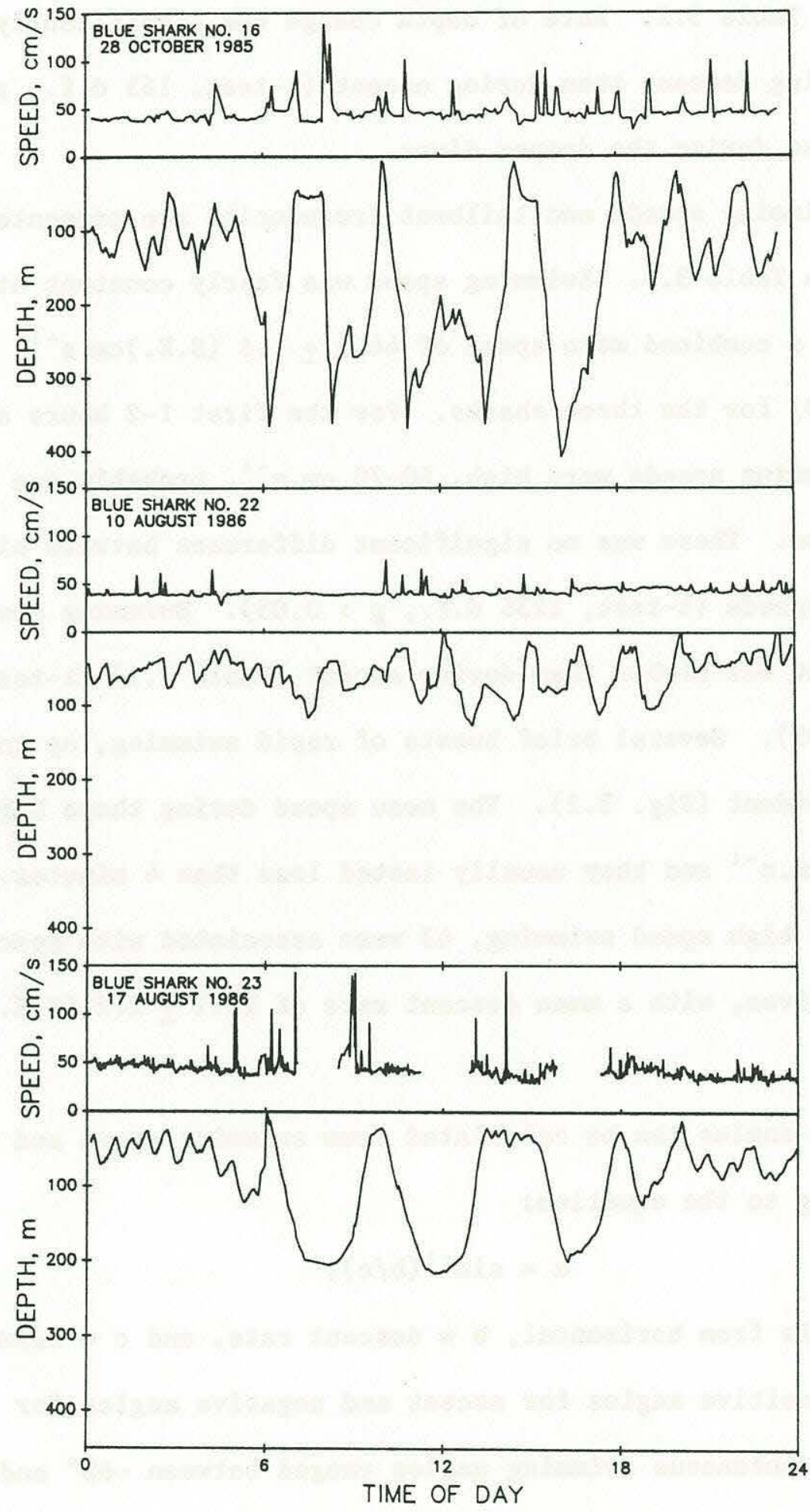

Fig. 3.2 Telemetry record of swimming speed (upper 1ine) and depth (lower 1ine) for blue sharks 16, 22, and 23. Each box represents one day. The speed sensor on shark 23 did not function at depths greater than about $200 \mathrm{~m}$. 
presented in Table 3.2. Rate of depth change was significantly greater during descent than during ascent (t-test, 165 d.f., p < $0.01)$, more so during the deeper dives.

Mean swimming speeds and tailbeat frequencies are presented for each shark in Table 3.3. Swimming speed was fairly constant at 40-50 $\mathrm{cm} . \mathrm{s}^{-1}$, with a combined mean speed of $44.5 \pm 1.6$ (S.E.) $\mathrm{cm}^{-\mathrm{s}^{-1}}$ (range 28-180) for the three sharks. For the first 1-2 hours after release, swimming speeds were high, $60-70 \mathrm{~cm} \cdot \mathrm{s}^{-1}$, probably due to tagging trauma. There was no significant difference between nighttime and daytime speeds (t-test, 2236 d.f., $p>0.05$ ). Swimming speed during descent was higher than during ascent (Table 3.1) (t-test, 93 d.f., p $<0.05)$. Several brief bursts of rapid swimming, up to 180 $\mathrm{cm} \cdot \mathrm{s}^{-1}$ are evident (Fig. 3.2). The mean speed during these bursts was over $80 \mathrm{~cm} \cdot \mathrm{s}^{-1}$ and they usually lasted less than 4 minutes. of 60 periods of high speed swimming, 43 were associated with descending portions of dives, with a mean descent rate of $15.1 \pm 2.2$ (S.E.) $\mathrm{cm} \cdot \mathrm{s}^{-1}$.

Swimming angles can be calculated from swimming speed and descent rate according to the equation:

$$
\alpha=\sin ^{-1}(b / c)
$$

where $\alpha=$ angle from horizontal, $\mathrm{b}=$ descent rate, and $\mathrm{c}=$ swimming speed, with positive angles for ascent and negative angles for descent. Instantaneous swimming angles ranged between $-60^{\circ}$ and $+30^{\circ}$, and were slightly steeper for descent than ascent, though the difference was not significant (Table 3.1) (t-test, 93 d.f., p > 0.05). Overal1, more than $90 \%$ of the time was spent swimming at 
Table 3.2. Rate of change in depth, swimming speed, swimming angle, and tail beat frequency for dives with depth change greater than $50 \mathrm{~m}$ and for dives with depth change greater than $150 \mathrm{~m}$. Values are mean $\pm \mathrm{S} . \mathrm{E}$.

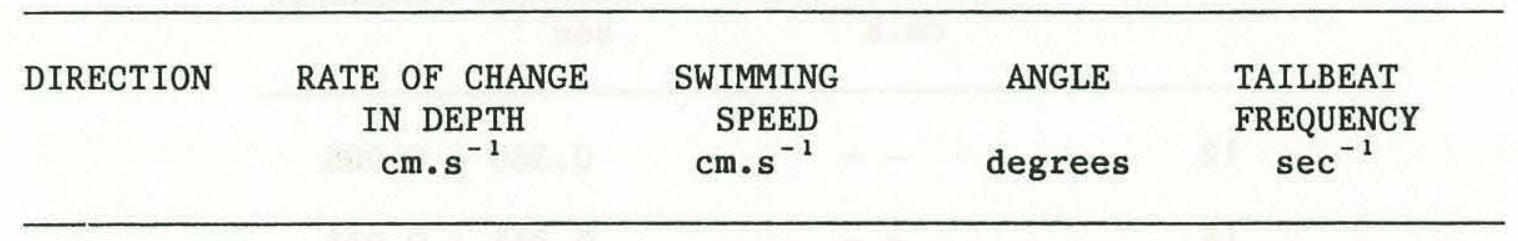

DIVES $\geq 50 \mathrm{M}$

$\begin{array}{lrlll}\text { DOWN } & 12.0 \pm 1.7 & 50.0 \pm 2.1 & 7.96 \pm 0.68 & 0.238 \pm 0.019 \\ \text { UP } & 5.6 \pm 0.3 & 45.2 \pm 5.2 & 6.37 \pm 0.45 & 0.369 \pm 0.006\end{array}$

DIVES $\geq 150 \mathrm{M}$

$\begin{array}{lllll}\text { Down } & 20.8 \pm 4.6 & 54.3 \pm 5.6 & 8.57 \pm 1.32 & 0.281 \pm 0.038 \\ \text { Up } & 7.5 \pm 0.7 & 48.7 \pm 1.8 & 7.70 \pm 1.05 & 0.367 \pm 0.008\end{array}$


Table 3.3. Mean swimming speeds and tailbeat frequencies for five blue sharks. Values are mean \pm S.E.

\begin{tabular}{ccc}
\hline SHARK NO. & $\begin{array}{c}\text { SWIMMING SPEED } \\
\mathrm{cm} . \mathrm{s}^{-1}\end{array}$ & $\begin{array}{c}\text { TAILBEAT FREQUENCY } \\
\mathrm{sec}^{-1}\end{array}$ \\
\hline 12 & -- & $0.360 \pm 0.006$ \\
14 & - & $0.351 \pm 0.011$ \\
16 & $47.4 \pm 0.5$ & -- \\
22 & $41.7 \pm 0.2$ & $0.293 \pm 0.004$ \\
23 & $44.3 \pm 0.3$ & --
\end{tabular}


angles within $10^{\circ}$ of the horizontal.

Tailbeat frequencies were generally very constant, with a combined mean of $0.335 \pm 0.021$ beats. $s^{-1}$ for three sharks, a1though high rates, up to 1.7 beats. $\mathrm{s}^{-1}$, were occasionally recorded. Mean descending tailbeat frequencies were significantly lower than ascending frequencies ( $t-t e s t, 73$ d.f., $p<0.01$ ). G1iding periods (periods with no tailbeats for at least 10 seconds) were also detected. For 49 gliding periods, the mean descent rate was $20.4 \pm$ 4.4 (S.E.) $\mathrm{cm} . \mathrm{s}^{-1}$, with a range of $2-180 \mathrm{~cm} \cdot \mathrm{s}^{-1}$. A11 of these gliding periods were associated with descending portions of dives. The glides were of short duration, ranging from 1 to 10 minutes. The data on gliding periods should be interpreted with some caution, however. Some gliding periods in early experiments may not have been detected, because the absence of tailbeat signals was mistaken for poor signal reception instead of gliding. Gliding descent rates are also subject to error. For those experiments in which depth data were taken manually, the time corresponding to a given depth measurement was recorded to the nearest minute. As a result, the timing error in descent rates calculated for short time intervals may be significant. In addition, gliding periods may not have lasted for the entire interval between consecutive depth measurements, and therefore gliding descent rates may actually represent a combination of gliding and swimming descent.

A11 sharks moved consistently in an offshore direction after release. Sharks 12 and 14, which were captured near Hudson Canyon, moved directly south. Shark 22, which was captured farther offshore, 
headed south for a day, then turned to the southeast. The track of shark 16 described a large semicircle within the boundary of a gulf stream eddy (warm core ring 85-C), circling east and then south, following the clockwise rotation of the eddy. Shark 23 moved southeast initially and later shifted course to the south. The course deflection followed the boundary of another gulf stream eddy (warm core ring $86-\mathrm{E})$.

The net rate of horizontal movement of a shark, as determined by plotting its course, is a resultant of the rate of movement of the shark relative to the water (swimming velocity) and the rate of movement of the water mass (current velocity). The maximum rate of horizontal movement would result if the shark swam in the same direction as the current, in which case the net rate of movement would equal the sum of the magnitudes of the swimming velocity and the current velocity. If the shark did not swim with the current, or if its path did not approximate a straight line between plotting points, the net rate of movement indicated by the Loran plot would be less than the arithmetic sum of swimming speed and current speed. The average rate of horizontal movement of shark 16 in warm core ring $85-\mathrm{C}$, as determined by hourly plotting, was $100 \mathrm{~cm} \cdot \mathrm{s}^{-1}(3.6$ $\left.\mathrm{km} \cdot \mathrm{hr}^{-1}\right)$. The mean swimming speed of the shark was $47 \mathrm{~cm} \cdot \mathrm{s}^{-1}(1.7$ $\mathrm{km} \cdot \mathrm{h}^{-1}$ ) (Table $3 \cdot 3$ ). Current speed in ring $85-\mathrm{C}$ was estimated from longline drift to be between 1.7 and $2.2 \mathrm{~km} / \mathrm{hr}$. The measured rate of horizontal movement $\left(3.6 \mathrm{~km} \cdot \mathrm{hr}^{-1}\right) \mathrm{falls}$ within the range calculated by adding swimming speed and current speed $\left(3.4-3.9 \mathrm{~km} \cdot \mathrm{hr}^{-1}\right)$, suggesting that the shark swam with the current on a direct course. 


\section{DISCUSSION}

The tagged blue sharks exhibited a swimming pattern consisting of periods of swimming at the surface, alternating with dives to depths of $100-450 \mathrm{~m}$. Periodic deep dives and directed offshore movements were observed in eight other blue sharks tracked in slope waters of the northwestern Atlantic during late summer and fall (Carey and Scharold in review). In the same study, several blue sharks tracked in shelf waters of Georges Bank during the summer remained near the surface and exhibited little directed movement, and several others tracked in slope waters during spring and early summer did not make regular deep dives. It appears that in the northwestern Atlantic, deep diving behavior is typical of blue sharks in deep waters beyond the continental shelf and occurs during the late summer and autumn, coinciding with the period of migration to the winter range (Casey 1985). Since the sharks in the present study displayed consistent, directed horizontal movement in conjunction with regular vertical excursions, this swimming pattern may be considered to represent a long range cruising mode.

The swimming speeds of these blue sharks fall within the range of speeds reported for blue sharks of similar size near California (Sciarrotta and Nelson 1977). The Pacific sharks exhibited an increase in swimming speed at night, coincident with directed onshore movements which were probably associated with feeding activity. The constant overall speed of the sharks in the present study may be related to long-distance migratory behavior. Based on energetic cost 
optimization, Weihs $(1973 \mathrm{~b}, 1977)$ developed a predictive equation for optimal swimming speed. This is the speed at which minimum energy is expended per unit of distance traveled, and is expected to be the swimming speed at which the total metabolic rate is approximately twice the standard rate. Several species of sharks have been observed to swim at speeds close to the predicted optimal value (Weihs et al 1981, Weihs 1984). The average swimming speeds of several species of sharks, taken from the 1iterature, are presented as a function of fork length in Fig. 3.3 along with the mean speed obtained for the blue shark in this study. The line indicates the theoretical optimum swimming speed (Weihs 1984). Most points fall close to the predicted line, but the speed for the blue shark falls considerably below the 1ine. This would be expected if the blue shark has a lower standard metabolic rate than similar-sized sharks, or if it possesses adaptations which enable it to swim more efficiently at slower speeds. In a study of hydrodynamic aspects of shark scales, Raschi and Musick (1984) found that the dimensions of blue shark scales were not optimal for drag reduction at the speeds predicted by the equation in Fig. 3.3. The ridges on the scales were higher and more widely spaced than expected for the predicted cruising speed, making them more suitable for lower speeds. This finding is consistent with the low swimming speeds exhibited by free-swimming blue sharks.

One factor influencing the swimming speed of fish that are denser than water is the minimum speed required to generate hydrodynamic lift to offset the weight of the fish (Magnuson 1970). Lift is related to 


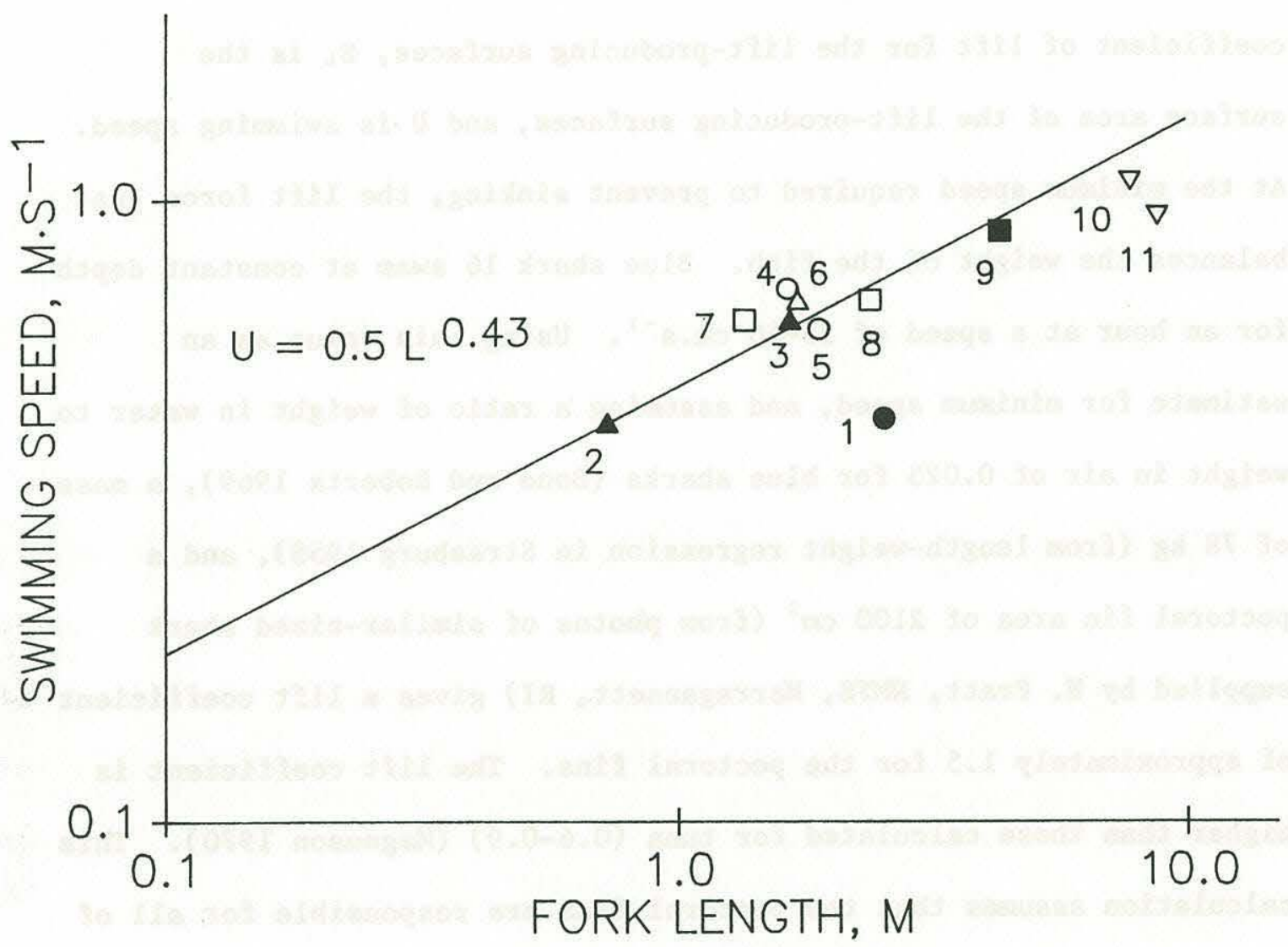

Fig. 3.3 Voluntary swimming speeds for large sharks as a function of fork length, modified and updated from Weihs (1984): 1-blue shark (Prionace glauca) (this study); 2, 3-sandbar shark (Carcharhinus plumbeus) (Weihs et al 1981, Medved and Marsha11 1983); 4,5-bull shark (c. leucas) (Weihs et a1 1981); 6-1emon shark (Negaprion brevirostris) (Gruber 1984); 7, 8-shortfin mako (Isurus oxyrinchus) (Carey et al 1981); 9-white shark (Carcharodon carcharias) (Carey et a1 1982); 10,11-basking shark (Cetorhinus maximus) (Q. Bone in Weihs 1984, Harden-Jones 1973). The line is a theoretical prediction of optimal swimming speed (Weihs, 1977). A11 points except 3-5 are from free-swimming fish. Error bars are contained within point for blue shark. 
swimming speed according to the following equation:

$$
L=1 / 2 \quad \rho \quad C_{L} \quad S_{L} U^{2}
$$

where $L$ is the lift force, $\rho$ is the density of water, $C_{L}$ is the coefficient of lift for the lift-producing surfaces, $S_{L}$ is the surface area of the lift-producing surfaces, and $U$ is swimming speed. At the minimum speed required to prevent sinking, the lift force just balances the weight of the fish. Blue shark 16 swam at constant depth for an hour at a speed of $35-40 \mathrm{~cm} \cdot \mathrm{s}^{-1}$. Using this value as an estimate for minimum speed, and assuming a ratio of weight in water to weight in air of 0.025 for blue sharks (Bone and Roberts 1969), a mass of $78 \mathrm{~kg}$ (from length-weight regression in Strasburg 1958), and a pectoral fin area of $2100 \mathrm{~cm}^{2}$ (from photos of similar-sized shark supplied by H. Pratt, NMFS, Narragansett, RI) gives a lift coefficient of approximately 1.5 for the pectoral fins. The lift coefficient is higher than those calculated for tuna (0.6-0.9) (Magnuson 1970). This calculation assumes that the pectoral fins are responsible for a11 of the lift, but the cambered body may generate a portion of the lift in sharks (Harris 1936).

B1ue sharks have large pectoral fins relative to body size (Compagno 1984), and low body density compared to several other species of sharks (Bone and Roberts 1969, Baldridge 1970). Large fin area and low density would reduce the fin loading and enable the blue shark to produce sufficient lift at lower swimming speeds than similar-sized fish with smaller fins or greater density. The observed minimum swimming speed required for 1 ift $\left(35 \mathrm{~cm} \cdot \mathrm{s}^{-1}\right.$ at constant depth) is lower than the mean cruising speed of shark 16 (Table 3.3). 
This suggests that lift production is not the major consideration determining swimming speed of the blue shark, as has been suggested for some other negatively buoyant fish, including tuna (Magnuson 1978).

The path of blue shark 16 appeared to follow the current associated with Ring $85-\mathrm{C}$. Since the current speed was somewhat greater than the shark's swimming speed, the movement of the shark could have been dominated by current effects; however, comparison of rate of horizontal movement, swimming speed, and current speed suggests that the shark was swimming in the direction of current flow. It is possible that blue sharks utilize currents to cover large distances with relatively low rates of energy expenditure. Tagging studies have demonstrated that blue sharks engage in transatlantic migrations, in addition to seasonal north-south migrations (Casey 1985), and the routes indicated by tagging coincide with major current systems. For three blue sharks that traveled more than $1700 \mathrm{~km}$ between release and recapture, the average straight-1ine rate of movement, based on time and distance between release and recapture, was $1.6 \mathrm{~km} \cdot \mathrm{hr}^{-1}$, and the maximum straight-1ine rate of movement for sharks traveling more than $1000 \mathrm{~km}$ was $1.8 \mathrm{~km} . \mathrm{hr}^{-1}$ (Casey 1985). The average swimming speed of blue sharks recorded by telemetry in this study was $1.6 \mathrm{~km} \cdot \mathrm{hr}^{-1}$. This swimming speed, coupled with an average current speed of $1 \mathrm{~km} \cdot \mathrm{hr}^{-1}$ over the major transatlantic routes indicated by tagging (Casey 1985), would be expected to produce a rate of movement of $2.6 \mathrm{~km} \cdot \mathrm{hr}^{-1}$. The actual path distance traveled by the sharks might be greater than the straight line distance, especially if the sharks follow currents. This would 
account for the apparently slower speed of the tagged sharks.

Fig. 3.4 is a plot of mean tailbeat frequencies as a function of relative swimming speed in several species of sharks, including the values obtained for the blue shark in this study. The blue shark follows the trend of increasing tailbeat frequency with increasing relative speed observed by Webb and Keyes (1982) in several other species of sharks.

A rough estimate for gliding drag can be calculated from descent rates observed during periods with no tailbeats by assuming that maximum descent rate is associated with a vertical dive with constant sinking velocity. The equation for drag is given in Webb (1975):

$$
\mathrm{D}=1 / 2 \quad \mathrm{C}_{\mathrm{D}} \rho \mathrm{S} \mathrm{U}^{2}
$$

where $D$ is the drag force, $C_{D}$ is the drag coefficient, $\rho$ is the density of water, $S$ is wetted surface area, and $U$ is velocity. In the case of constant speed sinking, the drag force is balanced by the submerged weight. The maximum observed gliding descent rate for shark 12 was $180 \mathrm{~cm}^{-1}$. Using 0.025 as the ratio of weight in water to weight in air for blue sharks (Bone and Roberts 1969) gives a net downward force of $2.91 \mathrm{~b}\left(1.29 \times 10^{6}\right.$ dynes) for a $53 \mathrm{~kg}$ shark (from length/weight regression in Strasberg 1958). The surface area of a similar-sized blue shark was estimated to be $2.23 \times 10^{4} \mathrm{~cm}^{2}$ (from photos provided by H. Pratt, NMFS, Narragansett, R.I.). These values give an estimated drag coefficient of $3.6 \times 10^{-3}$.

The total drag force calculated above is a combination of drag due to frictional forces and form or pressure drag resulting from 


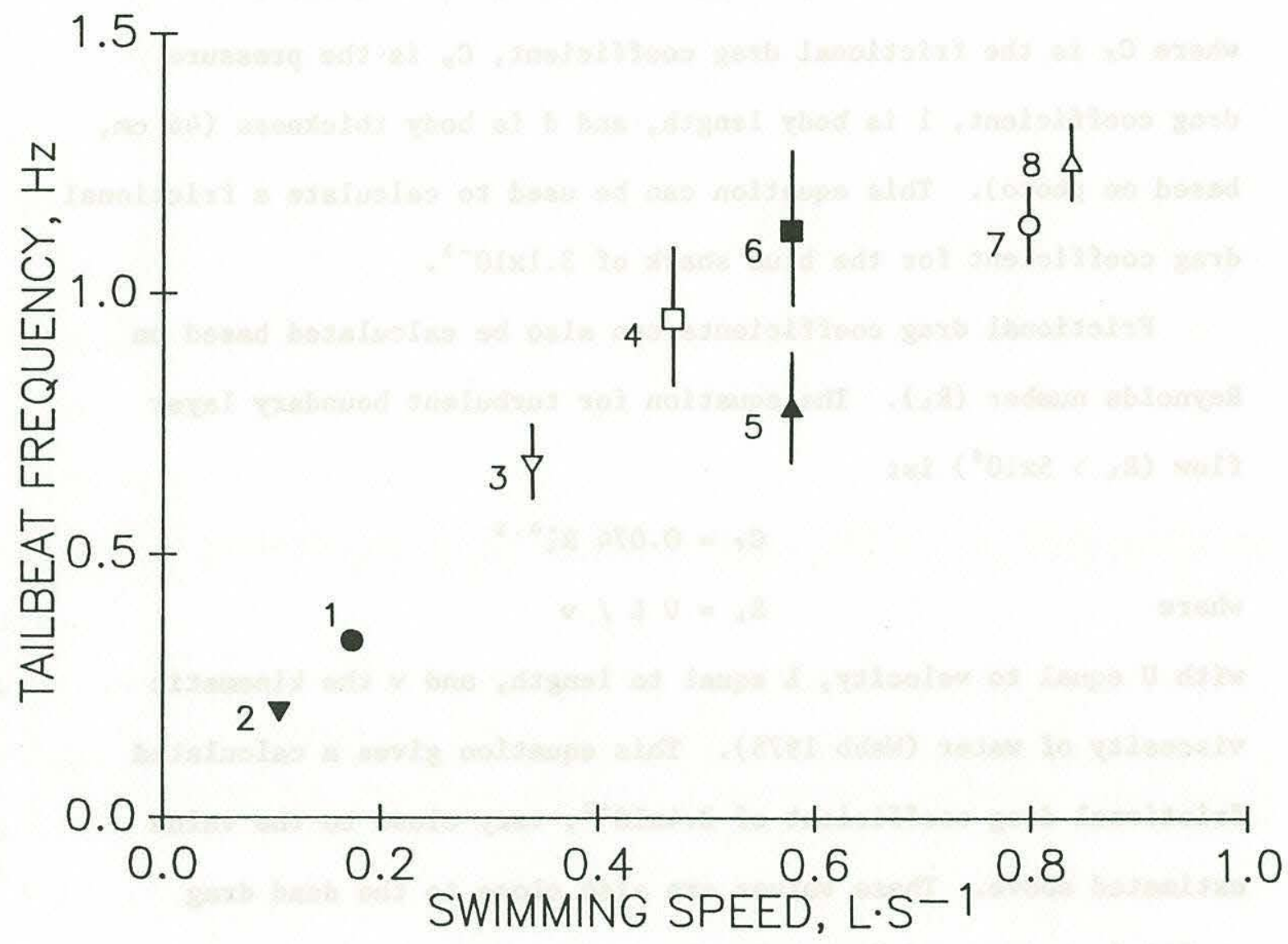

Fig. 3.4 Mean tailbeat frequency as a function of mean voluntary swimming speed expressed in body lengths. $\mathrm{s}^{-1}$ for several species of sharks. 1-blue shark (Prionace glauca) (present study); 2-basking shark (Cetorhinus maximus) (Harden-Jones 1973); 3- nurse (Ginglymostoma cirratum), 4- lemon (Negaprion brevirostris), 5- bu11 (Carcharhinus leucas), 6leopard (Triakis semifasciata), 7- blacktip (Carcharhinus melanopterus), and 8- bonnethead (Sphyrna tiburo) sharks (Webb and Keyes 1982). Error bars are contained within point for blue shark. 
distortion of flow around the body. The combined drag coefficient $C_{D}$ is given by the equation (Bainbridge 1961):

$$
C_{D}=C_{f}+C_{p}=C_{f}\left[1+1.5(d / 1)^{1.5}+7(d / 1)^{3}\right]
$$

where $C_{f}$ is the frictional drag coefficient, $C_{p}$ is the pressure drag coefficient, 1 is body length, and d is body thickness $(46 \mathrm{~cm}$, based on photo). This equation can be used to calculate a frictional drag coefficient for the blue shark of $3.1 \times 10^{-3}$.

Frictional drag coefficients can also be calculated based on Reynolds number $\left(R_{L}\right)$. The equation for turbulent boundary layer flow $\left(R_{L}>5 \times 10^{5}\right)$ is:

$$
C_{f}=0.074 R_{L}^{-0.2}
$$

where $\quad \mathrm{R}_{\mathrm{L}}=\mathrm{U} \mathrm{L} / \mathrm{V}$

with $U$ equal to velocity, I equal to length, and $v$ the kinematic viscosity of water (Webb 1975). This equation gives a calculated frictional drag coefficient of $3.4 \times 10^{-3}$, very close to the value estimated above. These values are also close to the dead drag coefficient measured for mackerel towed at a speed of 1 body length/sec $\left(4.3 \times 10^{-3}\right)$ and are lower than the drag coefficients estimated by towing dead dogfish ( Squalus sp) $\left(1.4 \times 10^{-2}\right)$ (Webb 1975) and from models of smooth dogfish (Mustelus canis) in a wind tunnel $\left(2.2 \times 10^{-2}\right)$ (Harris 1936). Drag estimates from dead fish are expected to be erroneously high, due in part to fluttering of the fins and body during towing (Webb 1975).

Friction and pressure drag account for $1 / 5$ to $1 / 3$ of the total drag on an actively swimming fish (Webb 1975, Lighthil1 1971). The additional drag results from induced drag associated with production 
of thrust and lift forces. Gill resistance also causes an additional drag force (Magnuson 1978). A negatively buoyant fish can reduce drag by reducing swimming activity, allowing its weight to supply forward thrust during gliding (Weihs 1973a).

Rates of depth change and swimming speeds were higher during descent than during ascent, while tailbeat frequencies were lower. This is to be expected, since the weight of the shark would provide a force contributing to downward motion. A number of descents were accompanied by periods with no tailbeats. These gliding periods were brief and were associated with the most rapid descent rates. The fact that some dives were accomplished by gliding suggests that blue sharks may be employing a variation of the two phase swimming pattern proposed by Weihs (1973a) to be energetically efficient for negatively buoyant fish. This behavior involves periods of passive sinking, allowing the submerged weight to provide forward thrust without swimming movements, alternating with active upward swimming back to the original depth. The net energy expended per unit of horizontal distance covered could theoretically be reduced to less than $50 \%$ of that required for horizontal swimming. The lower energy cost of locomotion in this mode results from the reduced drag forces experienced by a gliding fish as compared to an actively swimming one.

The potential energy savings for the glide-and-swim behavior depend on the ratio of swimming drag to gliding drag ( $k$ ) and on the 
angles of descent and ascent. Energy savings can be calculated using the equation:

$$
S=1-[\tan \alpha /(\sin \beta+\tan \alpha \cos \beta)][1+(\sin \beta / \mathrm{k} \sin \alpha)]
$$

where $S$ is the energy saving expressed relative to the energy cost of horizontal swimming, $\alpha$ is the gliding angle from the horizontal, and $B$ is the ascent angle (Weihs 1973a). $K$ is estimated to be 3-5 for anguilliform swimmers, including sharks (Webb 1975). For a given glide angle, the value of $\beta$ for which the saving is maximal can be calculated as:

$$
\beta_{\mathrm{max}}=\cos ^{-1}(1 / \mathrm{k})-\alpha .
$$

In Fig. 3.5, the relative saving in energy is plotted as a function of swimming angle for $k=4$ and a range of gliding angles. For a given $k$ value, energy savings are highest for relatively shallow gliding angles and steep swimming angles. Steeper descent angles result in smaller maximum savings and a smaller range of ascent angles at which energy savings occur.

The swimming patterns observed in the blue sharks included both gliding periods and active swimming at reduced tailbeat frequencies during descent. The potential energy savings for the gliding portions of dives can be calculated using the equations given above if angles of descent and ascent are known. Because no records of swimming speed were obtained during known gliding periods, instantaneous gliding angles cannot be calculated; however, the mean gliding descent rate was $20 \mathrm{~cm} . \mathrm{s}^{-1}$, and gliding was generally associated with the deepest dives. For dives greater than $150 \mathrm{~m}$, the mean swimming speed during descent was $54 \mathrm{~cm} \cdot \mathrm{s}^{-1}$ (Table 3.2). These values give an estimated 


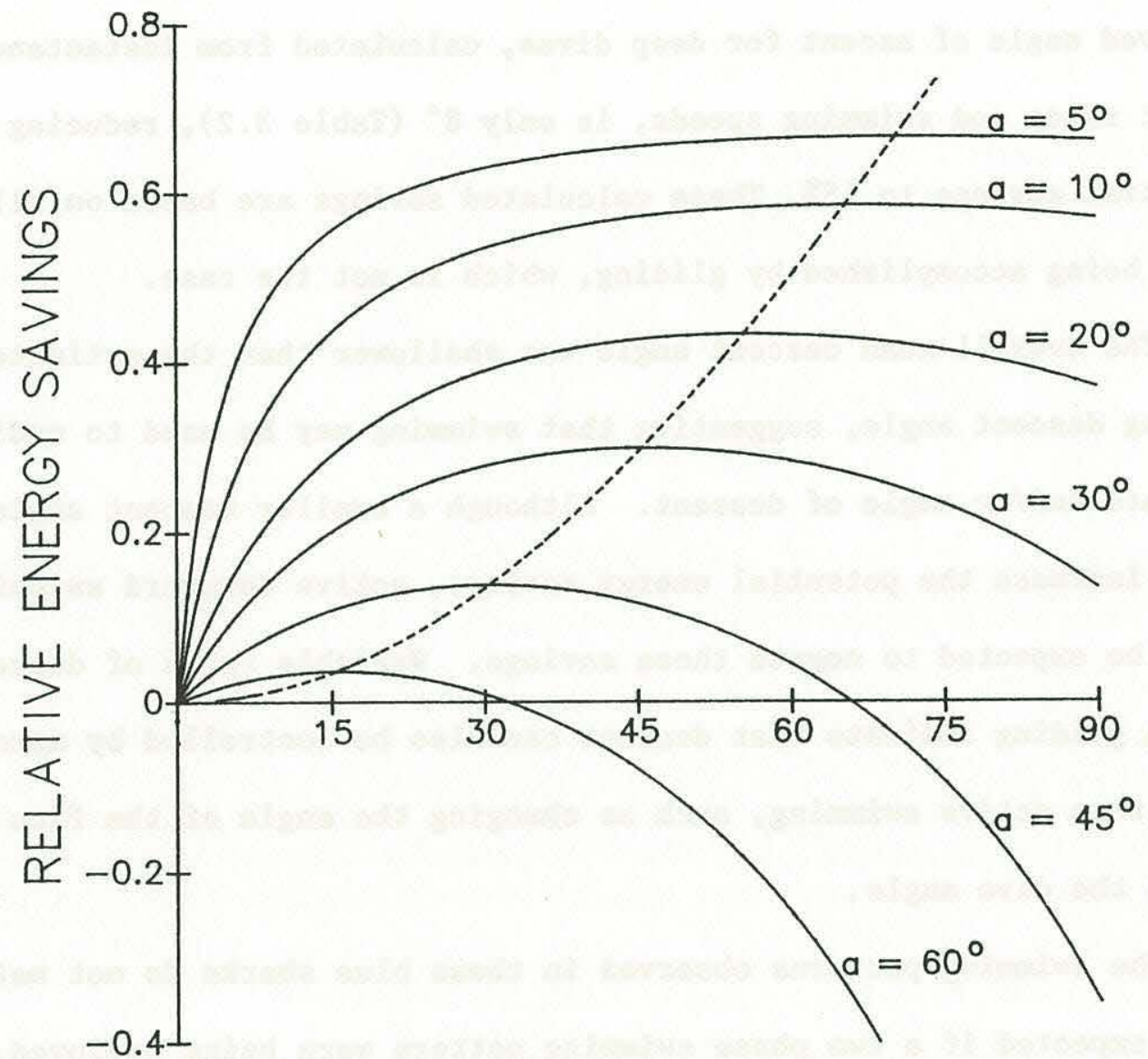

SWIMMING ANGLE, $\beta^{\circ}$

Fig. 3.5 Nondimensional energy savings achieved by glide-and-swim behavior as a function of swimming angle, $B$, when $k=4$, for various gliding angles, a. Dotted line shows maximum saving. (After Weihs 1973a). 
gliding angle for the blue shark of $22^{\circ}$. For this descent angle, with $k$ equal to 4 , the maximum energy savings would be $40 \%$, if the shark swam upward at the optimal ascent angle of $54^{\circ}$. The mean observed angle of ascent for deep dives, calculated from instantaneous ascent rates and swimming speeds, is only $8^{\circ}$ (Table 3.2 ), reducing potential savings to $18 \%$. These calculated savings are based on all dives being accomplished by gliding, which is not the case.

The overa11 mean descent angle was shallower than the estimated gliding descent angle, suggesting that swimming may be used to modify the rate and/or angle of descent. Although a smaller descent angle would increase the potential energy savings, active downward swimming would be expected to negate these savings. Variable rates of descent during gliding indicate that descent can also be controlled by means other than active swimming, such as changing the angle of the fins to adjust the dive angle.

The swimming patterns observed in these blue sharks do not match those expected if a two phase swimming pattern were being employed. Gliding periods are brief, and the major portion of the dives are accomplished by active downward swimming. Descent rates during gliding are greater than during active downward swimming, and the estimated gliding angle is steeper than the mean upward swimming angle. This is in contrast to the relatively shallow gliding angles and steep swimming angles required for maximum energy savings according to theory (Weihs 1973a; Fig. 3.5). It does not appear that the diving behavior exhibited by these blue sharks serves the purpose of minimizing the energy cost of long-distance migration. 
An alternative explanation is that the observed swimming behavior may represent a feeding strategy. Blue sharks are known to feed on several species of cephalopods and fish, many of which inhabit the depth ranges reached by the deeper dives (Strasberg 1958, Stevens 1973, Tricas 1979, Lu and Roper 1979). The diving behavior observed in the blue sharks may represent a search pattern covering the entire water column, or rapid dives may be a means of reaching deep feeding grounds (Carey and Scharold in review). Episodes of high, irregular tailbeat frequencies and bursts of high speed swimming at depth may be related to feeding activity.

The amount of time that is spent at depth may be limited by cooling. Carey and Gibson (1987) found that muscle temperature of swimming blue sharks rapidly responded to changes in water temperature, with a cooling half-time of 18 minutes for temperature changes of $7-9^{\circ} \mathrm{C}$. In that study, the minimum observed muscle temperature was $13^{\circ} \mathrm{C}$. The rate of warming is greater than the rate of cooling, making it possible for the shark to maintain a body temperature as much as $4^{\circ} \mathrm{C}$ above the mean water temperature it experiences (Carey and Scharold in review). Thus the diving patterns may be influenced by behavioral temperature regulation.

The results of this study indicate that blue sharks exhibit periods of passive gliding during dives; however, they do not follow the patterns predicted by theory to be most energetically efficient if the two phase swimming behavior proposed by Weihs (1973a) were being utilized. Nevertheless, it appears that the blue shark, a large pelagic predator exploiting an oceanic environment with scattered food 
resources, employs a strategy of minimizing energy expenditure.

Morphological and behavioral adaptations for efficient low speed cruising include a streamlined body shape, long narrow pectoral fins, reduced density, drag-reducing scales, slow sustained speeds, and utilization of currents. These, coupled with vertical ranging, would enable the blue shark to effectively search large volumes of water with minimal energy cost. 
IV. TELEMETERED HEART RATE AS A MEASURE OF METABOLIC RATE

IN THE LEMON SHARK, Negaprion brevirostris

\section{$\underline{\text { ABSTRACT }}$}

Heart rate, metabolic rate, and activity were simultaneously recorded from juvenile lemon sharks for 24 hour periods to determine whether heart rate might be a suitable indicator of energy expenditure for field studies. Heart rate was monitored by acoustic telemetry using a frequency modulated ECG transmitter. Metabolic rate was measured as oxygen consumption rate in a flow through respirometer. In 7 sharks, mean resting values for heart rate and oxygen consumption rate were $52.0 \pm 0.4$ (S.E.) beats. $\mathrm{min}^{-1}$ and $162.0 \pm 2.0$ (S.E.) $\mathrm{mg}$ $0_{2} \cdot \mathrm{kg}^{-1} \mathrm{hr}^{-1}$, respectively. Both parameters increased significantly $(p<0.001)$ during swimming, to means of $55.9 \pm 0.2$ beats.min ${ }^{-1}$ and $233.6 \pm 2.3 \mathrm{mg} 0_{2} \cdot \mathrm{kg}^{-1} \mathrm{hr}^{-1}$, at a mean swimming speed of $0.400 \pm 0.003$ body lengths. $\mathrm{s}^{-1}$. The observed elevation in heart rate from rest to spontaneous exercise accounts for $19 \%$ of the increase in oxygen uptake, leaving the remainder to be accounted for by increases in stroke volume and/or arteriovenous oxygen difference. Although a significant linear regression of oxygen consumption on heart rate was obtained, the small contribution of heart rate to changes in the oxygen transport system may limit its value as a measure of metabolic rate. 


\section{INTRODUCTION}

Quantification of energy expenditures of sharks in the field is important in addressing numerous ecological questions, including trophic relationships, production, and behavioral and physiological responses to environmental conditions. Metabolic rates of sharks have been measured in the laboratory using indirect calorimetry, in which energy expenditure is calculated from oxygen consumption rates (Piiper et a1 1977, Brett and Blackburn 1978, Bushne11 1982, Nixon and Gruber 1988). This method requires confining the animal in a chamber or attaching water sampling devices to the gills, techniques which are not amenable to field studies and do not permit the normal range of behavior expected in the field.

The development of acoustic telemetry techniques has made direct measurement of various environmental and physiological parameters from free-swimming fish possible (Stasko and Pincock 1977, Kanwisher et a1 1974). Several of these parameters have been investigated as potential correlates of metabolic rate, with varying degrees of success. Location transmitters have been used to estimate swimming speeds, which can be interpreted using relationships between speed and metabolic rate that have been established in the laboratory (Young et al 1972, Holliday et al 1974, Hawkins et al 1974). However, this technique does not account for path curvature and variations in speed that may occur between position fixes and so gives at best minimal estimates of swimming speed and thus of metabolic rate (Weatherley 1976). Tailbeat frequency transmitters have been used to give a more 
accurate measure of swimming activity (Stasko and Horral1 1976, Ross et al 1981), although the relationship between tailbeat frequency and swimming speed is not clearly defined due to variations in amplitude at slower speeds (Webb 1975). A telemetry system has been used to record electromyograms (EMGs) from epaxial muscles of trout as a measure of activity (Rogers et al 1984). Averaged EMG values were correlated to oxygen consumption rates measured in a respirometer, but separate regressions were obtained for spontaneous and forced swimming activity (Weatherley et a1 1982). EMGs from opercular muscles have been proposed as a measure of metabolic rate, but opercular EMGs were not correlated with oxygen consumption under conditions of spontaneous activity in laboratory trout (Rogers and Weatherley 1983).

Heart rate telemetry has been used to estimate energy expenditures in higher vertebrates and has been suggested as a means of estimating field metabolic rates in fish (Priede 1983). Heart rate has been found to be correlated with swimming activity (Sutterlin 1969, Priede 1974, Wardle and Kanwisher 1974). Priede and Young (1977) used ultrasonic telemetry to monitor heart rate from free ranging trout and made estimates of metabolic rate based on relationships between heart rate and oxygen consumption established in the 1aboratory (Priede and Tytler 1977). In the present study, the relationship between heart rate and oxygen consumption in the lemon shark is examined, to evaluate the potential of heart rate as an estimator of energy expenditure for free-ranging elasmobranchs. 
METHODS

\section{Capture and Maintenance}

Juvenile lemon sharks, 1 to 3 years old, were captured by angling with barbless hooks in the Florida Keys. For transport, the sharks were placed in plastic bags with sufficient seawater to cover the gills. Ice was added and the bags were filled with oxygen and sealed. The sharks were subsequent1y held at the Rosenstiel School of Marine and Atmospheric Science in a 66001 recirculating seawater aquarium in a temperature controlled room. The aquarium was supplied with biological and mechanical filtration and ultraviolet light sterilization. Trichlorophan (Dylox) was added to the water to prevent skin infections. Temperature was maintained at $25 \pm 1^{\circ} \mathrm{C}$, salinity at $31 \pm 3 \mathrm{ppt}$, and oxygen levels at saturation. Lighting was on a 12L:12D cycle. The diet consisted of blue runner (Caranx chrysos) fillets presented ad $\underline{1 \mathrm{ib}}$ 2-3 times week1y, with a week1y multivitamin supplement. The aquarium system is described in detail in Gruber and Keyes (1981). Heart rate

Heart rate was monitored using an ultrasonic, frequency modulated electrocardiogram (ECG) transmitter. A schematic of the circuit is shown in Fig. 4.1. The ECG voltage is picked up by a signal lead placed near the heart and amplified by a dual op amp circuit (Texas Instruments TLC27L2) with high and low pass filters. The $3 \mathrm{db}$ cutoff frequencies are 23 and $2 \mathrm{~Hz}$, and the amplifier has a gain of 300 at 20 Hz. The amplified signal controls the frequency of an oscillator (Texas Instruments L555) which is set to an $86 \mathrm{kHz}$ center frequency, 


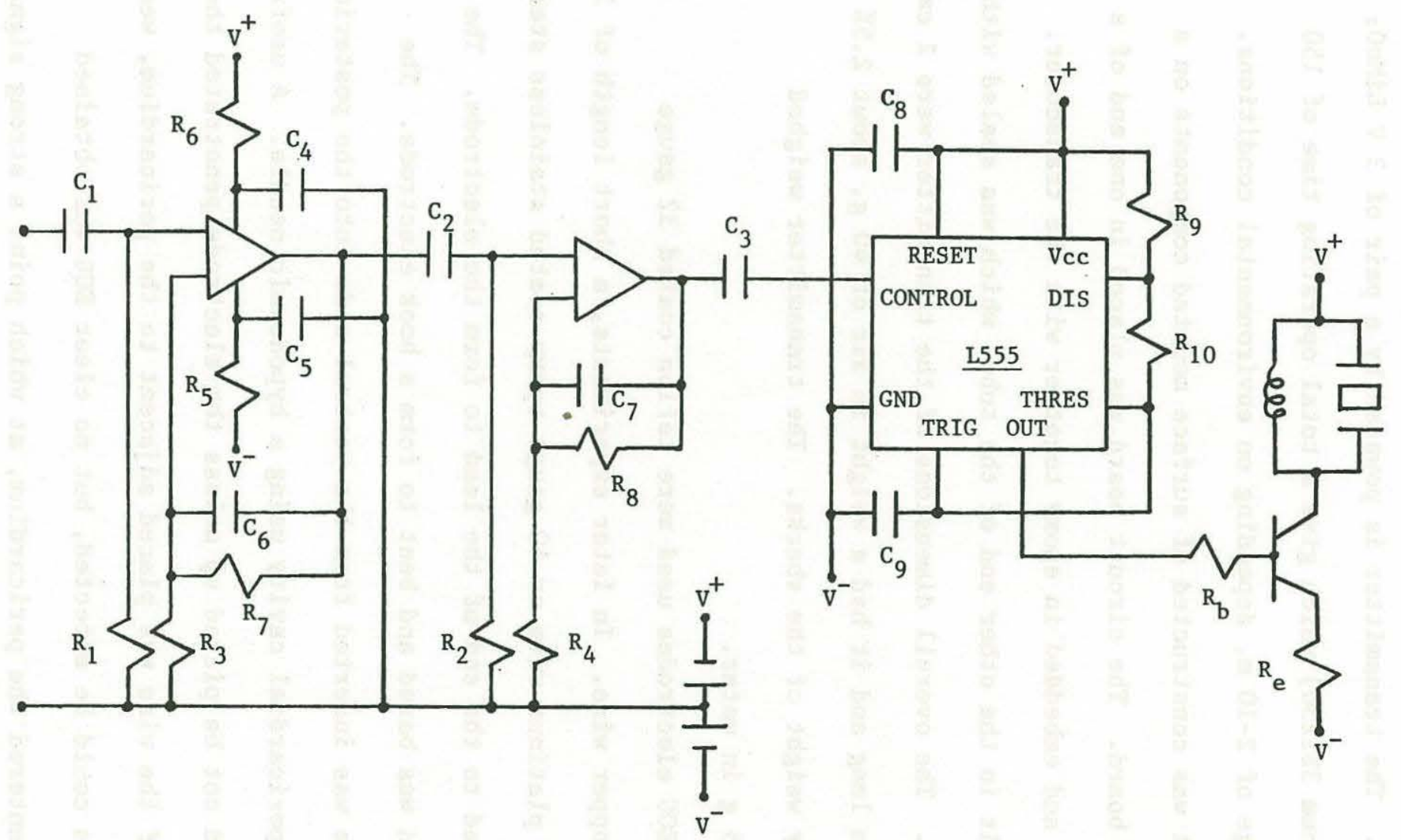

Fig. 4.1 Circuit for the ultrasonic electrocardiogram (ECG) transmitter. 
and the oscillator output is used to drive a cylindrical PZT

transducer. In this way the ECG signal is converted to variations in sound frequency. The transmitter is powered by a pair of $3 \mathrm{~V} \mathrm{LiMnO}_{2}$ cells (E1ectrochem 3B1230) which give a total operating time of 150 hours and a range of $2-10 \mathrm{~m}$, depending on environmental conditions.

The circuit was constructed of surface mounted components on a printed circuit board. The circuit board was placed in one end of a fiberglass tube and embedded in epoxy together with the transducer. The batteries fit in the other end of the tube, which was sealed with an "0"-ring cap. The overall dimensions of the transmitter were $2 \mathrm{~cm}$ diameter by $8 \mathrm{~cm}$ long and it had a weight in air of $40 \mathrm{~g}$, about $2.5 \%$ of the mean body weight of the sharks. The transmitter weighed approximately $15 \mathrm{~g}$ in water.

The first ECG electrodes used were teflon coated 32 gauge multistranded copper wire. In later experiments, a short length of 26 gauge insulated platinum wire or 40 gauge epoxy-coated stainless steel wire was attached to the end of the lead to form the electrode. The tip of each lead was bared and bent to form a hook electrode. The signal electrode was inserted from the ventral side into the posterior portion of the pericardial cavity using a hypodermic needle. A useful ECG signal could not be picked up unless the electrode penetrated the pericardium. If the wire was placed adjacent to the pericardium, weak ventilation EMGs could be detected, but no clear ECG was obtained until the lead entered the pericardium, at which point a strong signal was usually detected. When first implanted, copper leads of ten gave a noisy signal which improved after several minutes. The signal 
remained acceptable during the course of an experiment, but the wire showed evidence of corrosion when inspected after several days. The platinum electrode gave a good signal, but the stiffness of the wire resulted in problems with the lead shifting or pulling out. The fine stainless steel wire gave a clean signal but was susceptible to abrasion and breakage. The best results were obtained by using a short length of 40 gauge epoxy coated stainless steel wire soldered to teflon coated copper wire with a waterproofed joint. The lead was secured to the skin with silk or monofilament sutures. The ground lead could be left free in the water, but cleaner signals were obtained by implanting the lead in the dorsal musculature. The body of the transmitter was tied onto the dorsal fin at two points of attachment. Positioning of the transmitter and the ECG leads are illustrated in Fig. 4.2.

The transmitter signal was picked up by a hydrophone and receiver (Communication Associates Inc. CR-40). Using a narrow bandwith setting $(300 \mathrm{~Hz})$, the receiver could be tuned off the center frequency so that only the peak of the deflection corresponding to the QRS wave of the ECG would be picked up, triggering one output logic pulse from the receiver per heartbeat. This output was sent to a pulse interval-to-frequency converter which was calibrated to produce a voltage output to a chart recorder (Linear Instruments $\mathrm{P} / \mathrm{N}$ 595) corresponding to heart rate in beats per minute (BPM). Thus heart rate could be read directly from the chart recorder output. Using these techniques, clear signals could be obtained for the life of the batteries, although shifts in the strength and frequency of the signal 


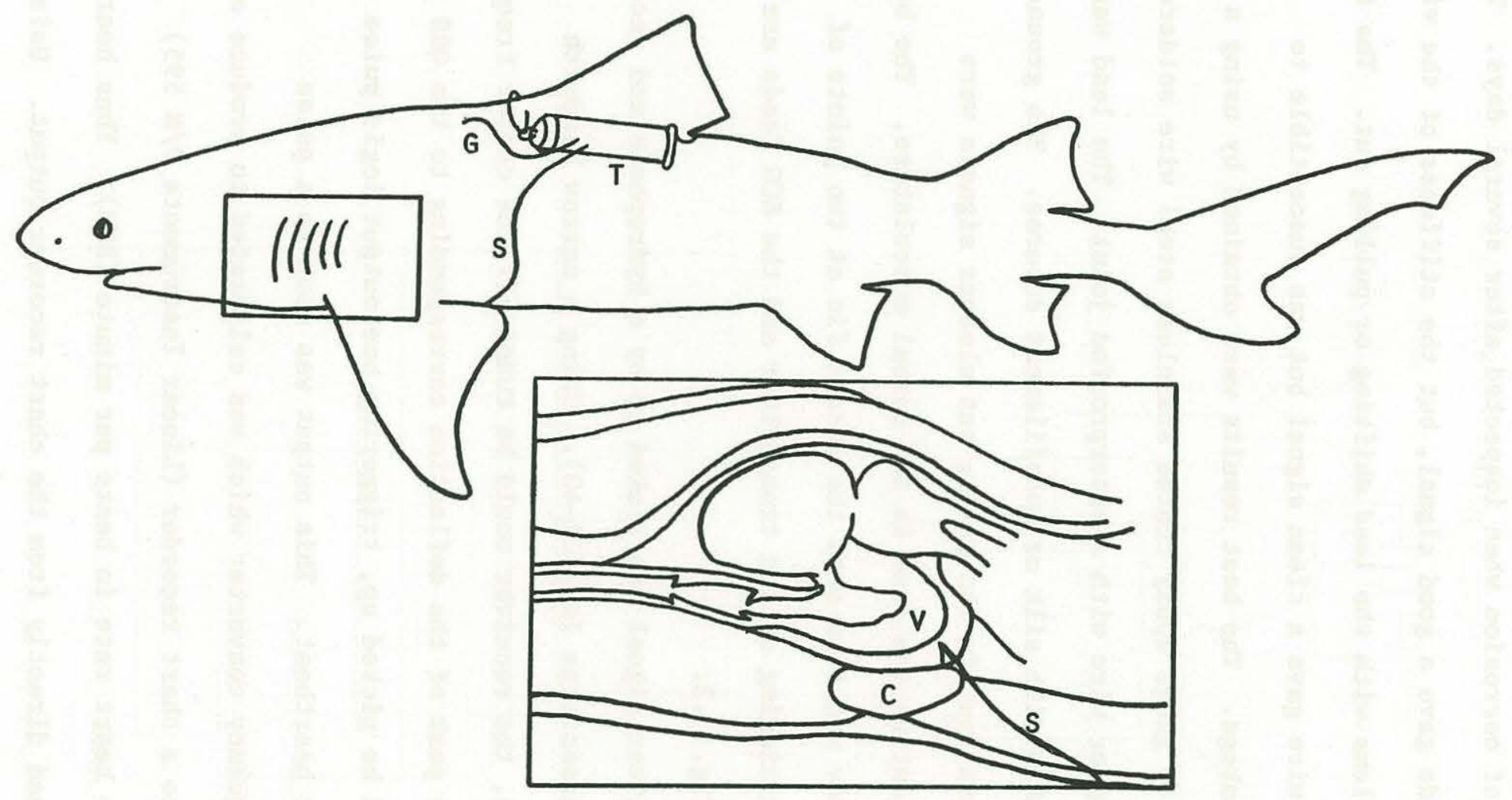

Fig. 4.2 Placement of the ECG transmitter and electrodes. The transmitter, $t$, was sutured to the dorsal fin. The tip of the ECG signal electrode, $s$, was placed in the pericardial cavity between the ventricle of the heart, $\mathrm{v}$, and the coracoid cartilage, $c$. The ground electrode, $g$, was placed in the dorsal musculature. 
necessitated occasional retuning of the receiver.

\section{Oxygen consumption}

Energy expenditure was determined by indirect calorimetry, measuring oxygen consumption rate in a flow-through respirometer system. The respirometer was an 801 annular plexiglass chamber, as described by Bushne11 (1982). Water was pumped from the main aquarium to a 10001 aerated tank which was situated $2 \mathrm{~m}$ above the respirometer and which had an overflow pipe to maintain constant head pressure. Inflow to the respirometer from the head tank was controlled by a valve. Outflow from the respirometer was returned to the main aquarium. A sma11 centrifugal pump (Teel 1P805A) connected to the respirometer ensured adequate mixing of water in the chamber, as determined by dye studies. Flow rate through the chamber was determined by measuring the amount of time required for the outflow to fill a 101 volume.

Partial pressure of oxygen $\left(\mathrm{PO}_{2}\right)$ of water entering and exiting the respirometer was monitored using a polarographic oxygen electrode (Radiometer E5047 or Strathkelvin 1302) mounted in a flow-through ce11 and connected to a Strathkelvin mode1 381 oxygen meter. A peristaltic pump (Masterflex 7553) equipped with a set of three-way valves directed inflowing or outflowing water through the sampling cel1 and back to the outflow pipe via tygon tubing. The output of the oxygen meter was recorded on one channel of the chart recorder. The oxygen electrode was calibrated with air-equilibrated seawater and a zero-oxygen solution every 24 hours. 
Activity

A photoelectric system (Arrowhead mode1 S2000) was used to monitor swimming activity. A transmitter placed on the outer wall of the respirometer produced an infrared light beam which was directed across the chamber to a receiver located on the inner wall, in the center of the respirometer. The receiver was connected as a switch in series with a DC vo1tage source and one channel of the chart recorder. Interruption of the beam closed the switch, producing a deflection of the chart recorder pen for each lap. The chart speed was adjusted so that multiple deflections caused by head, fins, and tail would be counted as a single lap. Experimenta1 procedure

Sharks were fasted for at least three days prior to being used in an experiment, and were weighed at the beginning and end of each experiment. Each shark was anaesthetized with MS222 $\left(0.1 \mathrm{~g} \cdot \mathrm{1}^{-1}\right)$ while the ECG leads were implanted and the transmitter attached as described above. After recovery, the shark was placed in the respirometer and allowed to stabilize for 24 hours.

At the beginning of each experimental run, the oxygen electrode was calibrated and readings of flow rate, temperature, and $\mathrm{PO}_{2}$ of inflowing water were taken. Then outflow $\mathrm{PO}_{2}$, heart rate, and activity were recorded continuously for 24 hours, with checks of flow rate, temperature, and inflowing $\mathrm{PO}_{2}$ at 2 to 8 hour intervals. The flow rate was adjusted using the inflow valve such that the oxygen content of outflowing water did not drop below $70 \%$ saturation. Water temperature was maintained at $25 \pm 1^{\circ} \mathrm{C}$. Lighting was on a 12L:12D 
cycle, with lights on at $0700 \mathrm{~h}$ and lights off at $1900 \mathrm{~h}$.

Outflowing oxygen content, heart rate, and activity were determined from the chart recorder output at ten minute intervals. Heart rate was determined by drawing a line through the center of the frequency trace on the chart recorder. Activity was measured as number of laps completed in a two minute period and converted to swimming speed using a path length of $180 \mathrm{~cm}$ per 1ap. Rate of oxygen consumption was calculated for each ten minute period using the .

formula:

$$
\text { V02 }=\left[F\left(\operatorname{Cin}-\left(\text { Cout }_{0}+\text { Cout }_{t}\right) / 2\right)+V\left(\text { Cout }_{0}-\text { Cout }_{t}\right) /(t-0)\right] / W w
$$

here $\dot{v} 02$ is weight-specific oxygen consumption rate in $\mathrm{mgO} \mathrm{O}_{2} \cdot \mathrm{kg}^{-1} \mathrm{hr}^{-1}, \mathrm{~F}$ is flow rate in $1 . \mathrm{hr}^{-1}, \mathrm{Cin}$ and Cout are

oxygen concentrations of inflowing and outflowing water in $\mathrm{mg} \cdot \mathrm{1}^{-1}, 0$ and $t$ refer to the beginning and end of the time period, $V$ is the volume of the chamber in 1 , and $W$ is the mass of the animal in $\mathrm{kg}$. This equation includes a correction for the $1 \mathrm{ag}$ in measurement in the flow-through system resulting from the volume of the chamber (Fry 1971). For analytical purposes, only steady-state values, those data for which the shark had been continuously swimming or resting for at least the ten minute period prior to the point, were used.

\section{RESULTS}

Physical characteristics of the experimental animals are given in Table 4.1. The sharks recovered from anaesthesia in 5-10 minutes and were usually swimming smoothly in the respirometer within 1-4 hours . The animals appeared to be in good health for the duration of the 
Table 4.1. Characteristics of lemon sharks used in experiments.

\begin{tabular}{llcl}
\hline SHARK NO. & SEX & $\begin{array}{c}\text { FORK LENGTH } \\
\mathrm{cm}\end{array}$ & $\begin{array}{c}\text { BODY MASS } \\
\mathrm{kg}\end{array}$ \\
\hline & & & \\
1 & $\mathrm{~F}$ & 60.0 & 1.35 \\
2 & $\mathrm{~F}$ & 62.0 & 1.61 \\
3 & $\mathrm{M}$ & 56.8 & 1.42 \\
4 & $\mathrm{~F}$ & 53.9 & 1.11 \\
5 & $\mathrm{~F}$ & 53.2 & 1.22 \\
6 & M & 58.9 & 1.57 \\
7 & F & 56.8 & 1.46 \\
\hline
\end{tabular}

Table 4.2. Oxygen uptake, heart rate, and swimming speed for seven juvenile lemon sharks (mean \pm S.E.).

\begin{tabular}{ccccc}
\hline N & $\begin{array}{c}\text { OXYGEN UPTAKE } \\
\mathrm{mg} \cdot \mathrm{kg}^{-1} \cdot \mathrm{hr}^{-1}\end{array}$ & $\begin{array}{l}\text { HEART RATE } \\
\text { beats } \cdot \mathrm{min}^{-1}\end{array}$ & $\begin{array}{l}\text { SWIMMING SPEED } \\
\text { body lengths. } \mathrm{s}^{-1}\end{array}$ \\
\hline REST & 301 & $162.0 \pm 2.0$ & $52.0 \pm 0.4$ & 0 \\
SWIM & 353 & $233.6 \pm 2.3$ & $55.9 \pm 0.2$ & $0.401 \pm 0.003$
\end{tabular}


experiments, judging from skin color, and all fed within two days of being removed from the respirometer at the end of an experiment. Two sharks were kept in the chamber for more than four days and fed while in the respirometer.

The sharks swam for an average of $50 \%$ of the time. Resting and swimming periods each averaged 35-50 minutes, although both ranged from a minute to more than two hours. One shark swam continuously for over 13 hours. Rest periods were of ten punctuated by some movement (1 or 2 laps) at approximately 15 minute intervals.

A representative 24-hour record of swimming speed, oxygen consumption, and heart rate for shark no. 4 is shown in Fig. 4.3. In general, for all sharks, variations in oxygen consumption and heart rate closely accompanied changes in activity. Mean metabolic rates and heart rates during rest and swimming are given in Table 4.2. Both metabolic rate and heart rate showed significant differences between resting and swimming values ( $t$-test, $p<0.001$ ). The mean swimming speed was 0.40 body lengths.s $\mathrm{s}^{-1}\left(\mathrm{~L} . \mathrm{s}^{-1}\right)$, and all the sharks swam within a fairly narrow range of speeds $\left(0.31-0.56 \mathrm{~L} . \mathrm{s}^{-1}\right)$, with no intermediate speeds being observed for more than a minute. V02 is plotted as a function of relative swimming speed in Fig. 4.4. V02 values are normalized, or expressed relative to the mean resting $\dot{V} 02$ for each shark, to adjust for individual differences in metabolic rate. A regression of normalized V02 $^{2}$ against relative swimming speed resulted in the exponential equation:

$$
\log \left(\dot{\mathrm{V} 02} / \dot{\mathrm{V}}_{0} 2_{\mathrm{r}}\right)=-0.008919+0.4904 \mathrm{U} \quad\left(\mathrm{r}^{2}=0.69, \mathrm{p}<0.001\right)
$$
where $\dot{\mathrm{V}} 02 / \mathrm{V} 02_{\mathrm{r}}$ is the normalized oxygen consumption rate and $U$ is 
SHARK NO. 4, 23 Sept. 1987
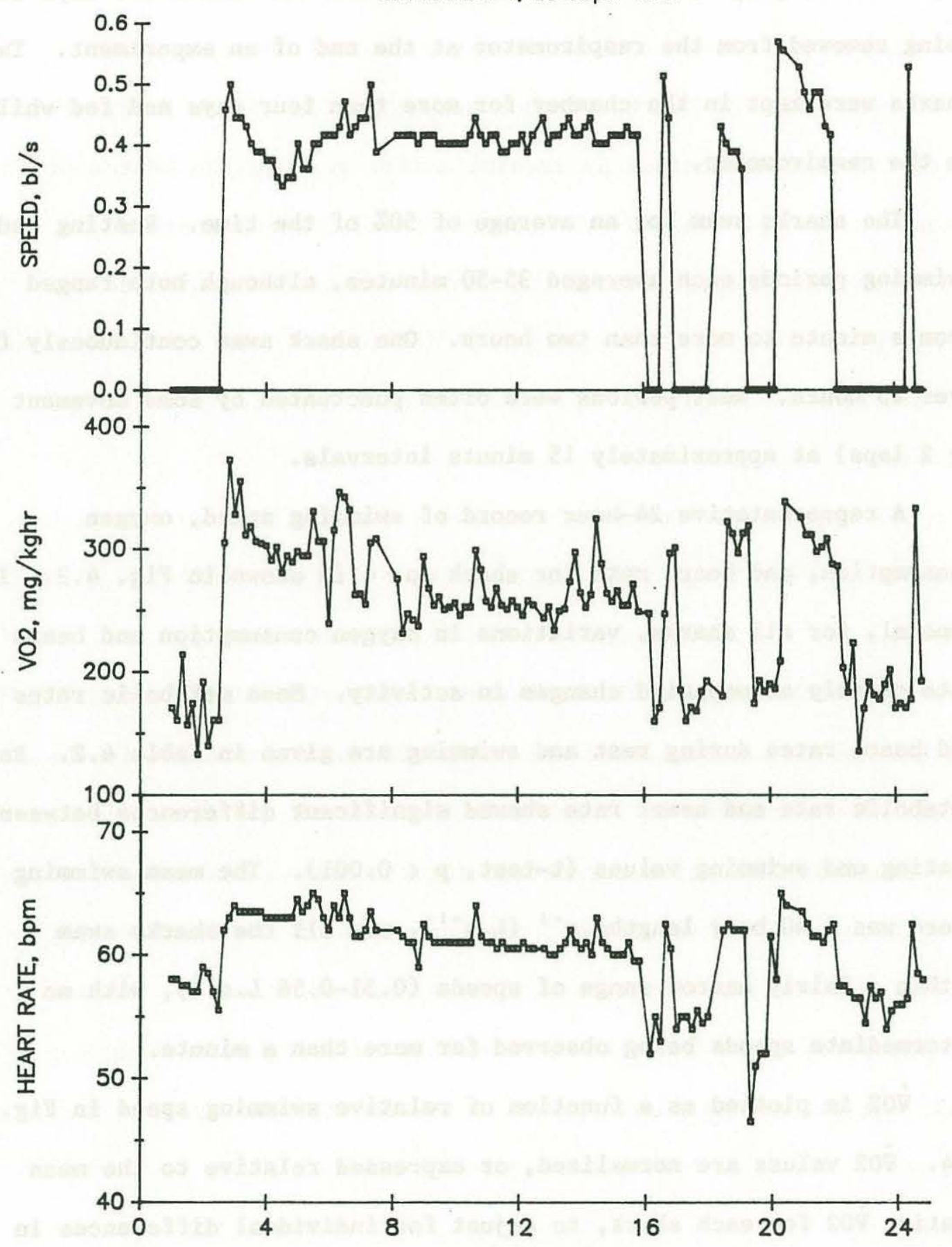

TIME OF DAY

Fig. 4.3 24-hour record of speed, oxygen consumption rate, and heart rate for a juvenile lemon shark. Record begins 30 hours af ter attachment of ECG transmitter. 


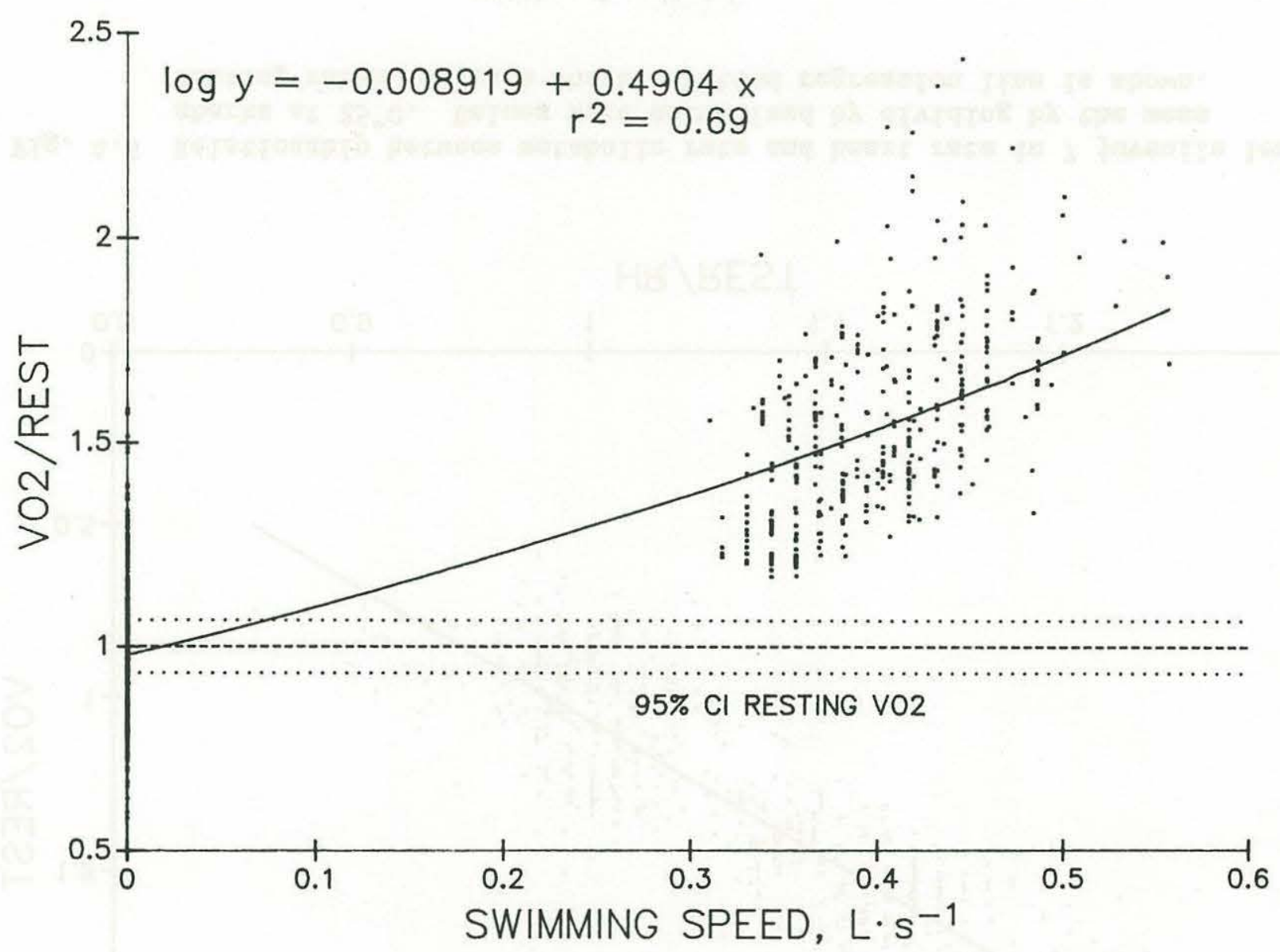

Fig. 4.4 Relationship of oxygen consumption rate and relative swimming speed in 7 juvenile lemon sharks at $25^{\circ} \mathrm{C}$. Oxygen consumption values were normalized by dividing by the mean resting rate for each shark. Fitted regression line (-), mean resting V02 (- - ), and $95 \%$ confidence interval of mean resting V02 ( $\cdots)$ are shown. 


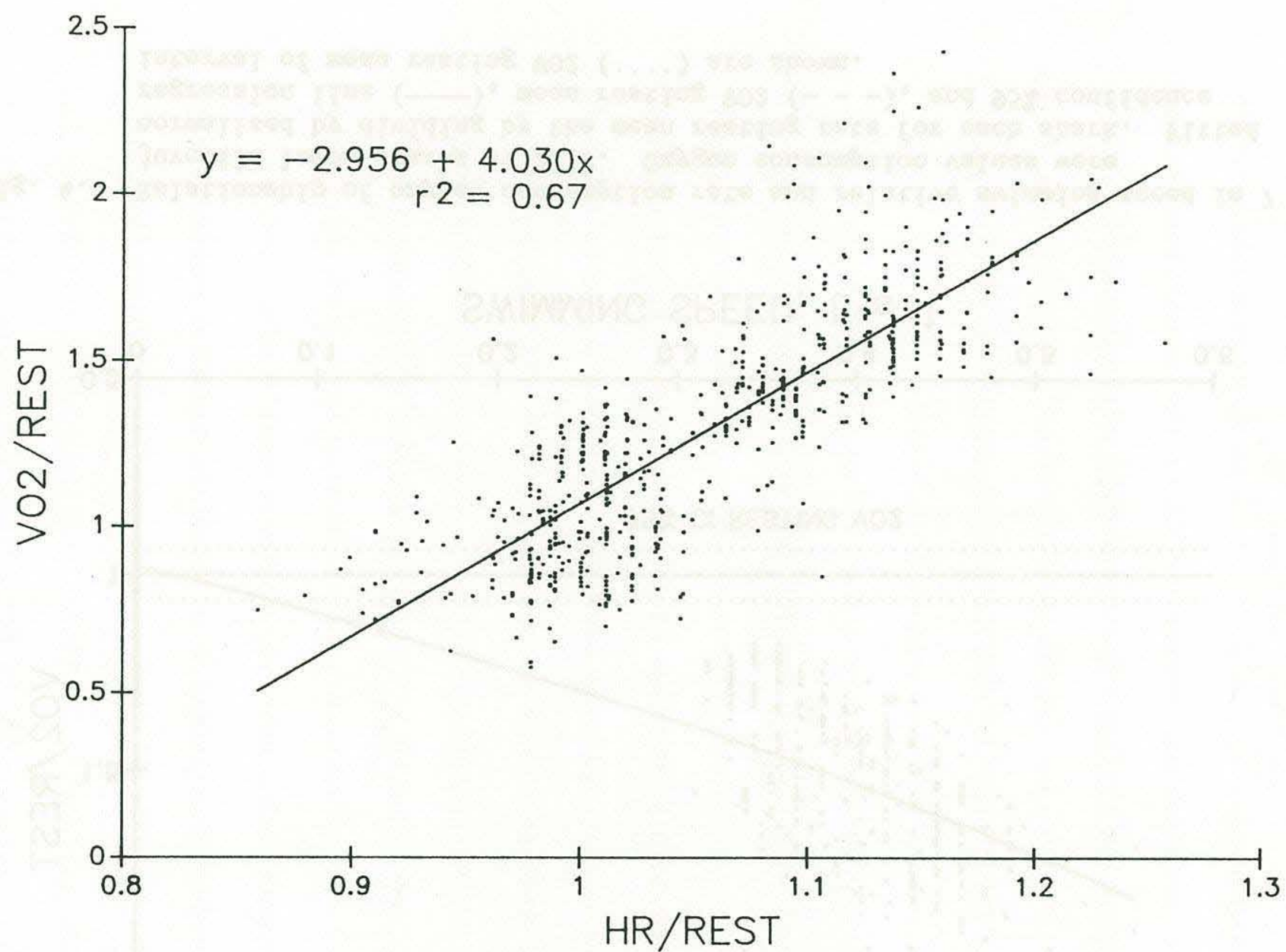

Fig. 4.5 Relationship between metabolic rate and heart rate in 7 juvenile lemon sharks at $25^{\circ} \mathrm{C}$. Values were normalized by dividing by the mean resting rates for each shark. Fitted regression line is shown. 


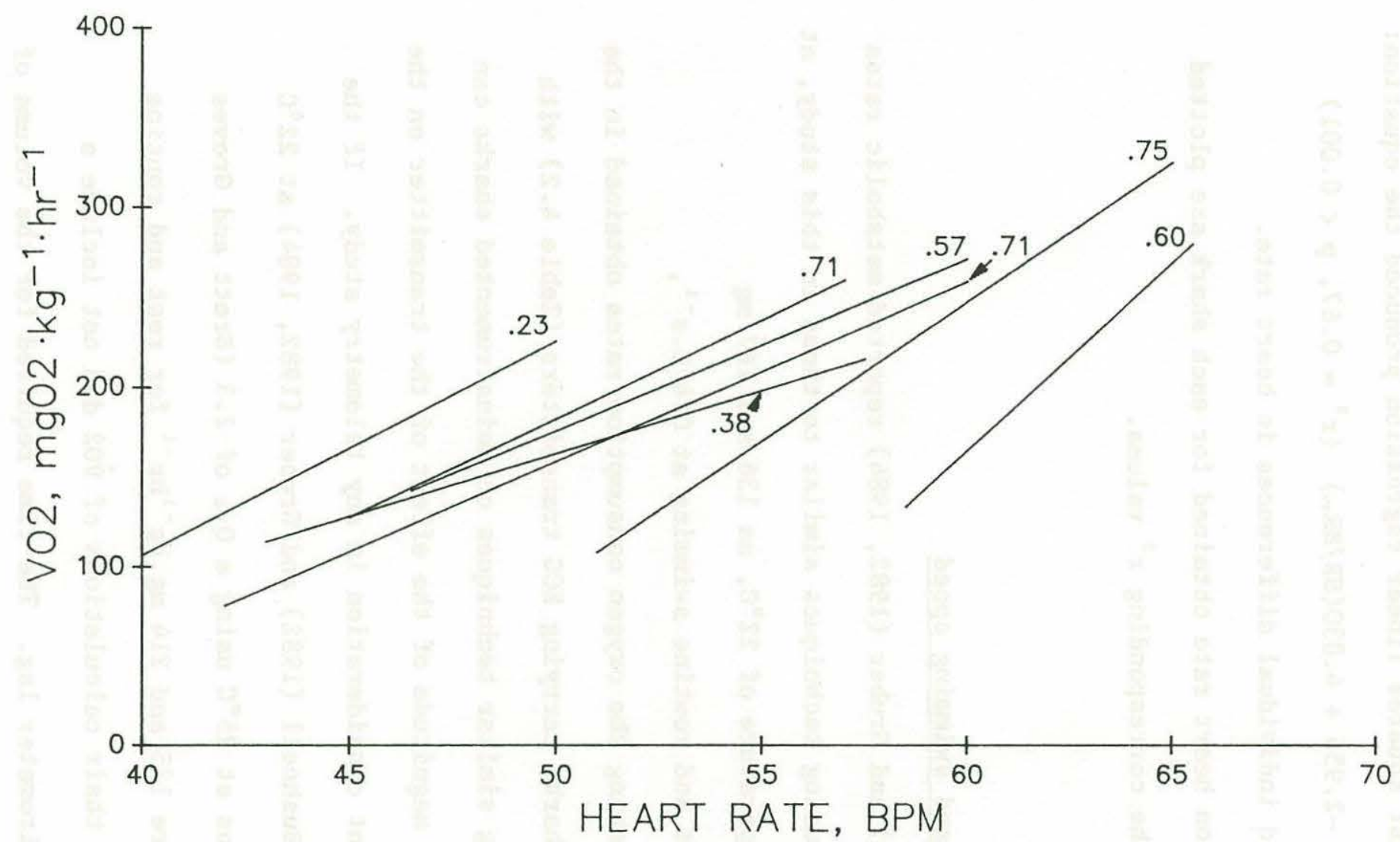

Fig. 4.6 Individual regressions of oxygen consumption rate on heart rate for 7 juvenile lemon sharks. $R^{2}$ values are given for each line. 
swimming speed in L.s $\mathrm{s}^{-1}$.

Normalized vo2 is plotted as a function of normalized heart rate in Fig. 4.5. A least squares linear regression produced the equation:

$$
\left(\dot{\mathrm{V} 02} / \dot{\mathrm{V}}_{02} \mathrm{r}\right)=-2.956+4.030\left(\mathrm{HR}_{\mathrm{HR}}\right) \quad\left(\mathrm{r}^{2}=0.67, \mathrm{p}<0.001\right)
$$

The sharks exhibited individual differences in heart rate.

Regressions of $\dot{v} 02$ on heart rate obtained for each shark are plotted in Fig. 4.6, with the corresponding $r^{2}$ values.

\section{$\underline{\text { DISCUSSION }}$}

\section{Oxygen consumption and swimming speed}

Bushne11 (1982) and Gruber (1982, 1984) reported metabolic rates of the lemon shark using techniques similar to those in this study, at an experimental temperature of $22^{\circ} \mathrm{C}$, as 136 and $167 \mathrm{mg}$ $0_{2} \cdot \mathrm{kg}^{-1} \mathrm{hr}^{-1}$ for rest and routine swimming at $0.4 \mathrm{~L} . \mathrm{s}^{-1}$, respectively. Comparing the oxygen consumption rates obtained in the present study for sharks carrying ECG transmitters (Table 4.2) with those obtained using similar techniques on uninstrumented sharks can give an idea of the magnitude of the effect of the transmitter on the animals, an important consideration in any telemetry study. If the values reported by Bushnel1 (1982) and Gruber $(1982,1984)$ at $22^{\circ} \mathrm{C}$ are adjusted to rates at $25^{\circ} \mathrm{C}$ using a $Q_{10}$ of 2.3 (Brett and Groves 1979), the values are 175 and $214 \mathrm{mg} \cdot \mathrm{kg}^{-1} \mathrm{hr}^{-1}$ for rest and routine swimming. However, their calculations of $\dot{0} 02$ did not include a correction for respirometer lag. The time required for the volume of the respirometer to be replaced in a flow-through system has the effect of damping fluctuations in oxygen content (Fry 1971). If the 
oxygen uptake rates obtained in the present study (Table 4.2) had not been corrected for $1 \mathrm{ag}$, but instead were calculated using the equation of Bushnel1 (1982), the mean rest and swimming rates would be 175 and $229 \mathrm{mg} \cdot \mathrm{kg}^{-1} \mathrm{hr}^{-1}$, close to the temperature-adjusted values reported for uninstrumented sharks. The resting $\dot{0} 02$ is very similar to that for uninstrumented sharks, suggesting that the transmitter and implanted electrodes do not severely stress the fish in a way that shows up as altered resting metabolic rate. The difference in vo2 during swimming between sharks with and without transmitters can be attributed to the extra work required to overcome the additional weight and drag of the transmitter. Thus it appears that the attachment of the transmitter may increase the cost of transport by about $7 \%$.

An exponential relationship between oxygen consumption rate and relative swimming speed has been found in several species of teleosts (reviewed by Beamish 1978). Normalized V02 values can be multiplied by the overall mean resting $\dot{0} 02$ to convert the equation to units of V02:

$$
\log \text { V02 }=2.201+0.4904 \mathrm{U} \text {. }
$$

This equation is plotted for comparison with power-performance curves found in the literature for several teleosts in Fig. 4.7.

The equation obtained using non-normalized V02 values is:

$$
\log \text { V02 }=2.201+0.3930 \mathrm{U}\left(\mathrm{r}^{2}=0.45\right) \text {, }
$$

which is similar to the power-performance curve reported for the lemon shark by Bushne11 (1982):

$$
\log \dot{\mathrm{V}} 02=2.100+0.3441 \mathrm{U} \text { (Fig. 4.7) }
$$




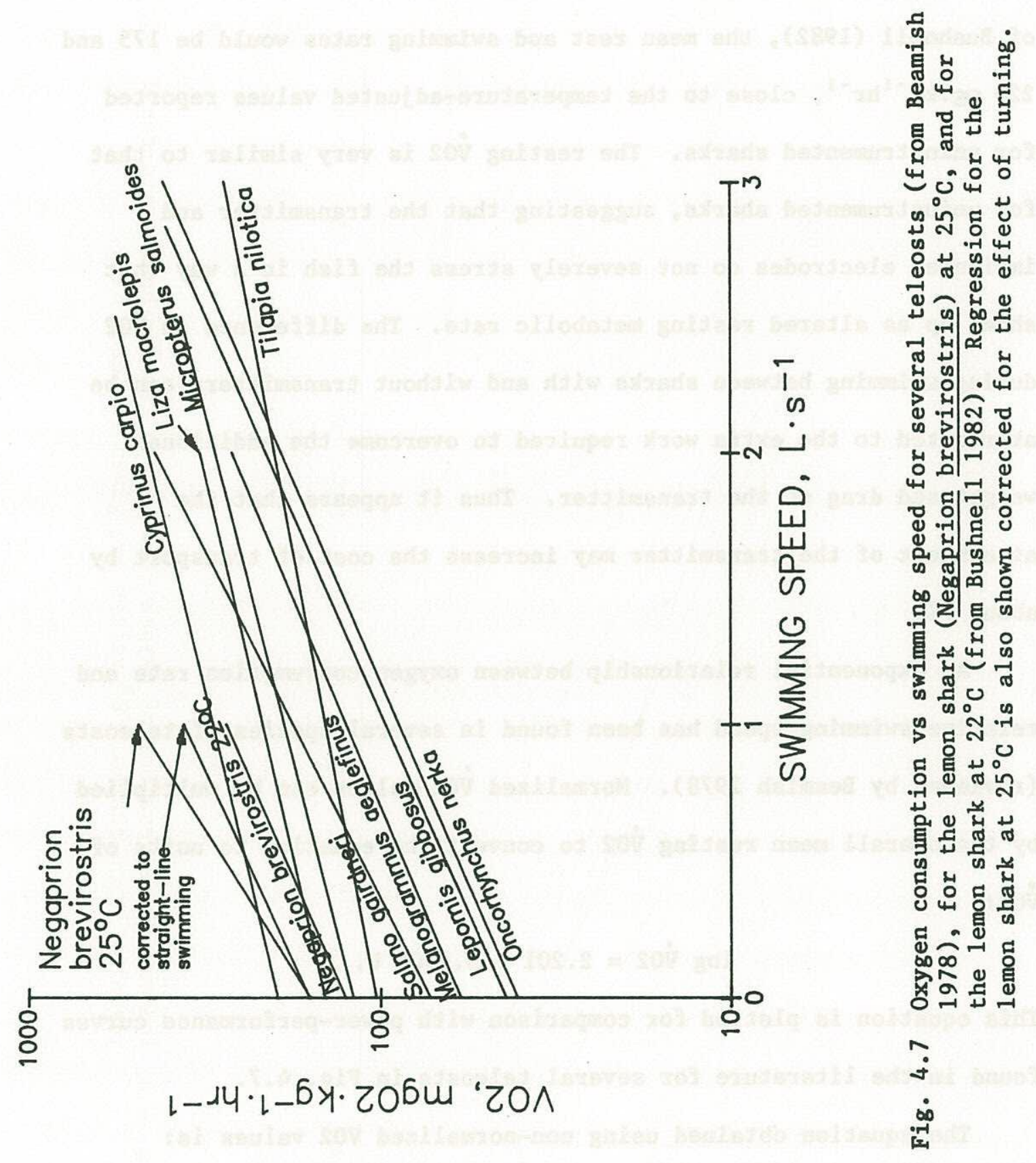


The steeper slope obtained in the present study is in accordance with the greater spread between resting and swimming vo2's, while the difference in intercept can be attributed to temperature, as discussed above.

When the vं02's are normalized by dividing by the mean resting v02 for each shark, the $\mathrm{r}^{2}$ of the $\dot{v} 02$-speed regression increases from 0.45 to 0.69 . Thus, correcting for individual differences in resting metabolic rate greatly improves the fit. Similarly, Brett (1964) found that the relationship between vo 2 and relative speed varied between individual salmon, and suggested that these differences might result from variations in body form, body composition, or physical condition.

When applying the results obtained in the respirometer to unconfined, straight-1ine swimming, it is important to consider the effect of turning on the energy cost of swimming. More energy is required to swim in a circle than to swim in a straight line at the same speed due to the force required to overcome centrifugal force (Weihs 1981b). The additional force required for turning can be supplied in two ways: production of asymmetric thrust and, in the case of negatively buoyant fish, banking. The sharks in the respirometer did exhibit banking, swimming with the belly angled toward the outer wa11. Since this behavior was observed, and since banking is theoretically much more efficient at the speeds observed, it will be assumed that centrifugal force was overcome solely by banking. Weihs (1981b) developed the following correction factor to convert v02 of a turning fish to the the vo2 that would be expected if 
the fish were swimming at the same speed in a straight line:

$$
\frac{\dot{V}_{02}}{\hat{V} O 2 t_{s}}=1+\frac{D_{1 s}}{D_{s}}\left[\left(\left(\frac{p_{f}+A_{p}}{P_{f}-P_{w}} \cdot \frac{U^{2}}{g R}\right)^{2}+1\right)\left(\frac{b_{s}}{b_{t}}\right)^{2}-1\right]
$$

where $\dot{V}_{0} 2_{\mathrm{t}}$ and $\dot{\mathrm{V}}^{0} 2_{\mathrm{s}}$ are oxygen consumption rates during turning and straight-1ine swimming, respectively, $D_{s}$ and $D_{1 s}$ are the total and induced drag while swimming, $\mathrm{p}_{\mathrm{f}}$ and $\mathrm{p}_{\mathrm{w}}$ are densities of the fish and water, $A$ is the added mass coefficient, $U$ is the swimming speed, $R$ is the turning radius, $g$ is the gravitational constant, and $b_{s}$ and $b_{t}$ are the pectoral fin spans in straight-1ine swimming and turning. In theory, banking causes a component of the lift force produced on the fins during swimming to be directed inward to offset centrifugal force, but the increased lift is accompanied by increased drag. The correction factor is strongly dependent on speed. Using a density of $1.064 \mathrm{~g} \cdot \mathrm{ml}^{-1}$ for the lemon shark (Baldridge 1970), turning radius of $28 \mathrm{~cm}$, added mass coefficient of 0.2 for a streamlined fish shape (Webb 1975), $D_{1 s} / D_{s}$ of 0.3 , a rough estimate from the value for tuna (Magnuson 1978), and bs/bt of 1 (assuming the fins are fully extended at low speeds) (Weihs 1981b), the correction factor is:

$$
\text { 迆 } 2_{t} / \dot{V}_{0} 2_{s}=1+0.421 \times 10^{-6}\left(U^{4}\right)
$$

This corresponds to an increase in energy expenditure of about $11 \%$ at the speeds observed. When the observed v02's are converted to equivalent straight swimming ${ }^{\circ} 02$ 's, the corrected power-performance curve for the lemon shark is:

$$
\log \text { Vं02 }=2.203+0.3608 U\left(r^{2}=0.55\right) \text {. }
$$

The slope of this line (Fig. 4.7) is the same as the value of 0.36 
given by Beamish (1978) as representative for several species of teleosts.

General1y, the sharks either rested, or swam within a narrow range of speeds, and did not exhibit intermediate speeds. The mean speed, $0.4 \mathrm{~L} . \mathrm{s}^{-1}$, is the same as that reported by Bushnel1 (1982) for juvenile lemon sharks swimming unrestrained in holding tanks, as we11 as in the respirometer, and agrees we11 with swimming speeds recorded from lemon sharks in the field (Gruber 1982, 1984). This suggests that the swimming ability of the sharks was not greatly restricted by the respirometer, and that this speed may correspond to some optimal or minimal swimming speed. In addition, it appears that the transmitter did not affect swimming speed.

\section{Oxygen consumption and heart rate}

The expected relationship between metabolic rate and heart rate is based on the fact that all oxygen consumed during respiration must be supplied to the tissues by the cardiovascular system. The relation between oxygen consumption and the cardiovascular variables is given by the Fick equation (Schmidt-Nie1sen 1979):

$$
\text { Vं02 }=\mathrm{HR} \times \mathrm{SV} \times(\mathrm{Ca}-\mathrm{Cv})
$$

where $\mathrm{HR}=$ heart rate, $\mathrm{SV}=$ stroke volume, and $(\mathrm{Ca}-\mathrm{Cv})$ is the arteriovenous oxygen difference. The term SV $\mathrm{x}(\mathrm{Ca}-\mathrm{Cv})$ is referred to as the oxygen pulse, the quantity of oxygen supplied per heart beat. In order to have a close relationship between heart rate and v02, the oxygen pulse must remain constant or change predictably with changes in metabolic rate (Webster 1967). A close correlation between metabolic rate and heart rate has generally been found in mammals and 
birds (Webster 1967, Holter et a1 1976, Renecker and Hudson 1985, Owen 1969, Wooley and Owen 1977, Lund and Folk 1976), although there has been some dispute concerning the usefulness of the relationship for predicting metabolic rate from heart rate (Brockway and McEwen 1969, Mautz and Fair 1980).

The observation that, in the lemon shark, distinct changes in heart rate of several beats. $\min ^{-1}$ were consistently and closely associated with changes from rest to swimming activity (accompanied by changes in metabolic rate) indicates that heart rate is one factor responsible for regulating oxygen supply. Although the 1inear relationship between $\dot{V} 02$ and heart rate is statistically significant, there is considerable variation in the data, with a range of vo2's observed for any given heart rate. This suggests that $\dot{\mathrm{v}} 02$ is varied by other factors independently of heart rate. One way to evaluate the importance of heart rate in meeting increased oxygen demands is to calculate the percent contribution of heart rate to increased oxygen consumption. This is given by the equation:

$$
\% \text { contribution }=\log \left(\mathrm{HR}_{\mathrm{s}} / \mathrm{HR}_{\mathrm{r}}\right) / \log \left(\dot{\mathrm{V} O} 2_{\mathrm{s}} / \text { VंO2 }_{\mathrm{r}}\right) \times 100
$$

Where the subscripts $r$ and $s$ refer to resting and swimming values, respectively. Using values obtained for the lemon shark from Table 4.2, the percent contribution of heart rate to the observed increase in oxygen consumption is $19 \%$. This value is presented in Table 4.3 with values calculated from the literature for trout, pike, spotted dogfish, and several mammals and birds. The estimated percent contribution of heart rate to 5-6 fold increases in metabolic rate in trout ranges from less than $10 \%$ to almost $50 \%$. The value for pike is 
Table 4.3. Percentage contribution of heart rate to increases in metabolic rate in several species of teleosts, elasmobranchs, mammals, and birds.

\begin{tabular}{|c|c|c|c|c|}
\hline SPECIES & $\begin{array}{l}\text { FACTOR OF } \\
\text { INCREASE IN } \\
\text { OXYGEN UPTAKE }\end{array}$ & $\begin{array}{l}\text { FACTOR OF } \\
\text { INCREASE IN } \\
\text { HEART RATE }\end{array}$ & $\begin{array}{l}\text { PERCENT } \\
\text { CONTRIBUTION } \\
\text { OF HEART RATE }\end{array}$ & \\
\hline$\frac{\text { Salmo }}{\text { gairdneri }}$ & 5.00 & 1.15 & $8.7 \%$ & $\begin{array}{l}\text { Stevens and } \\
\text { Randa11 } 1967\end{array}$ \\
\hline S. gairdneri & 5.60 & 1.36 & $17.8 \%$ & $\begin{array}{l}\text { Kiceniuk and } \\
\text { Jones } 1977\end{array}$ \\
\hline S. gairdneri & 6.62 & 2.56 & $49.7 \%$ & $\begin{array}{l}\text { Priede and } \\
\text { Tytler } 1977\end{array}$ \\
\hline Esox 1ucius & 2.29 & 2.75 & $122.1 \%$ & Armstrong 1986 \\
\hline $\begin{array}{l}\text { Scyliorhinus } \\
\text { stellaris }\end{array}$ & 1.47 & 1.07 & $17.6 \%$ & $\begin{array}{l}\text { Piiper et a1 } \\
1977\end{array}$ \\
\hline$\frac{\text { Negaprion }}{\text { brevirostris }}$ & 1.44 & 1.08 & $19.8 \%$ & Present study \\
\hline
\end{tabular}

\begin{tabular}{|c|c|c|c|c|}
\hline Sheep & 2.18 & 1.89 & $81.7 \%$ & Webster 1967 \\
\hline Moose & 3.70 & 2.19 & $59.9 \%$ & $\begin{array}{l}\text { Renecker and } \\
\text { Hudson } 1985\end{array}$ \\
\hline $\begin{array}{l}\text { White-tailed } \\
\text { deer }\end{array}$ & 2.42 & 1.63 & $55.3 \%$ & $\begin{array}{l}\text { Mautz and Fair } \\
1980\end{array}$ \\
\hline Mule deer & 2.80 & 1.80 & $57.1 \%$ & $\begin{array}{l}\text { Kautz et a1 } \\
1981\end{array}$ \\
\hline Prairie dog & 5.39 & 3.00 & $65.2 \%$ & $\begin{array}{l}\text { Lund and Folk } \\
1976\end{array}$ \\
\hline $\begin{array}{l}\text { Blue-winged } \\
\text { teal }\end{array}$ & 2.25 & 4.00 & $171.0 \%$ & Owen 1969 \\
\hline Black duck & 2.85 & 3.00 & $104.9 \%$ & $\begin{array}{l}\text { Wooley and } \\
\text { Owen } 1977\end{array}$ \\
\hline
\end{tabular}


over $100 \%$, indicating that stroke volume and/or arteriovenous oxygen difference must decrease. Heart rate accounts for $18 \%$ of the increase in metabolic rate associated with the change from rest to routine swimming in dogfish, similar to the value obtained for the lemon shark. In mammals and birds, the percent contribution of heart rate to changes in metabolic rate is generally higher than that seen in fish, ranging from $60 \%$ to greater than $100 \%$.

The results of three studies in which oxygen consumption, heart rate, and arterial and venous oxygen concentrations were measured are presented in Table 4.4 to examine the details of the relationship more closely. Stevens and Randall $(1967 a, b)$ found that a five fold increase in $\dot{v} 02$ in trout was accompanied by a $15 \%$ increase in heart rate, an $11 \%$ increase in $\mathrm{Ca}-\mathrm{Cv}$, and almost a fourfold increase in stroke volume. Kiceniuk and Jones (1977) reported a 5.6 fold increase in $\dot{v} 02$ in trout from rest to swimming at $90 \%$ of the critical speed (maximum swimming speed sustainable for one hour), achieved by a $36 \%$ increase in heart rate, a $121 \%$ increase in $\mathrm{Ca}-\mathrm{Cv}$, and an $87 \%$ increase in stroke volume. When swimming speed was increased to $100 \%$ of the critical speed, the $\dot{\mathrm{v}} 2$ increased to 7.75 times the resting rate, with no further increase in heart rate. The results of these and other studies led Jones and Randall (1978) to conclude that heart rate changes make only a minor contribution to increases in oxygen transport during exercise in salmonids. In the spotted dogfish, a $47 \%$ increase in vं02 with spontaneous swimming was associated with a $7 \%$ increase in heart rate (Piiper et al 1977). These values are similar to those obtained for the lemon shark, as mentioned previous $1 \mathrm{y}$. The 
Table 4.4. Cardiovascular adjustments to exercise in trout, dogfish, and the lemon shark

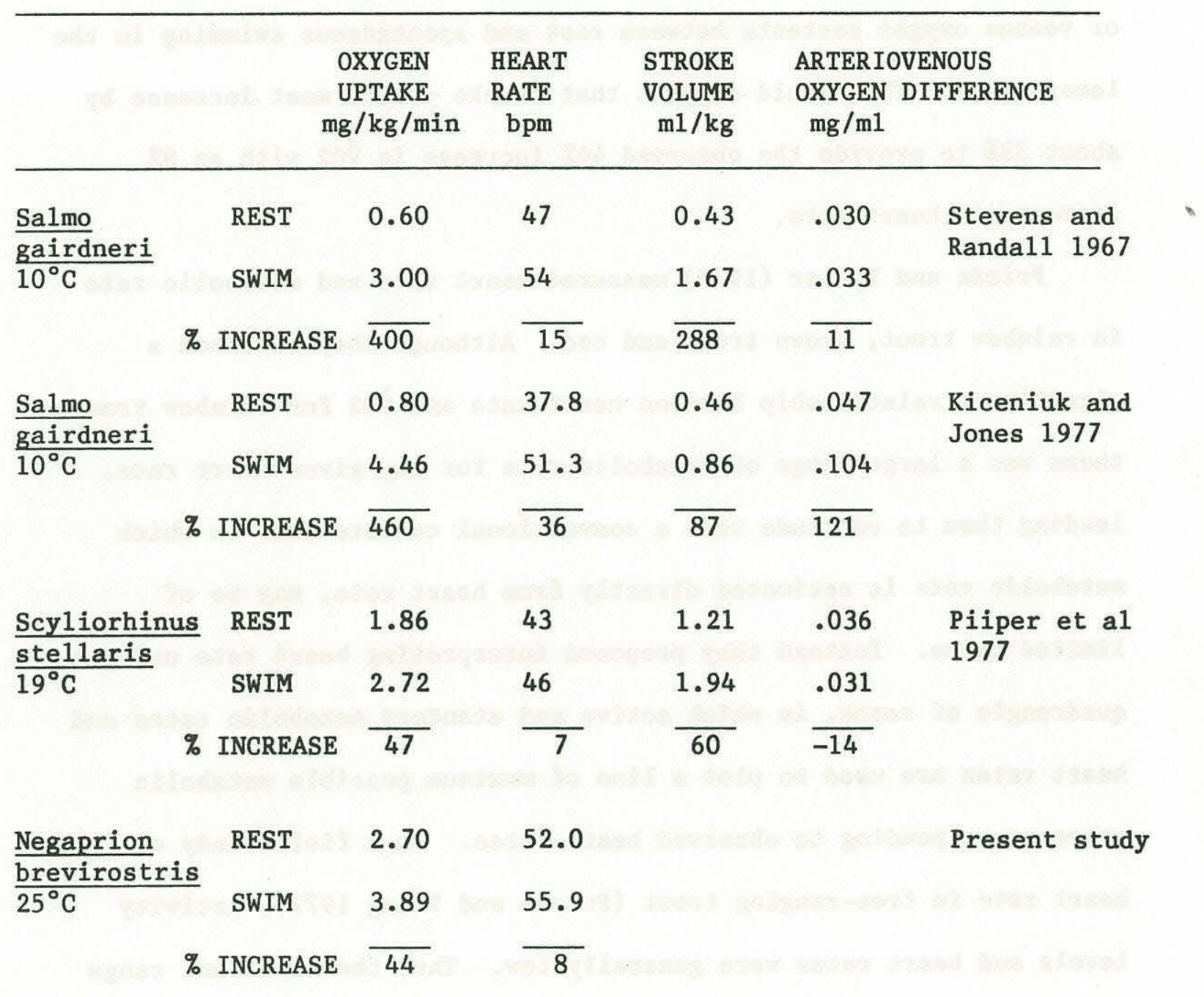


arteriovenous oxygen content in the dogfish decreased $14 \%$, leaving the remainder of the increase in $\dot{0} 2$ to be supplied by a $60 \%$ increase in stroke volume. Bushnell et al (1982) reported no change in arterial or venous oxygen contents between rest and spontaneous swimming in the lemon shark. This would suggest that stroke volume must increase by about $33 \%$ to provide the observed $44 \%$ increase in vं02 with an $8 \%$ increase in heart rate.

Priede and Tytler (1977) measured heart rate and metabolic rate in rainbow trout, brown trout and cod. Although they obtained a significant relationship between heart rate and vo 2 for rainbow trout, there was a large range of metabolic rate for any given heart rate, leading them to conclude that a conventional calibration, in which metabolic rate is estimated directly from heart rate, may be of limited value. Instead they proposed interpreting heart rate using a quadrangle of scope, in which active and standard metabolic rates and heart rates are used to plot a line of maximum possible metabolic rates corresponding to observed heart rates. In a field study of heart rate in free-ranging trout (Priede and Young 1977), activity levels and heart rates were generally low. Thus the resultant range of metabolic rates for measured heart rates was sma11, and considerable information about metabolic rate could be obtained from changes in heart rate.

Armstrong (1986) recorded metabolic rate and heart rate from laboratory pike during rest, activity, feeding, and digestion, and found a significant relationship between metabolic rate and heart rate, within a range of 5 and 55 beats. $\mathrm{min}^{-1}$. Using post-prandial 
heart rate records, he estimated energy expenditure associated with food processing, and from this was able to estimate the energy content of meals with an error of less than $10 \%$. Thus it appears that heart rate in fish may be closely correlated with increases in metabolic rate associated with feeding as well as with activity.

Separate regressions were obtained between $\dot{\mathrm{V}} 02$ and heart rate for each shark (Fig 4.6). Normalizing both v́02 and heart rate to adjust for individual differences increased the combined $r^{2}$ from 0.39 to 0.67. The fact that separate relationships were obtained for different animals indicates that individual calibration would be necessary to predict metabolic rate from heart rate in the lemon shark. Individual differences in the heart rate-metabolic rate relationship have been found in several studies on mammals and birds, and body size and sex have been suggested as possible sources of variation (Kautz et a1 1981).

It appears that for the lemon shark, while there is a significant relationship between heart rate and metabolic rate, the usefulness of the relationship may be limited by the small percent of the change in v02 that is accounted for by heart rate (19\%), and by the confounding effects of changes in oxygen pulse. It would be of interest to investigate how stroke volume and oxygen utilization coefficient change with changes in نं02 to gain further understanding of the heart rate-نं02 relationship. There was no control over activity in this study; thus, variations in metabolic rate resulted from spontaneous changes in activity, and active metabolic rate could not be determined. The heart rate-نO2 relationship should be investigated 
over the widest possible range of metabolic rates, which might be feasible using a swimming tunnel, in which swimming speed is contolled by altering the flow rate of a current against which the animal swims (Brett 1964, Brett and Blackburn 1978). It is also important to determine whether observed heart rate-نं02 relationships are stable over time, and whether a single relationship holds over a range of conditions, or whether different relationships are applicable to different conditions of temperature, feeding, etc.

If variations in metabolic rate of free-ranging animals were due solely to variations in swimming speed, then field metabolic rate could be determined by using speed sensors to develop a time-activity budget and using laboratory-derived vio2-speed relationships to calculate metabolic rate. Telemetered electromyograms from swimming muscles also show promise as a measure of activity metabolism (Weatherley et a1 1982). However, there are other factors affecting metabolic rate, such as temperature, feeding, and stress, which would not be detectable by monitoring activity, but which may be sufficiently correlated to changes in heart rate. The results of this study suggest that heart rate of the lemon shark may be a useful indicator of metabolic rate for field studies, and that further investigations into the vo2-heart rate relationship are warranted. 
V. METABOLIC RATE, HEART RATE, AND TAILBEAT FREQUENCY DURING

SUSTAINED SWIMMING IN THE LEOPARD SHARK, Triakis semifaciata

\section{ABSTRACT}

Heart rate, metabolic rate, and tailbeat frequency were simultaneous $1 y$ recorded from seven leopard sharks during steady swimming at controlled speeds to evaluate the usefulness of heart rate as a measure of metabolic rate for field studies. Heart rate was monitored by acoustic telemetry using a frequency modulated ECG transmitter. Metabolic rate was measured as oxygen consumption rate in a swimming tunne1 respirometer. For instrumented sharks, mean resting oxygen consumption rate and heart rate were $105.3 \pm 35.6$ (S.E.) mg $0_{2} \cdot \mathrm{kg}^{-1} \cdot \mathrm{hr}^{-1}$ and $36.6 \pm 1.8$ (S.E.) beats.min ${ }^{-1}$, respectively. Mean rates while swimming at the maximum sustained speed $(0.84 \pm 0.03$ lengths. $\mathrm{s}^{-1}$ ) were $229.3 \pm 13.2 \mathrm{mg} 0_{2} \cdot \mathrm{kg}^{-1} \cdot \mathrm{hr}^{-1}$ and $46.9 \pm 0.9$ beats.min ${ }^{-1}$. The observed elevation in heart rate from rest to maximum sustained exercise accounts for $32 \%$ of the increase in oxygen uptake, leaving the remainder to be achieved by increases in stroke volume and/or arteriovenous oxygen difference. Although a significant linear regression was obtained between metabolic rate and heart rate, a low overall correlation coefficient may result from the existence of separate individual regressions and confounding changes in oxygen pulse. Heart rate was approximately as closely correlated to oxygen consumption rate as swimming speed was. A significant linear relationship was obtained between tailbeat frequency and swimming speed to speeds of 0.75 lengths.s $\mathrm{s}^{-1}$. 


\section{INTRODUCTION}

Bioenergetic studies, in which energy flow through an organism is partitioned and quantified, can provide a useful framework in which to examine the relationships of an animal to its environment. An important element of the energy budget is the energy expended in metabolism. A number of studies have used indirect calorimetry to measure energy expenditures of elasmobranchs, but most of these have recorded only resting metabolic rates from restrained animals (Brett and Blackburn 1978). A few workers have measured metabolic rates of sharks during spontaneous activity (Piiper et al 1977, Brett and Blackburn 1978, Bushne11 1982, Nixon and Gruber 1988), but none of these studies measured energy expenditures during prolonged periods of exercise over a range of steady, controlled swimming speeds. Brett and Blackburn (1978) attempted to use a large tunnel respirometer similar to that described by Brett (1964) to record active metabolic rates in the spiny dogfish, Squalus acanthias, but were unable to induce the animals to swim steadily.

Indirect calorimetry, or respirometry, involves measuring energy expenditure as oxygen consumption rate. This technique requires monitoring the oxygen content of water entering and exiting the gills, or in a closed chamber in which the animal is confined, and cannot be used in the field. Acoustic telemetry has made it possible to directly monitor various physiological parameters from animals in the field (Stasko and Pincock 1977). Heart rate is one such parameter which has been suggested as a potential correlate of field metabolic 
rate for fish (Priede 1983). The basis for the expected relationship between heart rate and metabolic rate is the requirement of oxygen to sustain metabolism, which is supplied to the tissues by the cardiovascular system. The relation between oxygen consumption rate and heart rate is given by the Fick equation (Schmidt-Nielsen 1979):

$$
\text { Vं02 }=\mathrm{HR} \times \mathrm{SV} \times\left(\mathrm{CaO}_{2}-\mathrm{Cv}_{2}\right)
$$

where $\dot{\mathrm{V}} 22$ is oxygen consumption rate, $\mathrm{HR}$ is heart rate, $\mathrm{SV}$ is stroke volume, and $\left(\mathrm{CaO}_{2}-\mathrm{Cv}_{2}\right)$ is the difference between arterial and venous oxygen contents. The product $\mathrm{SV} \times\left(\mathrm{Ca}_{2}-\mathrm{Cv}_{2}\right)$ is called the oxygen pulse, the quantity of oxygen supplied per heart beat. In order to have a close relationship between heart rate and metabolic rate, the oxygen pulse must remain constant or change predictably with changes in oxygen supply (Webster 1967). Relationships between heart rate and metabolic rate have been demonstrated in several teleosts (Priede and Tytler 1977, Armstrong 1986), and Priede and Young (1977) measured heart rates from free-swimming trout and were able to use heart rate records to estimate field metabolic rate. Scharold and Gruber (in review) reported a relationship between heart rate and metabolic rate in the lemon shark, Negaprion brevirostris, under conditions of spontaneous activity (rest or a narrow range of speeds). In the present study, heart rate and metabolic rate were simultaneously measured in leopard sharks, Triakis semifasciata, swimming over a range of controlled speeds in a tunnel respirometer, in order to evaluate heart rate as an indicator of metabolic rate. 
METHODS

Maintenance of animals

Leopard sharks, 2.2 to $5.8 \mathrm{~kg}$, were held at the Scripps

Institution of Oceanography in 4700 1iter, circular fiberglass tanks supplied with aerated, continuously flowing seawater at ambient temperatures $\left(12-18^{\circ} \mathrm{C}\right)$. Lighting was on an ambient photoperiod. The animals were fed squid and cut mackere1 week1y. Each shark was fasted for at least one week prior to being used in an experiment to ensure that it was in a post-absorptive state.

\section{Heart Rate}

Heart rate was monitored using an ultrasonic, frequency modulated electrocardiogram (ECG) transmitter, described by Scharold and Gruber (in review). The transmitters were $2 \mathrm{~cm}$ diameter by $8 \mathrm{~cm} 1$ ong and weighed $40 \mathrm{~g}$, or about $1.1 \%$ of the mean body weight of the sharks. The transmitter produced a continuous $86 \mathrm{kHz}$ carrier wave which was modulated by the ECG voltage. This signal was picked up by a hydrophone and receiver (Communication Associates Inc. CR-40). Using a narrow bandwidth setting, the receiver could be tuned off the center frequency so that only the peak of the deflection corresponding to the QRS wave of the ECG would be picked up, resulting in one signal per heart beat.

The ECG leads were teflon coated 32 gauge multistranded copper wire with a short length of 40 gauge epoxy-coated stainless steel wire attached to the end to form the electrodes. The joint was soldered and waterprofofed with epoxy. The tip of each electrode was bared and bent to form a hook. A hypodermic needle was used to place the signal 
electrode percutaneously, from the ventral side at a point anterior to the coracoid bar, into the pericardial space adjacent to the ventricle. Penetration of the pecicardium by the electrode was necessary to obtain a useful signal. The ground electrode was placed percutaneously into the dorsal musculature anterior to the dorsal

fin. The leads were secured in place with silk or monofilament sutures. The transmitter was attached to the body adjacent to the the first dorsal fin by passing nylon string through holes punctured in the skin at the base of the fin.

\section{Oxygen Consumption}

Energy expenditure was estimated as oxygen consumption rate (ن்2) in a large (2400 1iter) water tunnel respirometer, similar to the type described by Brett (1964). The working section of the tunnel was 150 cm long x $42 \mathrm{~cm}$ wide x $51 \mathrm{~cm}$ high. Flow speed was controlled by a $440 \mathrm{~V}$ variable speed motor and was calibrated with a flow meter (General Oceanics, Inc. mode1 2035-MKIII). The respirometer was operated as a closed system. The oxygen content of the water in the respirometer was monitored using an oxygen meter (YSI mode1 54A) and a temperature compensated polarographic oxygen electrode (YSI 5450/5750) housed in a plexiglass sampling chamber. A peristaltic pump (Masterflex mode1 7553-50) circulated water via Tygon tubing from the respirometer, through the sampling chamber, and back into the respirometer at a point downstream of the sampling port. The oxygen electrode was air-calibrated once each day. Water temperature in the respirometer was continuously monitored with a thermocouple. 


\section{Experimental procedure}

Each shark was anaesthetized with MS-222 $\left(0.1 \mathrm{~g} .1^{-1}\right)$ while the ECG transmitter and electrodes were attached. After recovering from anaesthesia, the shark was placed in the respirometer and trained to swim against the current. The shark was then left in the respirometer overnight with ambient seawater flowing through the chamber. Experiments were begun 18-24 hours after surgery. A set of $\dot{0} 02$ experiments was run on control sharks, which were not anaesthetized or instrumented with ECG transmitters. In addition, heart rate was monitored from three sharks with ECG transmitters in a large (5 x 10 m) poo1 for 2 to 3 days each.

Each experiment consisted of a series of "runs", in which the respirometer was cleared of air bubbles and sealed and the shark was induced to swim at a set speed for a period of time while oxygen content, temperature, heart rate, and tailbeat frequency were recorded. The first run was at the slowest flow speed at which the shark would swim steadily. Most sharks would not rest, even at the slowest speed, but resting oxygen consumption rates and heart rates were recorded when possible. Speed was increased in increments of approximately $5-10 \mathrm{~cm} \cdot \mathrm{s}^{-1}$ and each speed was maintained for $30-90$ minutes. When the oxygen content dropped below $70 \%$ saturation, the respirometer was opened and the oxygen levels replenished by adding fresh seawater, during which time the shark continued swimming at the speed of the last run. The experiment continued until a speed was reached at which the shark was unable to keep its tail from brushing the grating at the rear of the swimming chamber. 
During each run, heart rate, tailbeat frequency, and oxygen content were recorded manually at 5-10 minute intervals. Heart rate was determined by using a stopwatch to time 15-30 pulses and calculating frequency in beats per minute (BPM). Tailbeat frequency was determined by timing the period required for a similar number of complete tailbeat cycles, such that one beat consisted of a complete oscillation of the tail from left to right and back again. 0xygen content was determined from the analog output of the oxygen meter. Water temperature during the course of the experiments ranged from $14^{\circ} \mathrm{C}$ to $18^{\circ} \mathrm{C}\left(\overline{\mathrm{x}}=16.4^{\circ} \mathrm{C}\right)$, but did not vary by more than \pm $0.6^{\circ} \mathrm{C}$ during any single run.

At the end of an experiment, the shark was removed from the respirometer, draining the smallest volume of water necessary. The respirometer was then refilled and sealed and a blank was run for 1-2 hours to determine background oxygen consumption rates. Oxygen consumption rate for each run was calculated as the slope of a least-squares linear regression of oxygen content on time. The blank value was subtracted from the total value to obtain the oxygen consumption rate of the animal. Replicate values of heart rate and tailbeat frequency were averaged for each run.

\section{RESULTS}

Heart rate and $\dot{v} 02$ were recorded from a total of seven experimental (instrumented) sharks, and vo2-only experiments were performed on 5 control (noninstrumented) sharks. Physical characteristics of the sharks used are given in Table 5.1. A11 
Table 5.1. Physical characteristics of 12 leopard sharks used in experiments. Sharks 1 to 7 were instrumented with transmitters; C-1 through C-6 were control animals.

\begin{tabular}{llll}
\hline NUMBER & SEX & $\begin{array}{c}\text { FORK LENGTH } \\
\text { cm }\end{array}$ & $\begin{array}{c}\text { MASS } \\
\mathbf{k g}\end{array}$ \\
\hline 1 & M & 86 & 4.40 \\
2 & F & 75 & 2.68 \\
3 & M & 95 & 4.72 \\
4 & M & 79 & 3.08 \\
5 & F & 72 & 2.22 \\
6 & M & 90 & 3.77 \\
7 & M & 83 & 3.23 \\
C-1 & M & 89 & 3.86 \\
C-2 & M & 83 & 3.23 \\
C-4 & F & 73 & 2.47 \\
C-5 & M & 75 & 2.65 \\
C-6 & M & 106 & 5.84 \\
& & &
\end{tabular}


experimental animals recovered from anaesthesia within 5-10 minutes. While in the respirometer, both experimental and control animals appeared to be in good condition. They showed no adverse effects after removal from the respirometer, and continued to feed normally back in the aquaria.

A11 sharks swam well in the respirometer after an initial training period, with the exception of one individual that would not swim consistently at any speed and was not used in an experiment. Usually having the tail contact the rear grating when the flow speed was increased was sufficient stimulus to induce a shark to increase swimming speed. Occasionally an animal would fall back against the rear grating during a run, but once it was pushed off by moving the rear grating forward it would resume steady swimming.

Position of the sharks in the swimming chamber was variable. At the slowest speeds, the sharks would swim at an angle, with the nose against the top of the front screen and the tail down. At faster speeds, the sharks swam level, of ten in the lower front section of the swimming chamber and against one side. When the maximum sustainable speed was exceeded, the shark would drift back until the tail was pushing against the rear screen, then make a series of short bursts to the front of the chamber, repeating the process until it collapsed against the rear grating. Most of the sharks would not rest at the slowest flow speed; thus resting oxygen consumption rates were obtained in only six runs from four individuals.

The mean maximum sustainable speed was $0.88 \pm 0.04$ (S.E.) body lengths. $\mathrm{s}^{-1}\left(\mathrm{~L} \cdot \mathrm{s}^{-1}\right)$. There was no difference between maximum 
sustainable speeds whether the runs were conducted for 30 or 60 minutes (paired-sample t-test, 6 d.f., p >0.1). Typically, the sharks were either able to swim at a given speed for the entire test period, or were unable to maintain the speed for more than about 10 minutes. There was no difference in the mean maximum sustained speeds of experimental and control sharks (t-test, 17 d.f., p > 0.1).

Tailbeat frequency is plotted as a function of relative swimming speed in Fig. 5.1. A 1inear relationship was obtained for speeds up to $0.75 \mathrm{~L} . \mathrm{s}^{-1}$, above which tailbeat frequency does not appear to increase. For speeds up to $0.75 \mathrm{~L} . \mathrm{s}^{-1}$, a linear regression of tailbeat frequency on speed produced the equation:

$$
\mathrm{TBF}=9.42+82.65 \mathrm{U}, \mathrm{r}^{2}=0.67, \mathrm{p}<0.001
$$

where $\mathrm{TBF}=$ tailbeat frequency in beats $\cdot \mathrm{min}^{-1}$, and $\mathrm{U}=$ relative swimming speed in $\mathrm{L}_{\mathrm{s}} \mathrm{s}^{-1}$. All points cluster about the regression line, with the exception of the largest individual, which exhibited marked1y lower tailbeat frequencies than the others. In Fig. 5.2, the mean tailbeat frequency \pm S.E. for all runs at a given speed setting is plotted as a function of speed expressed relative to the mean body length of al1 sharks in the group for instrumented and control sharks. There is no apparent difference in tailbeat frequency between instrumented and control sharks at any speed.

When $\dot{\mathrm{V}} 02$ is plotted as a function of relative swimming speed (Fig. 5.3), separate regressions are obtained for instrumented and control animals. In both cases, the best-fit lines are described by exponential equations. For instrumented sharks the equation is:

$$
\log \dot{\mathrm{V}} 02=1.90+0.54 \mathrm{U}, \mathrm{r}^{2}=0.44, \mathrm{p}<0.001
$$




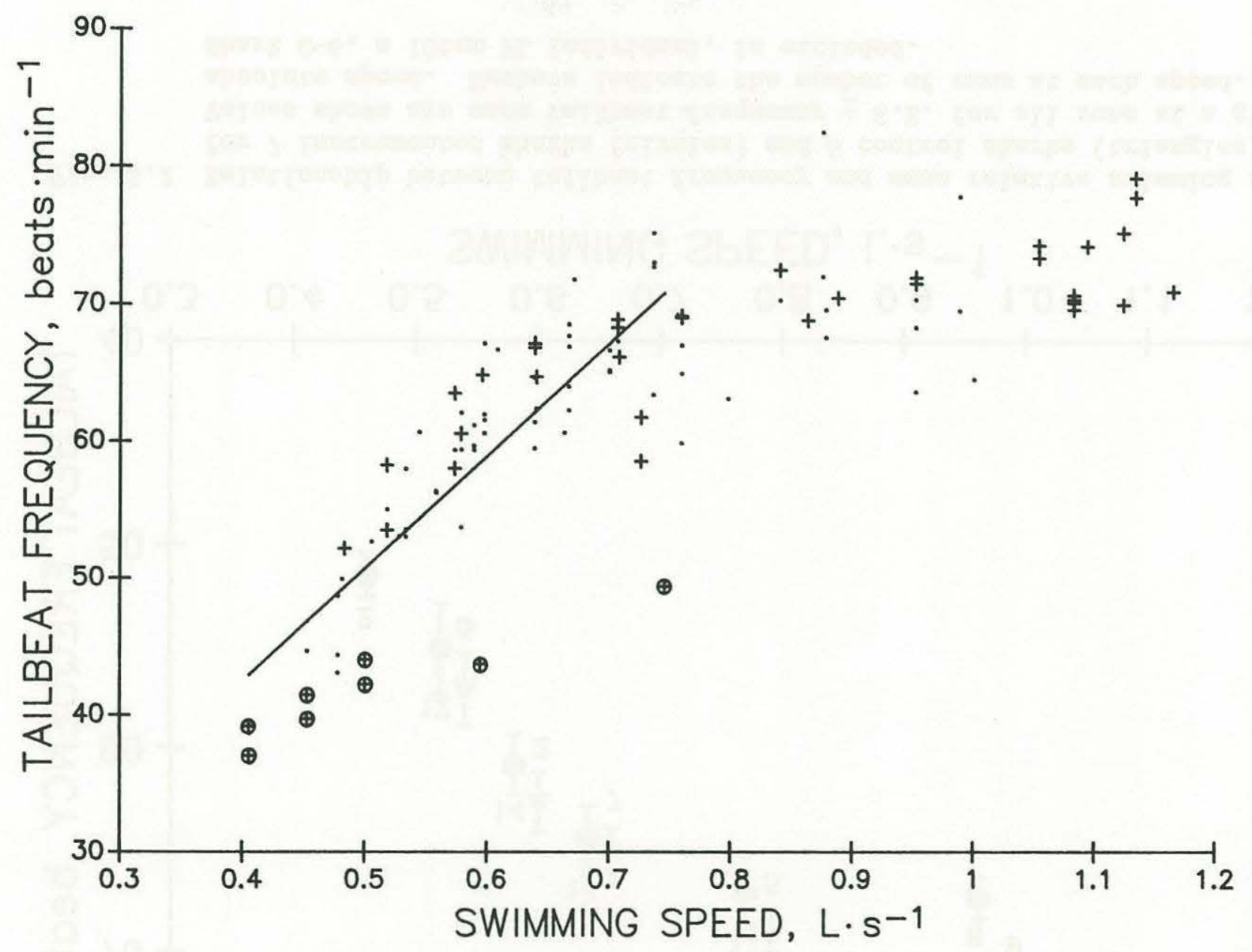

Fig. 5.1 Relationship between tailbeat frequency and relative swimming speed for 12 leopard sharks. Dots represent sharks carrying ECG transmitters; crosses represent control sharks; circled crosses indicate values for shark C-6, a $106 \mathrm{~cm} \mathrm{FL} \mathrm{individual.} \mathrm{Regression} \mathrm{line} \mathrm{for} \mathrm{speeds} \mathrm{to} 0.75$ lengths. $\mathrm{s}^{-1}$ is shown. 


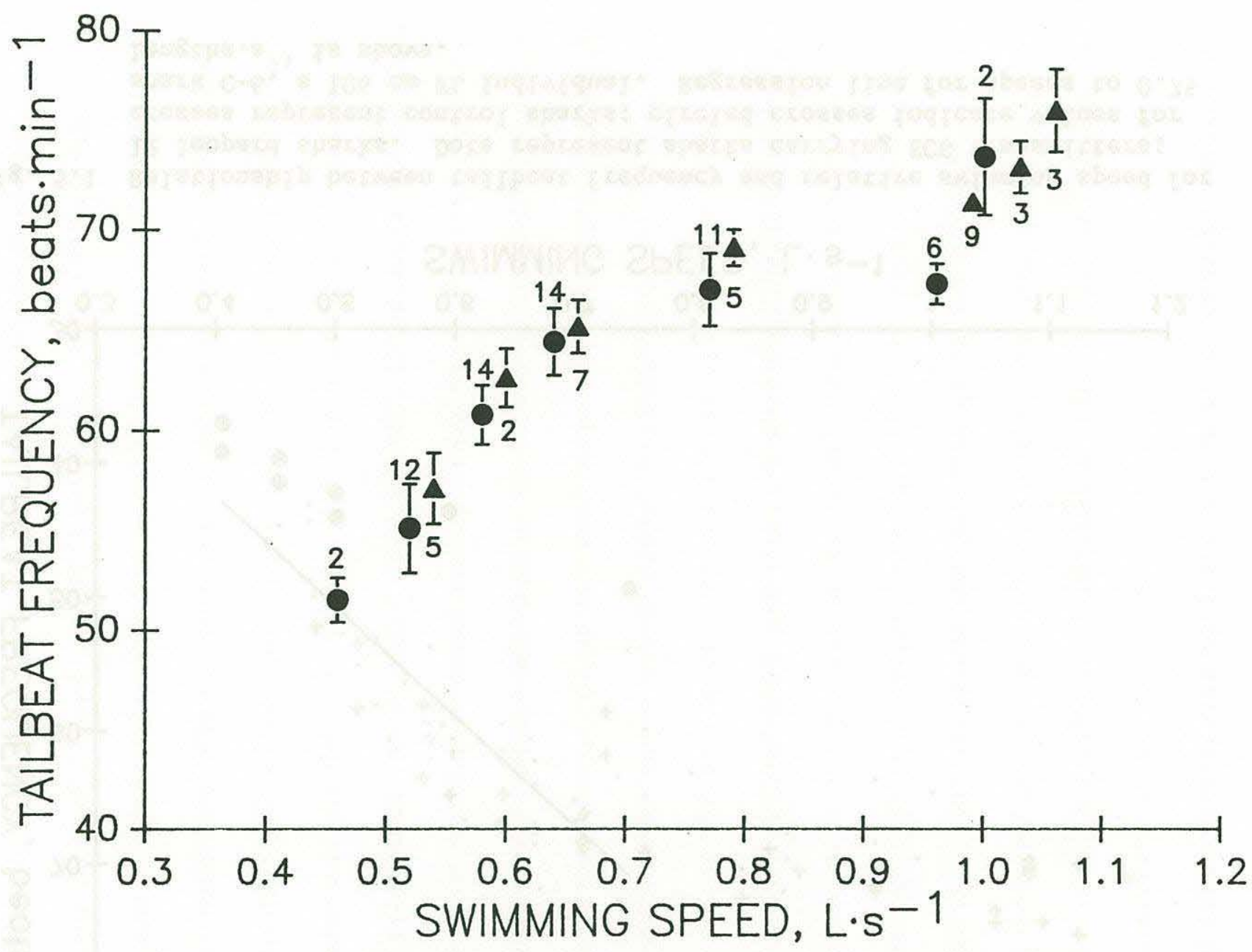

Fig. 5.2 Relationship between tailbeat frequency and mean relative swimming speed for 7 instrumented sharks (circles) and 4 control sharks (triangles). Values shown are mean tailbeat frequency $\pm S . E$. for all runs at a given absolute speed. Numbers indicate the number of runs at each speed. Shark C-6, a $106 \mathrm{~cm}$ FL individual, is excluded. 
and for control sharks the equation is:

$$
\text { log V́02 }=2.02+0.20 \mathrm{U}, \mathrm{r}^{2}=0.39, \mathrm{p}<0.001
$$

where $\dot{\mathrm{V}} 02$ = oxygen consumption rate in $\mathrm{mgO} \mathrm{O}_{2} \cdot \mathrm{kg}^{-1} \cdot \mathrm{hr}^{-1}$ and $\mathrm{U}=$ relative swimming speed in L.s ${ }^{-1}$. In Fig. 5.4, the mean V́02 \pm S.E. for a11 runs at a given speed setting is plotted as a function of speed expressed relative to the mean body length of all sharks in the group for instrumented and control sharks. The mean resting vio2's for the two groups are not significantly different (t-test, 4 d.f., p > 0.1 ), but vं02 during exercise is higher in instrumented sharks than in contro1 sharks at a11 speeds. Mean resting نं02, ㅂo2 at maximum sustained speed, and mean maximum sustained speeds are presented for instrumented and control sharks in Table 5.2. ํㅜㅇ at maximum speed for instrumented sharks is $37 \%$ higher than the value for control sharks.

V02 is plotted as a function of heart rate for all runs in Fig. 5.5. A least-squares linear regression produced the equation:

$$
\text { Vं02 }=-173.6+8.0 \mathrm{HR} \quad \mathrm{r}^{2}=0.38, \mathrm{p}<0.001
$$

where $\dot{\mathrm{V}} 02=$ oxygen consumption rate in $\mathrm{mgO} \mathrm{O}_{2} \cdot \mathrm{kg}^{-1} \cdot \mathrm{hr}^{-1}$ and $\mathrm{HR}=$ heart rate in beats. $\mathrm{s}^{-1}$. In Fig. 5.6, all runs at a given speed are averaged, and mean \pm S.E. values of $\dot{0} 02$ and heart rate are plotted. Table 5.2 presents mean heart rates at rest and at maximum sustainable speed. For the three sharks in the large pool, the mean heart rate during rest and routine swimming at temperatures of $12.5-14.5^{\circ} \mathrm{C}$ was $30.2 \pm 1.9$ (S.E.) beats. $\mathrm{min}^{-1}$. Resting rates ranged from 24-32 beats.min ${ }^{-1}$, and swimming rates were $28-37$ beats.min ${ }^{-1}$. The resting heart rates in the pool were close to the resting rates of the 


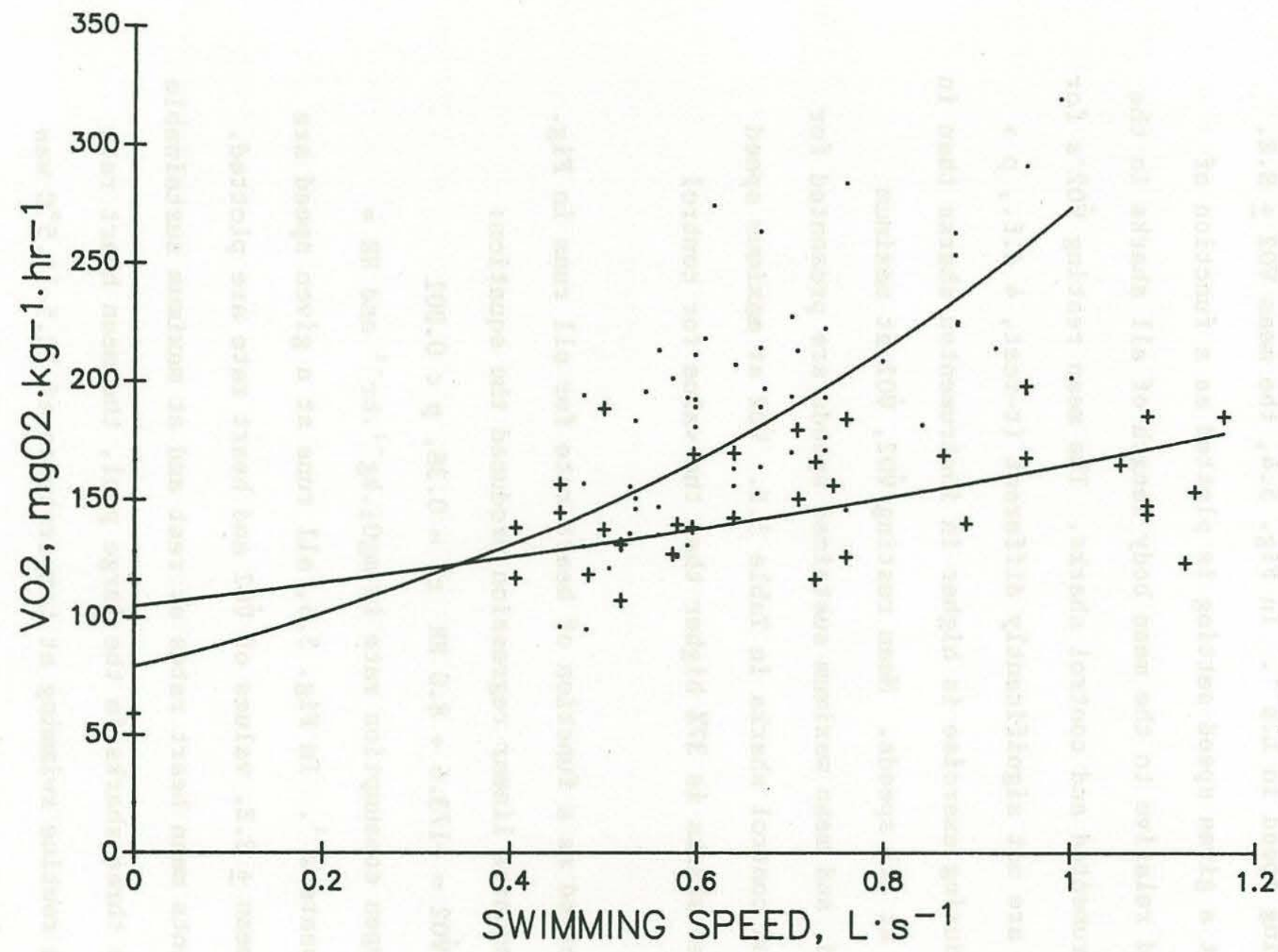

Fig. 5.3 Relationship between oxygen consumption rate and relative swimming speed for 12 leopard sharks. Separate best-fit regression 1 ines are shown for instrumented sharks (dots) and control sharks (crosses). 


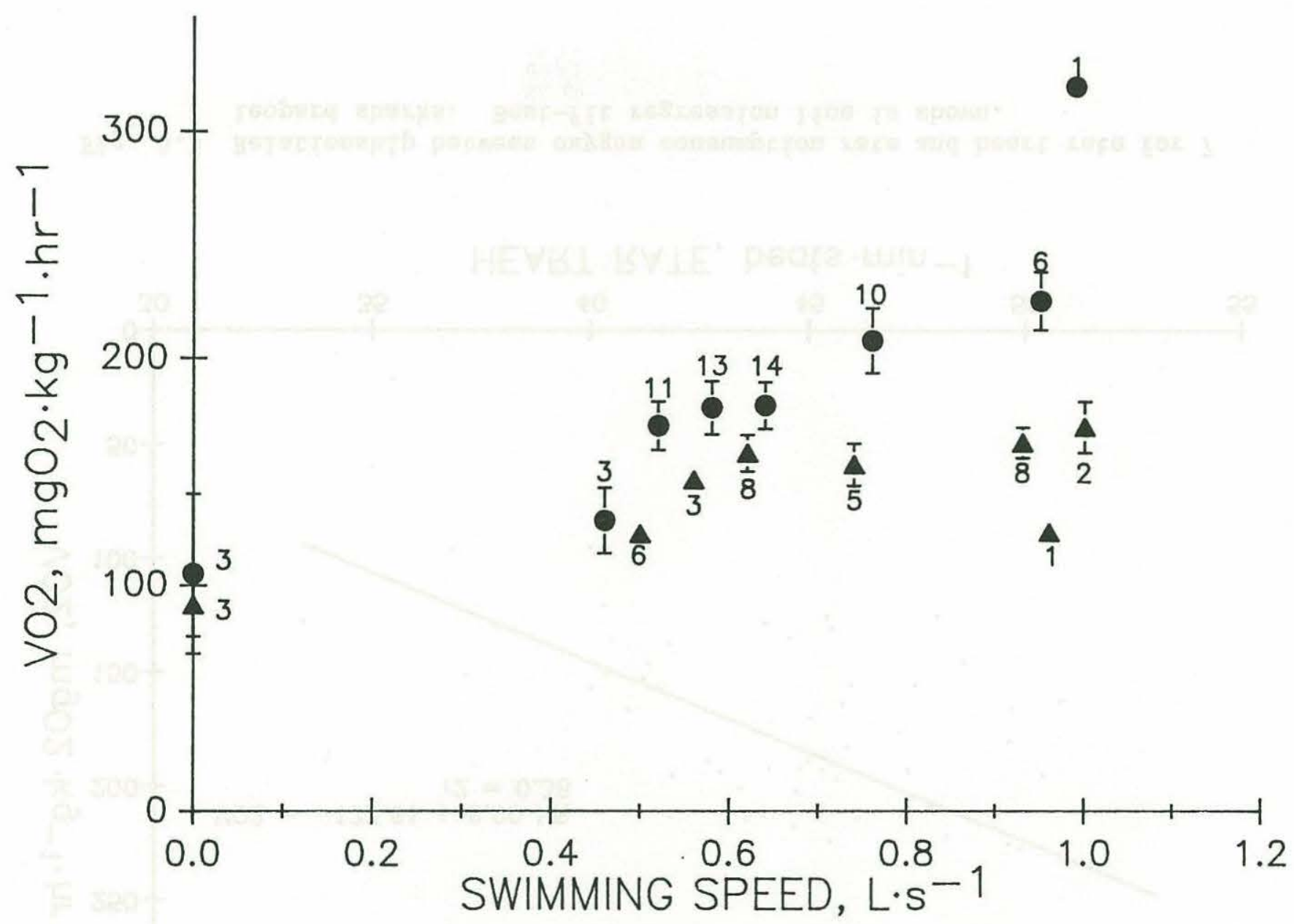

Fig. 5.4 Relationship between oxygen consumption rate and mean relative swimming speed for 7 instrumented sharks (circles) and 5 control sharks (triangles). Values shown are mean oxygen consumption rate \pm S.E. for a11 runs at a given absolute speed. Numbers indicate the number of runs at each speed. 


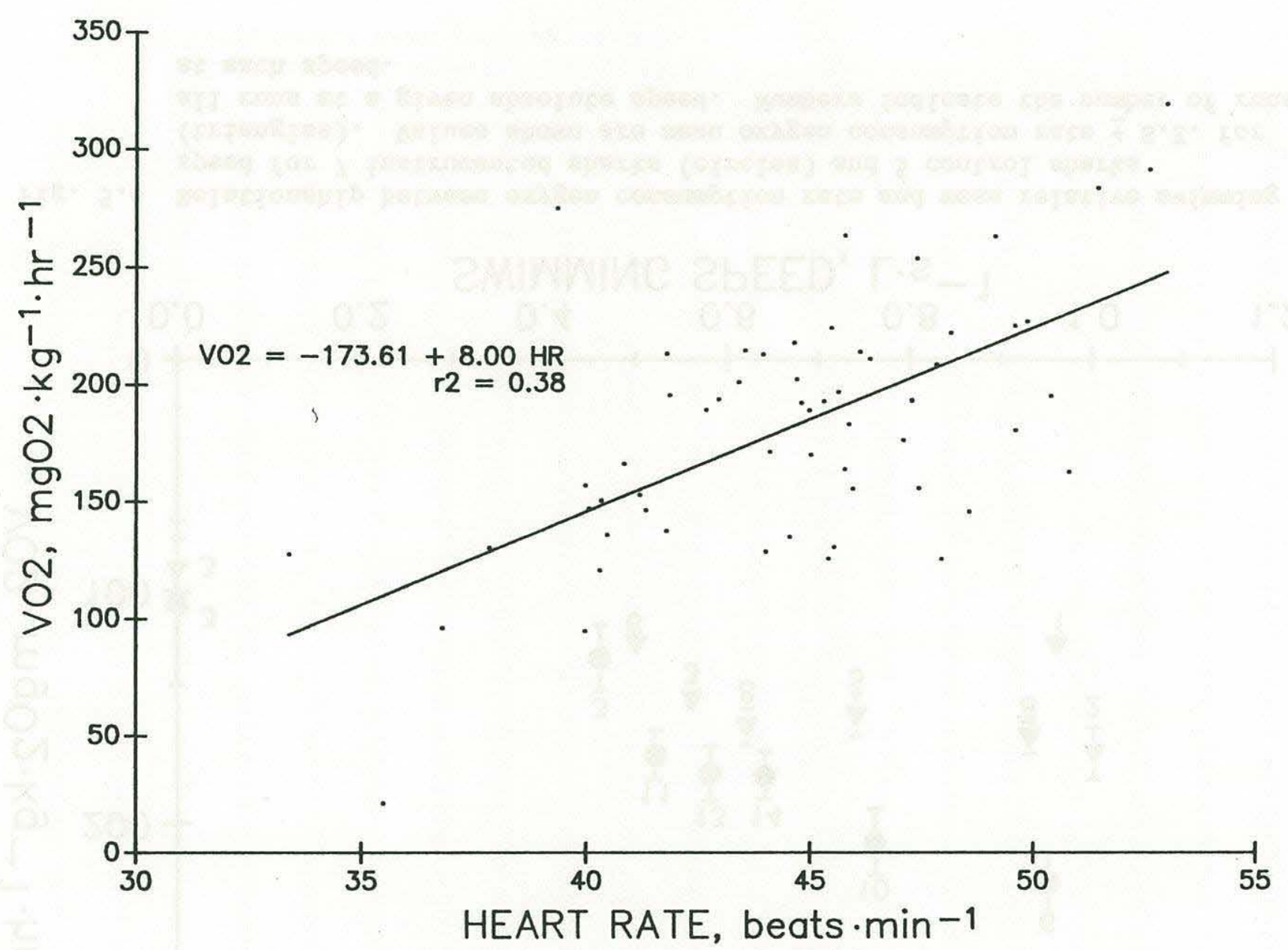

Fig. 5.5 Relationship between oxygen consumption rate and heart rate for 7 leopard sharks. Best-fit regression line is shown. 


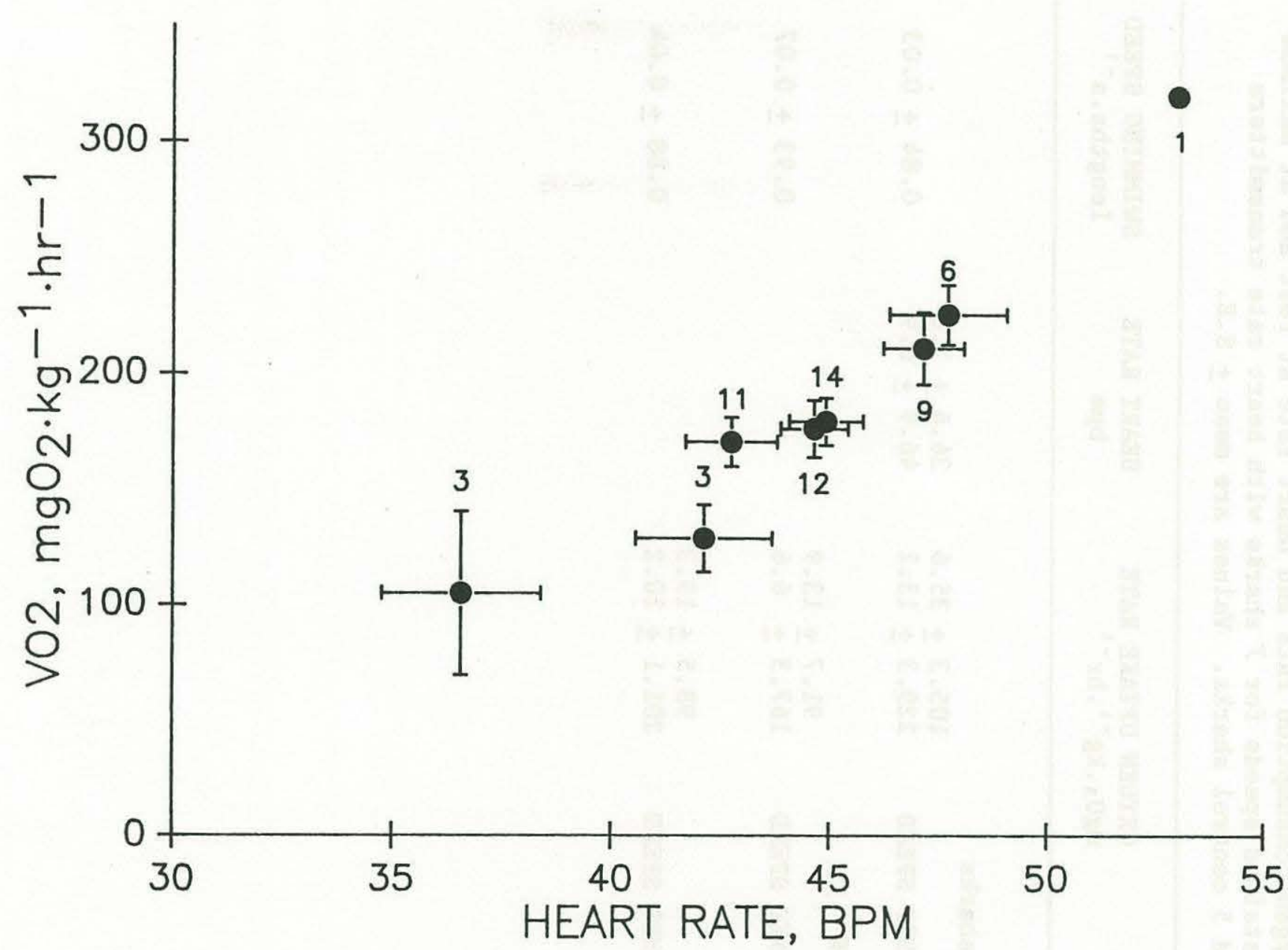

Fig. 5.6 Relationship between oxygen consumption rate and heart rate for 7 leopard sharks. Values shown are mean oxygen consumption rate and mean heart rate + S.E. for all runs at a given absolute speed. Numbers indicate the number of runs at each speed. Point at lower left represents mean resting values. 
Tab1e 5.2. Oxygen consumption rate and heart rate at rest and at maximum sustained speeds for 7 sharks with heart rate transmitters and 5 control sharks. Values are mean \pm S.E.

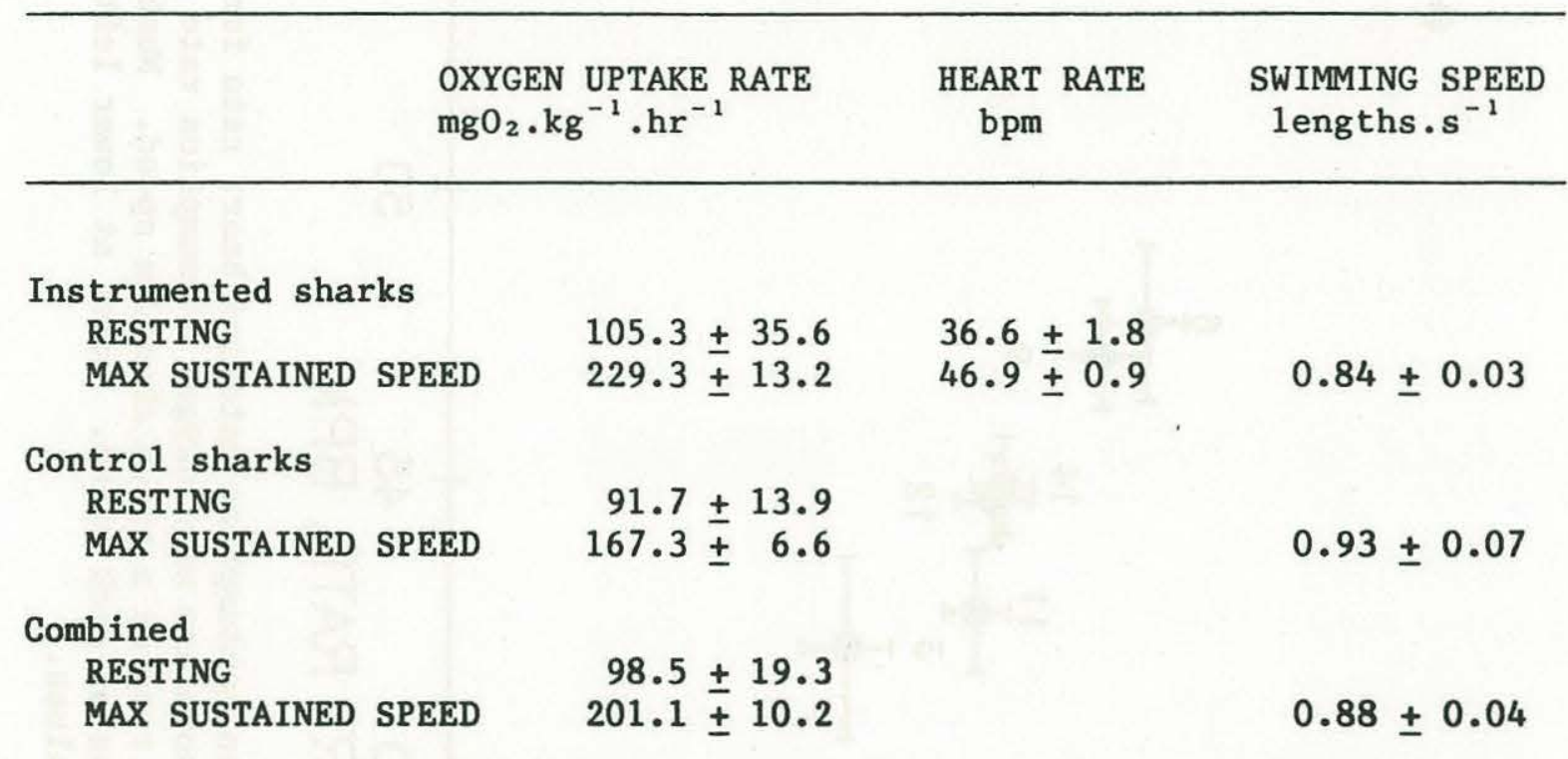


same sharks in the respirometer at similar temperatures (26-34

beats. $\left.\min ^{-1}\right)$.

\section{$\underline{\text { DISCUSSION }}$}

\section{Tailbeat frequency and swimming speed}

A positive linear relationship between tailbeat frequency and swimming speed has been found in a number of teleosts (Bainbridge 1958, Hunter and Zwiefel 1971). A single general equation, reported by Bainbridge (1958), was found to adequately describe the relationship between tailbeat frequency and relative speed for all sizes of individuals of all teleost species examined by Hunter and Zweife1 (1971). A linear relationship between tailbeat frequency and speed has also been observed in the smooth-hound shark (Mustelus henlei) (a single shark) in a swimming tunnel (Hunter and Zweifel 1971 ) and in Pacific blacktip sharks (Carcharhinus melanopterus) in aquaria (Webb and Keyes 1982). The relationship obtained for the leopard shark in the present study can be compared with those for teleosts and other sharks in Fig. 5.7. Webb and Keyes (1982) found that the slope of the equation for the blacktip shark was steeper than those for teleosts. The slope for the leopard shark is intermediate between those for the blacktip and the smooth-hound, and is similar to that for teleosts.

In all other species of teleosts and sharks studied, tailbeat frequency did not level off at high speeds as it did in the leopard shark, but continued to increase linearly with speed to the maximum observed speeds (4-10 lengths. $\left.\mathrm{s}^{-1}\right)$. An increase in speed with no 


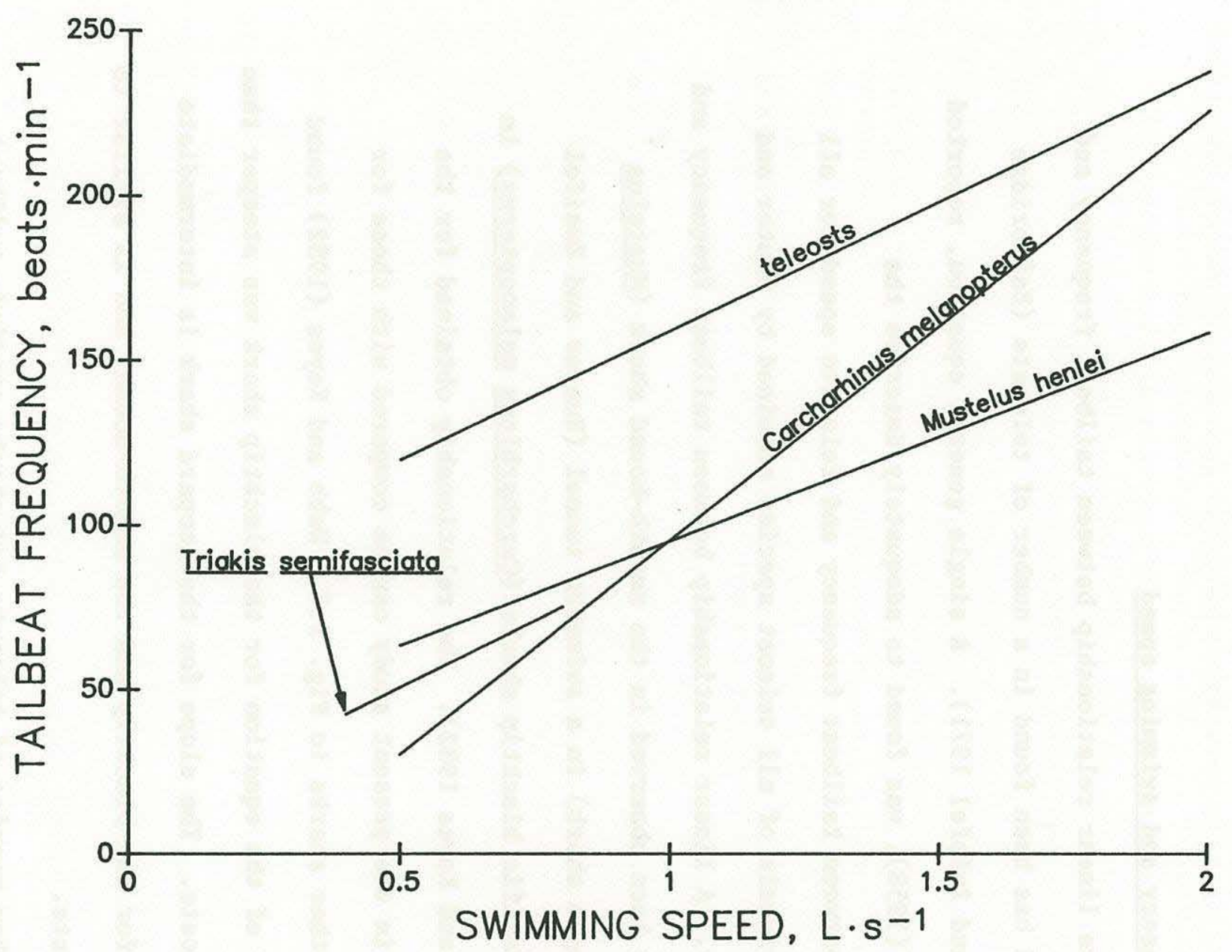

Fig. 5.7 Relationships between tailbeat frequency and relative swimming speed for teleosts (from Bainbridge 1958), the blacktip shark (C. melanopterus) (Webb and Keyes 1982), the brown smooth hound (M. henlei) (Hunter and Zweifel 1971) and the leopard shark (T. semifasciata). 
increase in tailbeat frequency means that thrust must be increased through changes in other variables. In teleosts the only kinematic variable modified with speed is tailbeat frequency (Webb and Keyes 1982). Tailbeat amplitude is constant over most of the speed range, being equal to a constant proportion of length (0.2) (Hunter and Zweife1 1971), and a third factor influencing thrust, the length of the propulsive wave, has also been found to remain constant with speed (Webb 1971a). Sharks, however, vary both amplitude and wavelength in addition to tailbeat frequency with changes in speed, possibly to obtain mechanical advantages from flow interaction between median fins (Webb and Keyes 1982). This suggests that the leopard sharks may have increased speed while keeping tailbeat frequency constant by increasing amplitude and/or wavelength, either of which would increase thrust (Webb and Keyes 1982).

The largest shark exhibited tailbeat frequencies markedly lower than those of other sharks at a given relative speed (Fig. 5.1). In teleosts, the slope and intercept of speed-tailbeat frequency regressions have been found to vary as a function of length, with larger fish exhibiting a lower slope when frequency is plotted as a function of speed (Hunter and Zweifel 1971).

0xygen consumption rate and swimming speed

Exponential relationships between $\dot{V} 02$ and swimming speed have been found in several species of teleosts (Brett 1964, Webb 1971b, review by Beamish 1978), and in the lemon shark, Negaprion brevirostris, swimming at voluntary speeds ( 0.3 to 0.6 lengths.s $\left.{ }^{-1}\right)$ (Bushne11 1982, Scharold and Gruber in review). The present study 
demonstrates a similar relationship in the leopard shark under conditions of forced swimming to $1.2 \mathrm{~L} . \mathrm{s}^{-1}$. The v02-speed regression obtained for control sharks in this study is plotted for comparison with relationships reported in the literature for lemon sharks and several teleosts in Fig. 5.8. The slope for the leopard shark is similar to those for teleosts and the lemon shark. The lower intercept (resting metabolic rate) for the leopard shark as compared to that for the lemon shark can be explained by the difference in experimental temperatures. The resting metabolic rate for the lemon shark at $22^{\circ} \mathrm{C}$ is $136 \mathrm{mgO} \cdot \mathrm{kg}^{-1} \cdot \mathrm{hr}^{-1}$ (Bushne11 1982), or approximately $83 \mathrm{mgO} \cdot \mathrm{kg}^{-1} \cdot \mathrm{hr}^{-}$when adjusted to a temperature of $16^{\circ} \mathrm{C}$ using a $Q_{10}$ of 2.3 (Brett and Groves 1979). Thus the resting metabolic rate for the leopard shark (Table 5.2) is close to that for the lemon shark and lies in the upper range of resting rates previous1y reported for elasmobranchs $\left(30-83 \mathrm{mg0} \cdot \mathrm{kg}^{-1} \cdot \mathrm{hr}^{-1}\right.$ at a mean temperature of $15^{\circ} \mathrm{C}$; reviewed by Brett and Blackburn 1978), and close to the average standard metabolic rate for teleosts ( 90 $\left.\mathrm{mgO} \mathrm{Hg}^{-1} \cdot \mathrm{hr}^{-}\right)($Brett and Groves 1979).

Bushnel1 (1982) reported a minimum estimate of active metabolic rate for a lemon shark swimming at $0.63 \mathrm{~L} . \mathrm{s}^{-1}$ of 323 $\mathrm{mgO} \mathrm{O}_{2} \cdot \mathrm{kg}^{-1} \cdot \mathrm{hr}^{-1}$ at $22^{\circ} \mathrm{C}$. This would be approximately 196 $\mathrm{mgO} \mathrm{O}_{2} \cdot \mathrm{kg}^{-1} \cdot \mathrm{hr}^{-1}$ at $16^{\circ} \mathrm{C}$, close to the $\dot{\mathrm{v}} 02$ of the leopard shark swimming at the 60-minute maximum sustainable speed $\left(0.88 \mathrm{~L} . \mathrm{s}^{-1}\right)$ (Table 5.2). Brett and Blackburn (1978) reported a maximium metabolic rate for the spiny dogfish, Squalus acanthias, of 100 $\mathrm{mg} 0_{2} \cdot \mathrm{kg}^{-1} \cdot \mathrm{hr}^{-1}$ at $10^{\circ} \mathrm{C}$, or $165 \mathrm{mg} 0_{2} \cdot \mathrm{kg}^{-1} \cdot \mathrm{hr}^{-1}$ at 


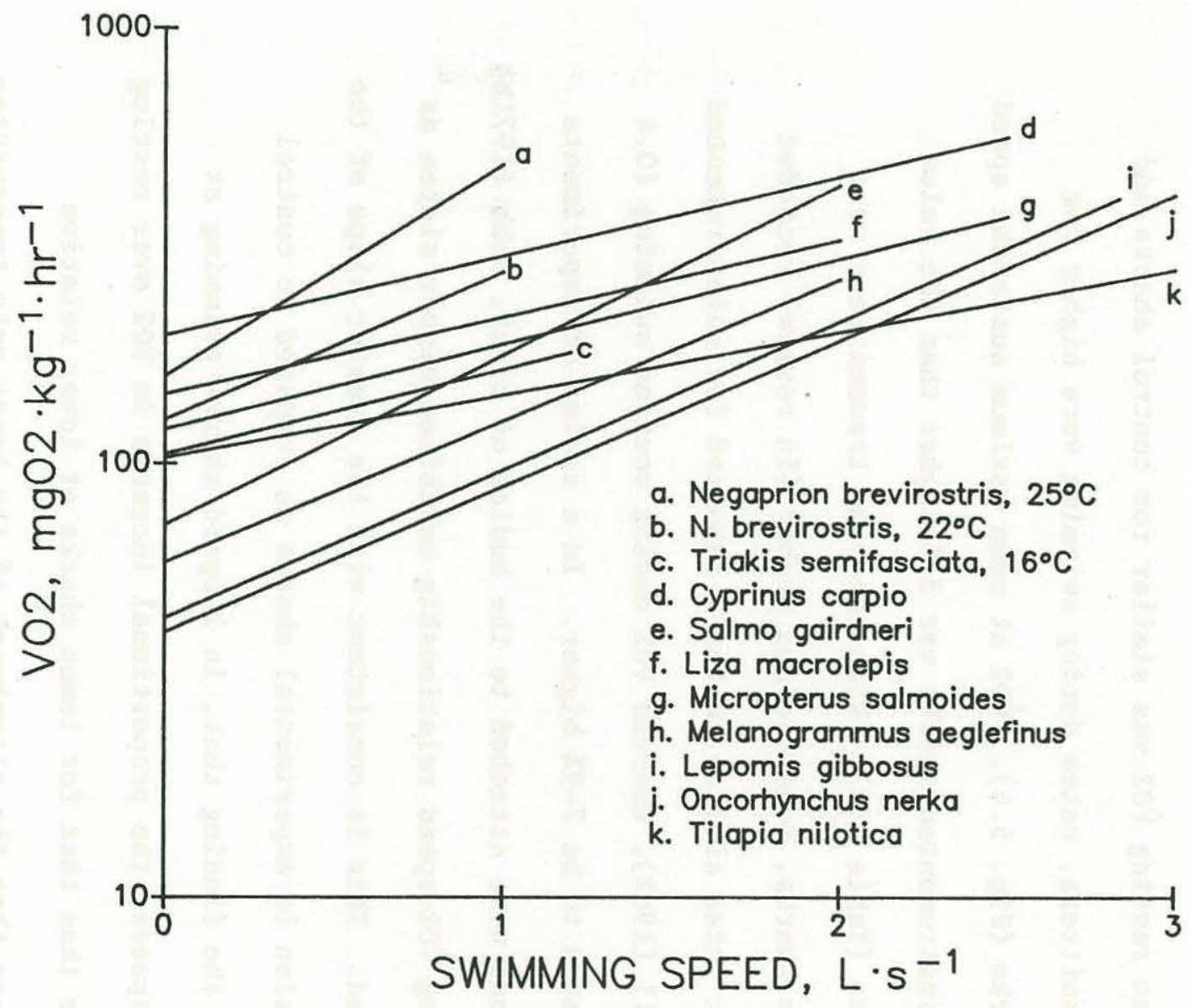

Fig. 5.8 Relationships between oxygen consumption rate and relative swimming speed for the leopard shark ( $\mathrm{T}_{0}$ semifasciata), the lemon shark ( brevirostris) at $22^{\circ} \mathrm{C}$ (Bushne11 1982) and at $25^{\circ} \mathrm{C}$ (Scharold and Gruber in review), and several teleosts (Beamish 1978). 
$16^{\circ} \mathrm{C}$. Active metabolic rates for teleosts at $16^{\circ} \mathrm{C}$ iie in the range of $200-900 \mathrm{mgO} \cdot \mathrm{kg}^{-1} \cdot \mathrm{hr}^{-1}$ (Brett and Groves 1979). The active metabolic rate of the leopard shark (Table 5.2) 1ies in the upper range of those reported to date for elasmobranchs and in the lower range of those for teleosts.

A1though mean resting v́02 was similar for control sharks and sharks with transmitters, rates during swimming were higher for instrumented sharks (Fig. 5.4). Vं02 at mean maximum sustained speed $\left(0.9 \mathrm{~L} . \mathrm{s}^{-1}\right)$ for instrumented sharks was $37 \%$ higher than the value for control sharks (Table 5.2). When the same transmitters were attached to lemon sharks, Scharold and Gruber (in review) recorded resting metabolic rates similar to those reported for uninstrumented sharks by Bushnel1 (1982), whereas $\dot{0} 02$ during routine swimming (0.4 L.s ${ }^{-1}$ ) was estimated to be $7-9 \%$ higher. In a series of experiments in which drag loads were attached to the bodies of trout, Webb (1971b) found that the $\log$ v02-speed relationship exhibited higher slopes as the load increased. This is consistent with the greater slope of the vं02-speed regression in experimental sharks as compared to control sharks, and with the finding that, in leopard sharks swimming at higher relative speeds, the proportional increase in vo2 over resting rates was greater than that for lemon sharks at lower relative speeds. It appears that the attachment of the heart rate transmitter does not stress the animals in a way that results in increased resting V02, and that the higher $\dot{v} 02$ during exercise of sharks carrying transmitters may be due to the increased thrust required to overcome the drag of the transmitter. It is interesting to note that tailbeat 
frequencies at a given speed were not higher for sharks with

transmitters as compared to contro1 sharks (Fig. 5.2), even though نं02 was (Fig. 5.4). This suggests that the increased thrust must have been supplied by some other means, such as increasing tailbeat amplitude or altering the propulsive wavelength (Webb and Keyes 1982). Oxygen consumption rate and heart rate

A significant linear relationship was obtained between $\dot{V}_{02}$ and heart rate over the speed range observed, suggesting that heart rate may serve as a useful indicator of metabolic rate for the leopard shark. However, the regression explained only $38 \%$ of the variation in V02 $\left(r^{2}=0.38\right)$. Part of the remaining variation resulted from individual differences between sharks. Separate relationships between heart rate and metabolic rate for different individual animals have been found in several studies of birds and mammals (Webster 1967, Wooley and Owen 1977, Kautz et a1. 1981), as well as in the lemon shark (Scharold and Gruber, in review), and indicate that individual calibration would be necessary before heart rate could be used as an estimator of metabolic rate in field studies. Because resting $\dot{V}_{02}$ could not be obtained for each shark, it was not possible to use resting rates to normalize heart rate and $\dot{v}_{02}$ values and adjust for individual variation.

Linear relationships between heart rate and metabolic rate have been reported for several species of teleosts (Priede and Tytler 1977, Armstrong 1986) and for the lemon shark (Scharold and Gruber in review). The results of several studies in which $\dot{v}_{02}$ and heart rate were simultaneously measured are presented in Fig. 5.9 along with the 


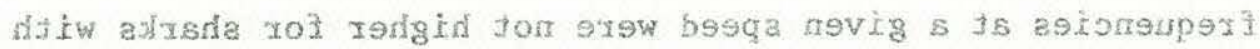

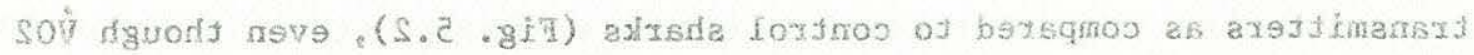

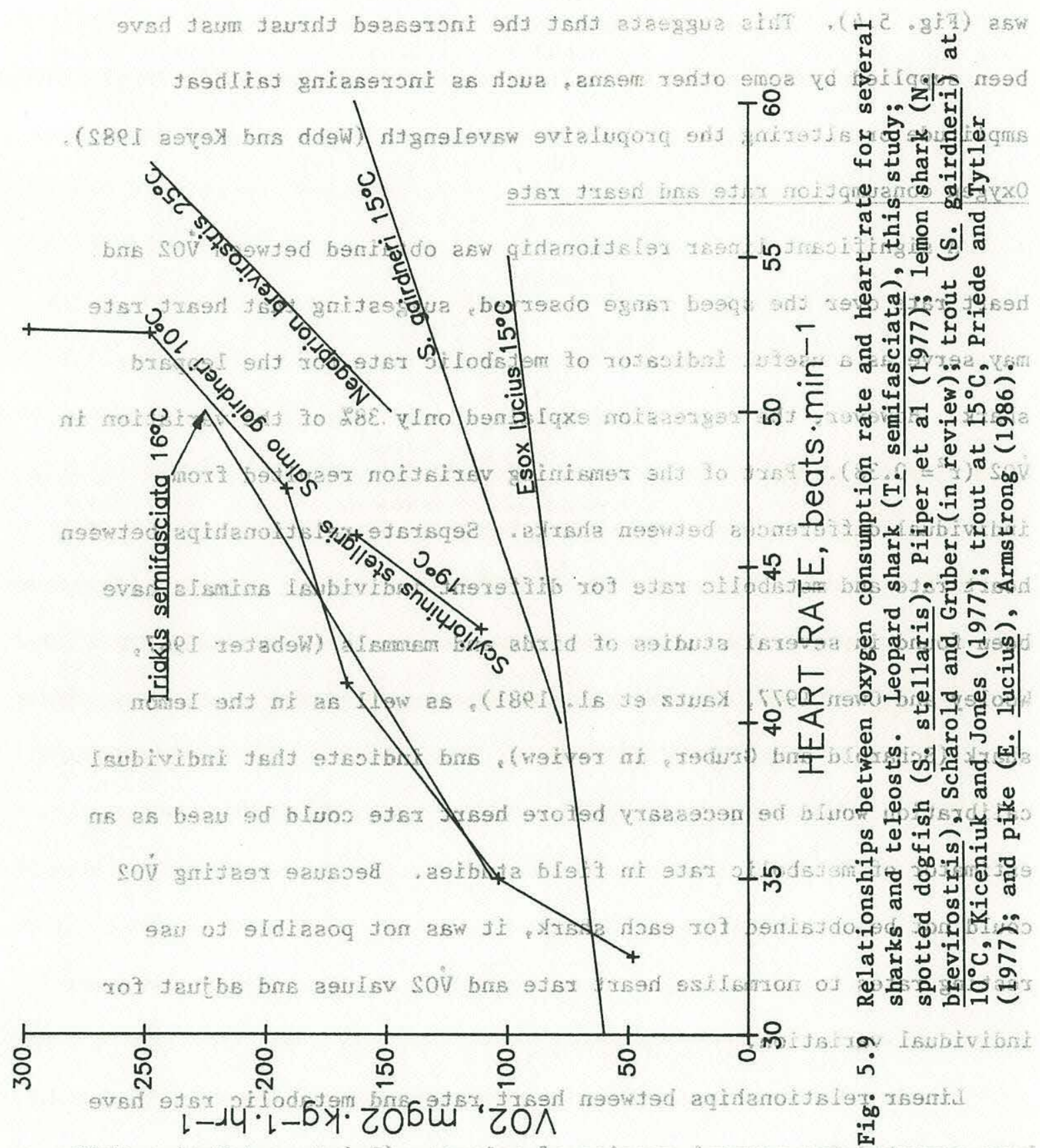

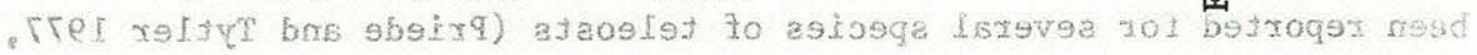

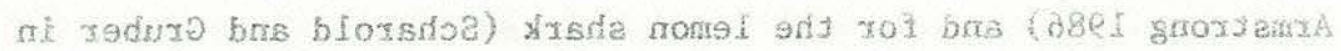

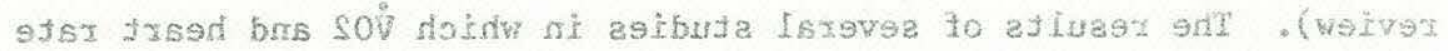

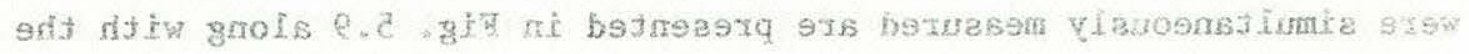


relationship obtained for the leopard shark. The curve for the leopard shark lies very close to the relationship obtained for trout at $10^{\circ} \mathrm{C}$ by Kicenciuk and Jones (1977). Lower heart rates were observed for the leopard shark than for the two other sharks, the lemon shark and the spotted dogfish, Scyliorhinus stellaris, which were recorded at higher temperatures. The positive effect of temperature on heart rate has been documented in both teleosts and elasmobranchs (Priede 1974, Hanson 1967).

For purposes of comparison, it is possible to calculate the percent contribution of heart rate to change in metabolic rate. This is the proportion of the observed increase in vo2 that can be considered to result from the observed increase in heart rate, and it is given by the equation:

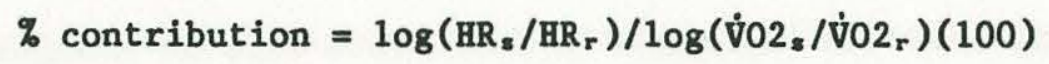

where HR is heart rate, V02 is oxygen consumption rate, and the subscripts $s$ and $\mathbf{r}$ refer to swimming and resting values, respectively (Scharold and Gruber, in review). For the leopard shark, the difference between mean resting $\dot{\mathrm{V}} 02$ and vo2 at maximum sustained speed (Table 5.2) corresponds to a 2.2-fold increase. The heart rate at maximum sustained speed represents an increase over the resting rate by a factor of 1.3 , and the increase in heart rate accounts for $32 \%$ of the observed increase in vo2. In trout, swimming produces 5 to 7 -fold increases in v02, associated with elevations in heart rate by factors of from 1.15 to 2.6 , with heart rate accounting for an estimated $9 \%$ to $50 \%$ of the increase in v02 (Kiceniuk and Jones 1977, Stevens and Randa11 1967a,b; Priede and Tytler 1977). In the spotted dogfish, a 
change from rest to spontaneous swimming was accompanied by a $47 \%$ increase in $\dot{0} 02$ and a $7 \%$ increase in heart rate, with heart rate accounting for $18 \%$ of the increase in vo2 (Piiper et a1. 1977). The lemon shark exhibited a very similar relationship, with a change from rest to routine swimming associated with a $44 \%$ increase in vo2 and an $8 \%$ increase in heart rate (Scharold and Gruber, in review). The range of $\dot{0} 2$ obtained for the leopard shark using the swimming tunnel was larger than that reported to date for other sharks, and it appears that heart rate is of relatively greater importance as a cardiovascular adjustment to exercise in the leopard shark during forced exercise than in the lemon shark or the spotted dogfish during routine swimming.

The portion of the increased oxygen consumption that does not result from observed increases in heart rate must be brought about by increases in the other cardiovascular parameters, such as stroke volume and arteriovenous oxygen difference. Both of these have been found to increase with exercise in trout (Stevens and Randa11 1967, Kiceniuk and Jones 1977). Bushnell et al (1982) reported no change in arteriovenous oxygen differences at rest and during spontaneous exercise in the lemon shark. Piiper et al (1977) found that the arteriovenous oxygen difference decreased during swimming in the dogfish. Thus the remainder of the increase in oxygen transport during routine swimming must be supplied by increased stroke volume in these two sharks. During forced exercise, however, arteriovenous oxygen difference was found to increase in the lemon shark, due to increased arterial oxygen content (Bushne11 et al 1982). Recent work 
with leopard sharks has documented exercise-induced increases in both stroke volume and arteriovenous oxygen difference (Lai et al, in prep).

A1though a significant relationship between heart rate and oxygen consumption rate was observed in the leopard shark, changes in other cardiovascular parameters may complicate the relationship and limit the usefulness of heart rate as an indicator of metabolic rate. Nevertheless, heart rate may still be of value in estimating metabolic rates in field studies. Heart rate was almost as closely correlated with نं02 as swimming speed was. In addition, heart rate may be correlated with changes in metabolic rate that result from factors other than activity, such as stress, excitement, temperature, feeding, and digestion, that would not be indicated by changes in swimming speed (Priede 1983, Armstrong 1986). More detailed studies are needed to determine the extent to which individual variation explains the variability in the heart rate-نं02 relationship, to elucidate how the various cardiovascular parameters change with changes in $\dot{0} 02$, and to investigate the heart rate-jo2 relationship under a wider range of environmental and physiological conditions. The tunnel respirometer makes it possible to perform such studies under controlled levels of exercise. 
134 
VI. CONCLUSION

The regular diving behavior exhibited by blue sharks in northwestern Atlantic slope waters during the summer and fall does not match patterns that would be predicted to provide maximum efficiency if the two-phase swimming behavior described by Weihs (1973a) were being employed. Theoretically, maximum energy savings would be achieved by long, shallow glides followed by relatively steep ascents. In most of the dives observed for these sharks, descent was associated with active swimming at reduced tailbeat frequencies, increased speeds, and increased rates of depth change relative to ascent; angles of descent and ascent were similar. Brief gliding periods occurred and were associated with descent rates that were higher than average. This suggests that energy saving is not the major function of this periodic diving behavior, although some energy savings relative to constant speed horizontal swimming may result. Instead, deep diving by blue sharks may represent a strategy for encountering prey, and may be influenced by temperature considerations (Carey and Scharold in review). If the dives are associated with hunting, gliding may be a means of descending rapidly with minimal environmental disturbance. Regular swimming movements may produce pressure waves which could be detected and recognized by potential prey. Sharks possess an electrosensory system, and are able to detect and capture prey by cueing in on bioelectric fields (Kalmijn 1971). 
It is possible that by reducing swimming activity, thereby minimizing electrical signals associated with muscle activity, the shark may increase its ability to detect bioelectric signals from prey. In view of the electrosense of sharks, it is interesting that when placing ECG electrodes for heart rate transmitters, a usable signal could be obtained only by placing the electrode in the pericardium. Even with the signal electrode adjacent to the pericardium, a1though weak signals associated with gill movement could be detected, no ECG signal was detected until the electrode entered the pericardium, at which point a strong ECG signal was obtained. This was the case in both lemon sharks and leopard sharks, as well as in preliminary trials with blue sharks, and suggests that the pericardium may provide a form of electrical insulation for the heart, which could be of value to a predator that hunts using an electrosense.

The blue sharks exhibited swimming speeds and tailbeat frequencies that were constant overal1, with brief periods of rapid speed and high tailbeat frequencies. The sustained swimming speed of the blue shark is lower than that predicted by theory to be most efficient based on general considerations, and is lower than cruising speeds observed in similar-sized sharks (Weihs 1984). The minimum speed required to maintain position in the water column, which is determined by the shark's density and the 1ift-producing characteristics of the fins and body, appears to be lower than the sustained speed. In those cases where it was possible to compare swimming speeds and currents, it appeared that the sharks tended to swim in the direction of the current, a finding that is supported on a 
larger scale by long-range movements indicated by tagging studies (Casey 1985).

These observations suggest that the blue shark is efficient at low-speed cruising, and that, as a predator in an environment with widely scattered food resources, it may employ an energy conserving strategy. Behavioral and morphological adaptations for efficient slow speed swimming, coupled with vertical ranging, would enable the blue shark to cover large volumes of water in search of prey while minimizing energy expenditure.

This is in contrast to the shortfin mako (Isurus oxyrinchus), another large pelagic shark, which appears to employ a strategy of energy speculation, similar to tunas (Stevens and Neil1 1978). The mako shark possesses adaptations for efficient high speed swimming, including a fusiform shape, lunate tail, caudal keels, carangiform swimming movements, and elevated body temperatures (Thomson and Simanek 1977, Magnuson 1978, Carey and Teal 1969). It is denser than the blue shark, with relatively smaller fin area, and so would have a higher minimum swimming speed. These characteristics would suggest that the mako is a highly active, fast-swimming predator with relatively high metabolic costs. Swimming speeds obtained by telemetry for free-ranging mako sharks were 64 to $69 \mathrm{~cm}^{-s^{-1}}(0.3$ to

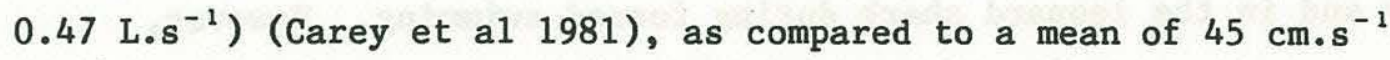
$\left(0.18{\mathrm{~L} . \mathrm{s}^{-1}}^{-1}\right)$ for the blue shark. However, by swimming at higher speeds, the mako would cover more territory and would be expected to encounter prey more of ten, thereby maximizing energy intake (Todd 1982). Based on analyses of stomach contents, the daily ration for 
the mako shark was estimated to be $3.1 \%$ of body weight per day, whereas the food consumption of the blue shark was estimated to be only $0.6 \%$ body weight per day (Stillwe11 and Kohler 1982, Kohler 1987). Thus, these two species of constantly swimming pelagic sharks appear to utilize different strategies in exploiting the same environment, with the blue shark minimizing energy expenditure and the mako maximizing energy intake (Todd 1982). It is interesting to note that mako sharks have been reported to dive to depths of several hundred meters, with a pattern similar to those observed in blue sharks (Carey et a1 1981, Carey and Scharold in review), suggesting that there is a common advantage to be gained from this behavior. Telemetry can be used to observe activity levels and behavior patterns of pelagic sharks, which can then be compared with those of other sharks and teleosts, as well as with those predicted to be most energetically efficient based on theory. However, the actual energy expenditures associated with activities observed in the field are not known.

The results of the present research indicate that heart rate telemetry may be useful in estimating field metabolic rates for sharks. Significant regressions of oxygen consumption rate on heart rate were obtained, both in the lemon shark during spontaneous activity and in the leopard shark during forced swimming. However, there was a considerable range of metabolic rates for any given heart rate, resulting in less than optimal $r^{2}$ values. In the lemon shark, part of this variation could be explained by taking into account the existence of different regressions for individual sharks. This means 
that individual calibration of the heart rate-metabolic rate relationship may be required before heart rate could be used as an indicator of metabolic rate in a field experiment. In both sets of experiments, heart rate was found to be about as closely correlated to oxygen consumption rate as swimming speed was. Since heart rate may vary with changes in metabolic rate that are not accompanied by changes in swimming speed, such as stress, temperature changes, feeding, and digestion (Priede 1983, Armstrong 1986), heart rate may prove to be a better estimator of total metabolic rate.

In the lemon shark, the change from rest to spontaneous swimming $\left(0.4{\mathrm{~L} . \mathrm{s}^{-1}}^{-1}\right)$ was accompanied by a $47 \%$ increase in oxygen consumption rate and an $8 \%$ increase in heart rate. In the leopard shark, swimming at maximum sustainable speed $\left(0.9 \mathrm{~L} . \mathrm{s}^{-1}\right)$ resulted in a $117 \%$ increase in oxygen uptake as compared to rest, with a $28 \%$ increase in heart rate. The increase in oxygen consumption that is not accounted for by increased heart rate must result from increases in the other cardiovascular variables, namely stroke volume and/or arteriovenous oxygen difference. Heart rate does show potential as an indicator of metabolic rate in sharks, but its value may be limited by the relatively small contribution of heart rate to increases in oxygen supp1y. Further studies are needed to examine how all three cardiovascular parameters vary with changes in oxygen demand, and to investigate how the relationship between metabolic rate and heart rate is affected by such factors as temperature, feeding, and physical condition, before heart rate telemetry can be used to estimate metabolic rate with any accuracy in field studies. 
The studies detailed above have increased our knowledge of swimming behavior and energetics of sharks in three ways: 1) field observations of behavioral strategies of free-ranging sharks, 2) examination of the relationship between energy expenditure and activity in the 1aboratory, and 3 ) investigation of a potential tool, heart rate telemetry, which would make it possible to utilize information acquired in the laboratory to assess energy costs of activity in the field. All three kinds of studies are needed to evaluate the swimming behavior of sharks in terms of energy efficiency, to test theories of energetic optimization, and to better understand the role of sharks in marine ecosystems. 


\section{REFERENCES}

Alexander, R. McN. 1965. The lift produced by the heterocercal tails of Selachii. J. Exp. Biol. 43:131-138.

Aleyev, Y.G. 1977. Nekton, W. Junk, Publishers, The Hague. 435pp.

Armstrong, J.D. 1986. Heart rate as an indicator of activity, metabolic rate, food intake and digestion in pike, Esox lucius. J. Fish Bio1. 29:207-221.

Bainbridge, R. 1958. The speed of swimming of fish as related to size and to the frequency and amplitude of the tail beat. J. Exp. Biol. $35: 109-133$.

Bainbridge, R. 1961. Problems of fish locomotion. Symp. Zoo1. Soc. Lond. 5: 13-32.

Baldridge, H.D. 1970. Sinking factors and average densities of Florida sharks as functions of liver buoyancy. Copeia 1970:744-754.

Baldridge, H.D. 1972. Accumulation and function of liver oil in sharks. Copeia 1972:306-325.

Baumgarten-Schumann, D. and J. Piiper. 1968. Gas exchange in the gills of resting unanesthetized dogfish (Scyliorhinus stellaris). Respir. Physio1. 5: 317-325.

Beamish, F.W.H. 1978. Swimming capacity. In: Fish Physiology, W.S. Hoar and D.J. Randa11, eds, Vo1. 7, pp. 101-187.

Bigelow, H.B. and W.C. Schroeder. 1953. Fishes of the Gulf of Maine. Fishery Bulletin of the Fish and Wildlife Service, Vol. 53. 577pp.

Blake, R.W. 1984. Fish Locomotion. Cambridge Univ. Press, NY. 208 pp.

Bone, Q. and J.V. Howarth. 1966. Report of the council. J. Mar. Biol. Assoc. U.K. 47:754-756.

Bone, Q. and B. L. Roberts. 1969. The density of elasmobranchs. J.

Mar. Bio1. Assoc. U.K. 49:913-937.

Bottoms, A. and J. Marlow. 1979. A new ultrasonic tag for the telemetry of physiological functions from aquatic animals. Mar. Biol. 50: $127-130$.

Breder, C.M. 1926. The locomotion of fishes. Zoologica 4:159-256. 
Brett, J.R. 1964. The respiratory metabolism and swimming performance of young sockeye salmon. J. Fish. Res. Bd. Can. 21:1183-1226.

Brett, J.R. 1972. The metabolic demand for oxygen in fish, particularly salmonids, and a comparison with other vertebrates. Respir. Physio1. 14: 151-170.

Brett, J.R. 1973. Energy expenditure of sockeye salmon, Oncorhynchus nerka, during sustained performance. J. Fish. Res. Bd. Can. 30:1799-1809.

Brett, J.R. and J.M. Blackburn. 1978. Metabolic rate and energy expenditure of the spiny dogfish, Squalus acanthias. J. Fish. Res. Bd. Can. 35:816-821.

Brett, J.R. and N.R. Glass. 1973. Metabolic rates and critical swimming speeds of sockeye slamon (Oncorhynchus nerka) in relation to size and temperature. J. Fish. Res. Bd. Can. 30: 379-387.

Brett, J.R. and T.D.D. Groves. 1979. Physiological energetics. In: Fish Physiology, W.S. Hoar and D.J. Randa11, eds, Vo1. 8, pp. 279-352.

Brockway, J.M. and E.H. McEwan. 1969. Oxygen uptake and cardiac performance in the sheep. J. Physiol. 202:661-669.

Brown, C.E. and B.S. Muir. 1970. Analysis of ram ventilation of fish gills with application to skipjack tuna. J. Fish. Res. Bd. Can. $27: 1637-1652$.

Bushne11, P.G. 1982. Respiratory and circulatory adjustments to exercise in the lemon shark, Negaprion brevirostris (Poey). M.S. Thesis, U. Miami. 90pp.

Bushne11, P.G., P.L. Lutz, J.F. Steffensen, A. Oikari and S.H. Gruber. 1982. Increases in arterial blood oxygen during exercise in the lemon shark (Negaprion brevirostris). J. Comp. Physiol. 147:41-47.

Butler, P.J. and E.W. Taylor. 1975. The effect of progressive hypoxia on respiration in the dogfish (Scyliorhinus canicula) at different seasona1 temperatures. J. Exp. Bio1. 63: 117-130.

Carey, F. G. and Q. H. Gibson. 1987. Blood flow in the muscle of free swimming fish. Physiol. Zoo1. 60:138-148.

Carey, F. G., J.W. Kanwisher, 0. Brazier, G. Gabrielson, J.G. Casey, and H. L. Pratt. 1982. Temperature and activities of a white shark, Carcharodon carcharias. Copeia 1982:254-260.

Carey, F.G. and B.H. Robison. 1981. Daily patterns in the activities of swordfish, Xiphias gladius, observed by acoustic telemetry. Fish. Bul1. 79:277-292. 
Carey, F.G. and J. Scharold. (in review) Movements of blue sharks in course and depth.

Carey, F.G. and J.M. Tea1. 1969. Mako and porbeagle: warm-bodied sharks. Comp. Biochem. Physio1. 28:205-213.

Carey, F. G., Tea1, J. M., and J. W. Kanwisher. 1981. The viscera1 temperatures of mackere1 sharks (Lamnidae). Physio1. Zoo1. 54:334-344.

Casey, J. G. 1985. Transatlantic migrations of the blue shark; a case history of cooperative tagging. p. 253-268 In: World Angling Resources and Challenges, R. H. Stroud (ed.). International Game Fish

Association, Fort Lauderdale.

Compagno, L.J.V. 1984. Sharks of the wor1d. FAO Fisheries synopsis No. 125, Vo1. 4

Davies, I. E. and R. P. Bradley. 1972. Deep observations of anchovy and blue sharks from Deepstar 4000. Fish. Bull. 70:510-511.

Frank, T.H. 1968. Telemetering the electrocardiogram of free swimming Salmo irideus. IEEE Trans. Biomed. Engrg. 15: 111-114.

Fry, F.E.J. 1971. The effect of environmental factors on the physiology of fish. In: Fish Physiology, W.S. Hoar and D.J. Randa11, eds, Vo1. 6, pp. 1-87.

Gilbert, P.W. and S.D. Douglas. 1963. Electrocardiographic studies of free-swimming sharks. Science 140:1396.

Glass, N.R. 1969. Discussion of calculation of power function with special reference to respiratory metabolism in fish. J. Fish. Res. Bd. Can. 26: 2643-2650.

Gray, J. 1933. Studies in animal locomotion. I. The movement of $\mathrm{fish}$ with special reference to the eel. J. Exp. Biol. 10:88-104.

Gruber, S.H. 1980. Keeping sharks in captivity. J. Aquar. 1: 6-14.

Gruber, S.H. 1982. Role of the lemon shark, Negaprion brevirostris

(Poey) as a predator in the tropical marine environment: a multidisciplinary study. Fla. Sci. 45:46-75.

Gruber, S.H. 1984. Bioenergetics of the captive and free ranging lemon shark (Negaprion brevirostris). AAZPA 1984 Ann. Conf. Proc., p. 340-373.

Gruber, S.H. and R.S. Keyes. 1981. Keeping sharks for research. In: Aquarium Systems, A.D. Hawkins, ed, pp. 373-402. 
Gruber, S.H., D.R. Nelson, and J.F. Morrissey. 1988. Patterns of activity and space utilization of lemon sharks, Negaprion brevirostris, in a shallow Bahamian lagoon. Bull. Mar. Sci. 43:61-76.

Hanson, D. 1967. Cardiovascular dynamics and aspects of gas exchange in chondrichthyes. Ph.D. Thesis, Univ. Washington. 178pp.

Harden-Jones, F. R. 1973. Tail beat frequency, amplitude, and swimming speed of a shark tracked by sector scanning sonar. J. Cons. Int. Explor. Mer. 35:95-97.

Harris, J.E. 1936. The role of the fins in the equilibrium of the swimming fish. I. Wind-tunne1 tests on a mode1 of Mustelus canis (Mitche11) J. Exp. Bio1. 15:32-47.

Hawkins, A.D., D.N. MacLennan, G.G. Urquhart and C. Robb. 1974. Tracking cod Gadus morhua in a Scottish sea loch. J. Fish Biol. $6: 225-236$.

Hoerner, M.F. 1965. Fluid-dynamic drag. M.F. Hoerner, Midland Park, NJ

Holliday, F.G.T., P. Tytler and A.H. Young. 1974. Activity levels of trout (Salmo trutta) in Airthrey Loch, Stirling, and Loch Leven, Kinross. Proc. R. Soc. Edin. B74:315-331.

Holter, J.B., W.E. Urban, H.H. Hayes, and H. Silver. 1976. Predicting metabolic from telemetered heart rate in white-tailed deer. J. Wild1. Manage. 40:626-629.

Hughes, G.M. and S. Umezawa. 1968. Oxygen consumption and gill water flow in the dogfish Scyliorhinus canicula. J. Exp. Bio1. 49: 557-564.

Hunter, J.R. and J.R. Zweife1. 1971. Swimming speed, tail beat frequency, tail beat amplitude, and size in jack mackere1, Trachurus symmetricus, and other fishes. Fish. Bull. 69:253-266.

Jobling, M. 1981. The influences of feeding on the metabolic rate of fishes: a short review. J. Fish Bio1. 18: 385-400.

Johansen, K., D.L. Franklin and R.L. Van Citters. 1966. Aortic blood flow in free-swimming elasmobranchs. Comp. Biochem. Physio1. 19: 151-160.

Jones, D.R. and D.J. Randa11. 1978. The respiratory and circulatory systems during exercise. In: Fish Physiology, W.S. Hoar and D.J. Randa11, eds, Vo1. 7, pp. 425-501.

Kanwisher, J., K. Lawson and G. Sudnes. 1974. Acoustic telemetry from fish. Fish. Bull. 72:251-255. 
Kautz, M.A., W.W. Mautz and L.H. Carpenter. 1981. Heart rate as a predictor of energy expenditure of mule deer. J. Wildl. Manage. $45: 715-720$.

Kerr, S.R. 1982. Estimating the energy budgets of actively predatory fishes. Can. J. Fish. Aquat. Sci. 39: 371-379.

Kiceniuk, J.W. and D.R. Jones. 1977. The oxygen transport system in trout (Salmo gairdneri) during sustained exercise. J. Exp. Biol. $69: 247-260$.

Kisch, B. 1948. Electrocardiographic investigation of the heart of fish. Exp1. Med. Surg. 6: 31-62.

K1eiber, M. 1961. The Fire of Life: An Introduction to Animal Energetics. John Wiley and Sons, New York. 454 pp.

Kneis, P. and R. Seigmund. 1976. Heart rate and locomotor activity in fish: correlation and circadian and circannual differences in Cyprinus carpio L. Experientia 32: 474-476.

Kohler, N.E. 1987. Aspects of the feeding ecology of the blue shark, Prionace glauca, in the western north Atlantic. Ph.D. thesis, Univ. Rhode Island, Kingston, 163pp.

Landesman, J.G. 1984. Horizontal and vertica1 movements and seasonal population shifts in the blue shark, Prionace glauca, near Santa Catalina Island, California. Master's thesis, C.S.U.L.B., 79 pp.

Lighthi11, M.J. 1969. Hydromechanics of aquatic animal propulsion. Ann. Rev. Fluid Mech. 1:413-446.

Lighthil1, M.J. 1970. Aquatic animal propulsion of high hydomechanical efficiency. J. Fluid Mech. 44:265-301.

Lighthi11, M.J. 1971. Large-amplitude elongated-body theory of $\mathrm{fish}$ locomotion. Proc. R. Soc. Lond. B. 179:125-138.

Lindsey, C.C. 1978. Form, function and 1ocomotory habits in fish. In: Fish Physiology, Vo1. 7, W.S. Hoar and D.J. Randa11, eds. Pp. 1-100.

Lu, C. C. and C. F. Roper. 1979. Cephalopods from deepwater dumpsite 106 (western Atlantic): vertical and seasonal abundance. Smithsonian Cont. Zoo1. 288:1-36.

Lund, G.F. and G.E. Folk, Jr. 1976. Simultaneous measurements of heart rate and oxygen consumption in black-tailed prairie dogs (Cynomys 1udovicianus). Comp. Biochem. Physio1. 55A:201-206.

Magnuson, J. J. 1970. Hydrostatic equilibrium of Euthynnus affinis, a pelagic teleost without a gas bladder. Copeia 1970:56-85. 
Magnuson, J.J. 1978. Locomotion by scombrid fishes: hydromechanics, morphology, and behavior. In: Fish Physiology, W.S. Hoar and D.J. Randa11, eds, Vo1. 7, pp. 239-313.

Mann, K.H. 1978. Estimating the food consumption of fish in nature. In: Ecology of Freshwater Fish Production, S.D. Gerking, ed. John Wiley and Sons, New York. pp. 250-273.

Mautz, W.W., and J. Fair. 1980. Energy expenditure and heart rate for activities of white-tailed deer. J. Wild1. Manage. 44:333-342.

Medved, R.J. and J.A. Marsha11. 1983. Short-term movements of young sandbar sharks, Carcharinus plumbeus (Pisces, Carcharinidae). Bull. Mar. Sci. 33:87-93.

Nelson, D.R. 1967. Cardiac responses to sounds in the lemon shark, Negaprion brevirostris. In: Sharks, Skates, and Rays, P.W. Gilbert, R.F. Mathewson, and D.R. Hall, eds. Johns Hopkins Press, Baltimore. pp. 533-544.

Nelson, D.R. 1977. On the field study of behavior in sharks. Amer. Zoo1. 17: 501-507.

Nixon, A.J. and S.H. Gruber. 1988. Diel metabolic and activity patterns of the lemon shark (Negaprion brevirostris). J. Exp. Zool. 248:1-6.

Nomura, S., T. Ibaraki, H. Hirose and S. Shirahata. 1972. Applications of back-pack cardiotelemeter for fishes. 1. Heart rate and cardiac reflex in fishes during unrestrained swimming. Bull. Jap. Soc. Scient. Fish. 38: 1105-1117.

011a, B.L., C.E. Samet and A.L. Studholme. 1972. Activity and feeding behavior of the summer flounder (Paralichthys dentatus) under controlled laboratory conditions. Fish. Bul1. 70:1127-1136.

Owen, R.B., Jr. 1969. Heart rate, a measure of metabolism in blue-winged tea1. Comp. Biochem. Physiol. 31:431-436.

Pethon, P. 1970. Occurrence of the great blue shark, Prionace glauca, in Norwegian waters. Rhizocrinus 1:1-5.

Piiper, J. M. Meyer, H. Worth and H. Willmer. 1977. Respiration and circulation during swimming activity in the dogfish Scyliorhinus stellaris. Respir. Physio1. 30:221-239.

Piiper, J. and D. Schumann. 1967. Efficiency of $\mathrm{O}_{2}$ exchange in the gills of the dogfish, Scyliorhinus stellaris. Respir. Physiol. 2: 135-148. 
Priede, I.G. 1974. The effect of swimming activity and section of the vagus nerves on heart rate in rainbow trout. J. Exp. Biol. 60:305-319.

Priede, I.G. 1983. Heart rate telemetry from fish in the natural environment. omp. Biochem. Physio1. 76A:515-524.

Priede, I.G. 1985. Metabolic scope in fishes. In: Fish Energetics: New Perspectives, P. Tytler and P. Calow, eds. Johns Hopkins Univ. Press, Baltimore. pp. 33-64.

Priede, I.G. and P. Tytler. 1977. Heart rate as a measure of metabolic rate in teleost fishes; Salmo gairdneri, Salmo trutta, and Gadus morhua. J. Fish Bio1. 10:231-242.

Priede, I.G. and A.H. Young. 1977. The ultrasonic telemetry of cardiac rhythms of wild brown trout ( $\underline{\mathrm{Salmo}}$ trutta $\mathrm{L}_{\text {.) }}$ ) as an indicator of bio-energetics and behaviour. J. Fish Biol. 10:299-318.

Pritchard, A.W., E. Florey and A.W. Martin. 1958. Relationship between metabolic rate and body size in an elasmobranch (Squalus suckleyi) and in a teleost (Ophiodon elongatus). J. Mar. Res. 17: 403-411.

Randa11, D.J. 1968. Functional morphology of the heart in fishes. Am. Zoo1. 8: 179-189.

Randa11, D.J. 1970. The circulatory system. In: Fish Physiology, W.S. Hoar and D.J. Randa11, eds. Vo1. 4. pp. 133-172.

Randa11, D.J. 1978. Circulation of blood. In: Animal Physiology, R. Eckert and D. Randa11, W.H. Freeman and Co., S.F. Pp. 433-468.

Raschi, W. and J. Elsom. 1986. Comments on the structure and development of the drag reduction-type placoid scale. In: Proc. 2nd Int1. Conf. on Indo-Pacific Fishes, T. Uyeno, R. Arai, T. Taniuchi, and K. Matsuura, eds. pp. 408-424.

Raschi, W. and J.A. Musick. 1984. Hydrodynamic aspects of shark scales. Spec. Rep. App1. Mar. Sci. Ocean Engineer. 272:1-82.

Reif, W.E. and A. Dinelacker. 1982. Hydrodynamics of the squamation in fast swimming sharks. N. Jahr. Geol. und Palaon. 164:184-187.

Renecker, L.A. and R.J. Hudson. 1985. Telemetered heart rate as an index of energy expenditure in moose (Alces alces). Comp. Biochem. Physio1. 82A:161-165.

Roberts, M.G., D.E. Wright and G.E. Savage. 1973. A technique for obtaining the electrocardiogram of fish. Comp. Biochem. Physiol. 44A: 665-668. 
Rogers, S.C., D.W. Church, A.H. Weatherley and D.G. Pincock. 1984. An automated ultrasonic telemetry system for the assessment of locomotor activity in free-ranging trout, Salmo gairdneri, Richardson. J. Fish Biol. 25:697-710.

Rogers, S.C. and A.H. Weatherley. 1983. The use of opercular muscle electromyograms as an indicator of the metabolic costs of fish activity in rainbow trout, Salmo gairdneri Richardson, as determined by radiotelemetry. J. Fish Biol. 23:535-547.

Ross, L.G., W. Watts and A.H. Young. 1981. An ultrasonic biotelemetry system for the continuous monitoring of tail-beat rate from

free-swimming fish. J. Fish Biol. 18:479-490.

Satche11, G.H. 1971. Circulation in Fishes. Cambridge Univ. Press. 131 pp.

Schmidt-Nielsen, K. 1979. Animal Physiology, 2d ed. Cambridge Univ. Press. 560pp.

Sciarrotta, T. C. and D. R. Nelson. 1977. Diel behavior of the blue shark, Prionace glauca, near Santa Catalina Island, California. Fish. Bu11. 75:519-528.

Short, S., E.W. Taylor and P.J. Butler. 1979. The effectiveness of oxygen transfer during normoxia and hypoxia in the dogfish (Scyliorhinus canicula L.) before and after cardiac vagotomy. J. Comp. Physiol.B. 132: 289-295.

Siegmund, R. and J. Voge1. 1977. The dependence of heart rate and locomotor activity on water temperature in the carp (Cyprinus carpio L.). Experientia 33: 1607-1609.

Smit, H. 1965. Some experiments on the oxygen consumption of goldfish (Carassius auratus L.) in relation to swimming speed. Can. J. Zool. $43: 623-633$.

Standora, E.A. and D.R. Nelson. 1977. A telemetric study of the behavior of free-swimming Pacific angel sharks, Squatina californica. Bul1. South. Calif. Acad. Sci. 76: 193-201.

Stasko, A.B. and R.M. Horra11. 1976. Methods of counting tailbeats of free-swimming fish by ultrasonic telemetry techniques. J. Fish. Res. Bd. Can. 33:2596-2598.

Stasko, A.B. and D.G. Pincock. 1977. Review of underwater biotelemetry, with emphasis on ultrasonic techniques. J. Fish. Res. Bd. Can. 34: 1261-1285. 
Stevens, E.D., G.R. Bennion, D.J. Randa11, and G. She1ton. 1972. Factors affecting arterial pressures and blood flow from the heart in intact, unrestrained 1ingcod, Ophiodon elongatus. Comp. Biochem. Physio1. 43A: 681-695.

Stevens, E.D. and W.H. Nei11. 1978. Body temperature relations of tunas, especially skipjack. In: Fish Physiology, W.S. Hoar and D.J. Randa11, eds. Vo1. 7. pp.315-359.

Stevens, E.D. and D.J. Randa11. 1967a. Changes in blood pressure, heart rate, and breathing rate during moderate activity in rainbow trout. J. Exp. Bio1. 46:307-315.

Stevens, E.D. and D.J. Randal1. 1967b. Changes in gas concentrations in blood and water during moderate swimming activity in trout. J. Exp. Bio1. 46:329-337.

Stevens, J. D. 1973. Stomach contents of the blue shark (Prionace glauca L.) off south-west England. J. Mar. Biol. Ass. U.K. 53:357-361.

Stevens, J.D. 1976. First results of shark tagging in the northeast Atlantic, 1972-1975. J. Mar. Bio1. Assoc. U.K. 56:929-937.

Stillwe11, C.E. and N.E. Kohler. 1982. Food, feeding habits, and estimates of daily ration of the shortfin mako (Isurus oxyrinchus) in the northwest Atlantic. Can. J. Fish. Aquat. Sci. 39:407-414.

Storeton-West, T.J., R.B. Mitson and M. Greer-Wa1ker. 1978. Fish heart rate telemetry in the open sea using sector scanning sonar. Biotelemetry 5: 149-153.

Strasberg, D. W. 1958. Distribution, abundance, and habits of pelagic sharks in the central Pacific ocean. Fish. Bull. 138:335-361.

Sudak, F.N. and C.G. Wilbur. 1960. Cardiovascualar and respiratory activity in dogfish. Biol. Bul1. 119: 341-342.

Sutterlin, S.M. 1969. Effects of exercise on cardiac and ventilation frequency in three species of freshwater teleosts. Physiol. Zool. $42: 36-52$.

Thomson, K.S. and D.E. Simanek. 1977. Body form and 1ocomotion in sharks. Amer. Zoo1. 17:343-354.

Todd, G. 1982. The mako and the blue: hydrodynamics and the evolution of constant swimming in two different pelagic sharks. Amer. Zoo1. $22: 861$.

Tricas, T.C. 1979. Relationships of the blue shark, Prionace glauca, and its prey species near Santa Catalina Island, California. Fish. Bu11. 77:175-182. 
Videler, J.J. and D. Weihs. 1982. Energetic advantages of burst-and-coast swimming of fish at high speeds. J. Exp. Bio1. 97: 169-178.

Wardle, C.S. and J.W. Kanwisher. 1974. The significance of heart rate in free swimming cod: some observations with ultrasonic tags. Mar. Behav. Physio1. 2:311-324.

Ware, D.M. 1975. Growth, metabolism and optimal swimming speed of a pelagic fish. J. Fish. Res. Bd. Can. 32: 33-41.

Ware, D.M. 1978. Bioenergetics of pelagic fish: theoretical change in swimming speed and ration with body size. J. Fish. Res. Bd. Can. 35: 220-228.

Weatherley, A.H. 1976. Factors affecting maximization of fish growth. J. Fish. Res. Bd. Can. 33:1046-1058.

Weatherley, A.H., S.C. Rogers, D.G. Pincock and J.R. Patch. 1982. Oxygen consumption of active rainbow trout, Salmo gairdneri Richardson, derived from electromyograms obtained by radiotelemetry. J. Fish Biol. 20:479-489.

Webb, P.W. 1971a. The swimming energetics of trout I. Thrust and power output at cruising speeds. J. Exp. Biol. 55:489-520.

Webb, P.W. 1971b. The swimming energetics of trout II. Oxygen consumption and swimming efficiency. J. Exp. Biol. 55:521-540.

Webb, P.W. 1975. Hydrodynamics and energetics of fish propulsion. Bul1. Fish. Res. Bd. Can. No. 190, 159p.

Webb, P.W. 1978a. Hydrodynamics: nonscombroid fish. In: Fish Physiology, Vo1. 7, W.S. Hoar and D.J. Randa11, eds. pp. 189-237.

Webb, P.W. 1978b. Partitioning of energy into metabolism and growth. In: Ecology of Freshwater Fish Production, S.D. Gerking, ed. John Wiley and Sons, New York. pp. 184-214.

Webb, P.W. and R.S. Keyes. 1982. Swimming kinematics of sharks. Fish. Bu11. 80:803-812.

Webster, A.J.F. 1967. Continuous measurement of heart rate as an indicator of the energy expenditure of sheep. Br. J. Nutr. 21:769-785.

Wooley, J.B., Jr. and R.B. Owen, Jr. 1977. Metabolic rates and heart rate-metabolism relationships in the black duck (Anas rubripes). Comp. Biochem. Physiol. 57A:363-367. 
Weihs, D. 1973a. Mechanically efficient swimming techniques for fish with negative buoyancy. J. Marine Res. 31:194-209.

Weihs, D. 1973b. Optimal fish cruising speed. Nature 245:48-50.

Weihs D. 1974. Energetic advantages of burst swimming of fish. J. Theor. Bio1. 48:215-229.

Weihs, D. 1977. Effects of size on sustained swimming speeds of aquatic organisms. In: Scale Effects in Animal Locomotion. T. J. Pedley, ed. pp. 333-338.

Weihs, D. 1981a. Body section variations in sharks- an adaptation for efficient swimming. Copeia 1981:217-219.

Weihs, D. 1981b. Effects of swimming path curvature on the energetics of fish motion. Fish. Bul1. 79:171-176.

Weihs, D. 1984. Bioenergetic considerations in fish migration. In: Mechanisms of Migration in Fishes, J.D. McCleave, G.P. Arnold, J.J. Dodson, and W.H. Neil1, eds. Plenum Press, N.Y. pp. 487-508.

Weihs, D., R.S. Keyes, and D. M. Stalls. 1981. Voluntary swimming speeds of two species of large carcharhinid sharks. Copeia 1981:219-222.

White, F.M. 1979. Fluid Mechanics. McGraw-Hi11, NY

Wu, T.Y. 1971. Hydromechanics of swimming propulsion. Part 1. Swimming of a two-dimensional flexible plate at variable forward speeds in an inviscid fluid. J. Fluid Mech. 46:337-355.

Young, A.H., P. Tytler, F.G.T. Holliday and A. MacFarlane. 1972. A sma11 sonic tag for measurement of locomotory behaviour in fish. J. Fish Bio1. 4:57-65.

Yuen, S.H. 1970. Behavior of skipjack tuna, Katsuwonus pelamis, as determined by tracking with ultrasonic devices. J. Fish. Res. Bd. Can. 27:2071-2079. 


\section{BIOGRAPHICAL NOTE}

The author was born in Cincinnati, Ohio on October 12, 1960, the daughter of Dr. Frank J. Scharold, Jr. and Judith F. Scharold. She graduated from Taylor High School, North Bend, Ohio, in 1978, and was class valedictorian. The same year she entered Michigan Technological University, where her studies were supported in part by the MTU United States Scholarship and a varsity basketball scholarship. In 1982 she graduated from Michigan Tech with high honors, receiving a B.S. degree in Biological Sciences. The author was admitted to the W.H.O.I./M.I.T. Joint Program in Biological Oceanography in 1982. In addition to being a graduate research assistant there, she served as a teaching assistant for the Fundamentals of Ecology course at M.I.T. in the fall semester of 1983, and participated as a research consultant in a mid-Atlantic ridge survey of benthic sharks for AT\&T during fall 1986. Past research activities include studies of plant ecology in fire-disturbed sites in Isle Royale National Park, Michigan; ecology of bats in the Keeweenaw Peninsula, Michigan; air quality monitoring in the Painted Desert, Arizona; benthic invertebrate communities in the Matamek River ecosystem, Quebec, Canada; swimming biology of squid; acoustic telemetry from free-ranging swordfish; ecology of the lemon shark in Bimini, Bahamas; and most recently, swimming behavior and energetics of sharks. The author has accepted a postdoctoral position at California State University, Fullerton. 